\title{
A COMPARISON OF SATELLITE IMAGES \\ CAPABLE OF DETECTING OCEAN \\ SURFACE FEATURES
}

\author{
Bruce William Platz
}


DULEY KNOX UBRAAY SCHOOL

DUDLEY KOSTGRADUATE 93940

MAVAL POSTEREY, CALIFORNIA 93940 


\section{NAVAL POSTGRADUATE SGHOOL Monterey, California}
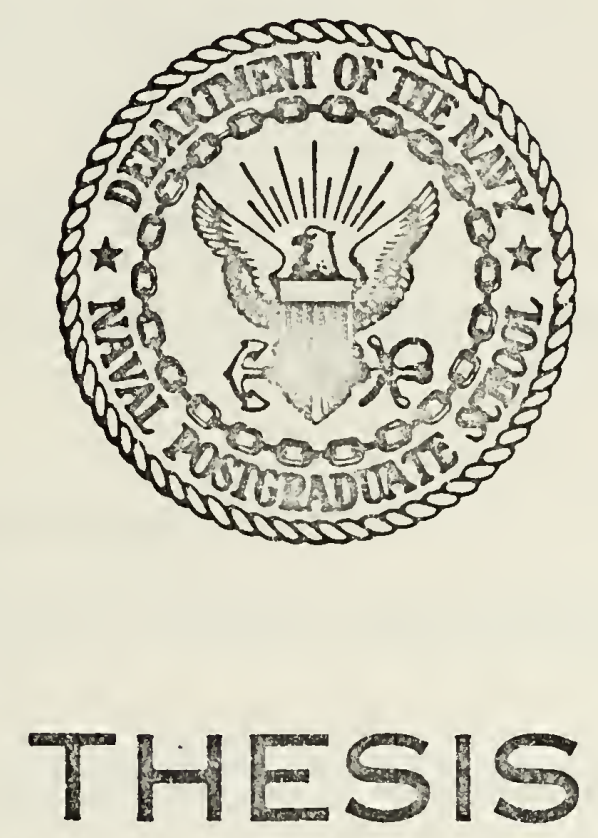

A COMPARISON OF SATELLITE IMAGES CAPABLE OF DETECTING OCEAN SURFACE FEATURES

$$
\text { by }
$$

Bruce William Platz, Jr.

$$
\text { September } 1975
$$

J. von Schwind

Thesis Advisors: E. Thornton

Approved for public release; distribution unlimited. 



\begin{tabular}{|c|c|}
\hline REPORT DOCUMENTATION PAGE & $\begin{array}{c}\text { READ INSTRUCTIONS } \\
\text { BEFORE COMPLETISG FORM }\end{array}$ \\
\hline 2. GOVT ACCESSION NO. & 3. RECIPIENT'S CATALOG NUMBER \\
\hline \multirow{2}{*}{$\begin{array}{l}\text { A. TITLE (and Subullo) } \\
\text { A Comparison of Sateliite Images } \\
\text { Capable of Detecting Ocean Surface } \\
\text { Features }\end{array}$} & $\begin{array}{l}\text { 5. TYPE OF REPORT A PERIOD COVEREO } \\
\text { Master'S Thesis: } \\
\text { September } 1975\end{array}$ \\
\hline & 6. PERFORMING ORG. REPORT NUMBER \\
\hline $\begin{array}{l}\text { 7. AUTHOR(•) } \\
\text { Bruce William Platz, Jr. }\end{array}$ & 0. CONTRACT OR GRANT NUMBER(*) \\
\hline $\begin{array}{l}\text { 9. PERFORMING ORGANIZATION NAME AND AODRESS } \\
\text { Naval POStgraduate School } \\
\text { Monterey, California } 93940\end{array}$ & $\begin{array}{l}\text { 10. PROGRAM ELEMENT PROJECT, TASK } \\
\text { AREA A WORK UNIT NUMBERS }\end{array}$ \\
\hline \multirow{2}{*}{$\begin{array}{l}\text { 11. CONTROLLING OFFICE NAME AND ADORESS } \\
\text { Naval Postgraduate School } \\
\text { Monterey, California } 93940\end{array}$} & $\begin{array}{l}\text { 12. REPORT DATE } \\
\text { SEPLEmbEr } 1975\end{array}$ \\
\hline & $\begin{array}{l}\text { 13. NUMBER OF PAGES } \\
91\end{array}$ \\
\hline \multirow[t]{2}{*}{ 14. MONITORING AGENCY NAME ADDRESS(II dilloront from COntrollind OIIICo) } & $\begin{array}{l}\text { 15. SECURITY CLASS. (ol thte roport) } \\
\text { UnClassified }\end{array}$ \\
\hline & $\begin{array}{l}\text { 150. DECLASSIFICATION/DOWNGRADING } \\
\text { SCHEDULE }\end{array}$ \\
\hline
\end{tabular}

16. DISTRIBUTION STATEMENT (OI thl R R०PORt)

Approved for public release; distribution unlimited.

17. DISTRIBUTION STATEMENT (Ol the ebotsact ontoped In Block 20, 11 dilforent from Ropost)

18. SUPPLEMENTARY NOTES

19. KEY WOROS (Continue on severse elde Il neceeceasy and ldentity by block number)

Satellites

Remote Sensors

Sea Surface

Oceanography
NOAA

DMSP

ERTS

20. ABSTRACY (Continue on reveree elde It neceeesry and ldentity by block number)

This study compares the capabilities of the images obtained from the archives for the satellites of National Oceanic and Atmospheric Administration (NOAA), Defense Meteorological Satellite Program (DMSP), and Earth Resources Technology Satellite (ERTS) systems for displaying information about oceanic currents and circulation features. Although these systems were not designed to collect sea surface data, large

$\begin{array}{ll}\text { DD FORM } 1473 & \text { EOITION OF I NOVBS IS OBSOLETE } \\ \text { (Page } 1 \text { ) } & \text { S/N 0102.014.6601I }\end{array}$

(Page 1)
$S / N O 102 \cdot 014 \cdot 6601$ I 



\section{(20. ABSTRACT Continued)}

scale coastal phenomena have been detected in the imagery of all three. In this analysis of the imagery, the ERTS data proved to be the most useful for displaying coastal processes, especially mixing and sediment transport, because of their availability and sensor abilities to detect sediment. The DMSP archived images proved to be of little value for looking at sea surface features. The NOAA archived images were scarce and only a few of the images requested during this investigation were available. The sensors showed a susceptibility to many atmospheric contaminations, primarily water vapor, which prevented delineation between sea and air phenomena at times. However, special image products were found which displayed sea surface features and flow patterns representative of flow around islands, points of land, and mixing. 

A Comparison of Satellite Images Capable of Detecting Ocean Surface Features

$$
\text { by }
$$

Bruce William Platz, Jr.

Lieutenant, United SÉtes coast Guard

B.S., United States Coast Guard Academy, 1971

Submitted in partial fulfillment of the requirements for the degree of

MASTER OF SCIENCE IN OCEANOGRAPHY

$$
\text { from the }
$$

NAVAL POSTGRADUATE SCHOOL

September 1975 
Thesis

P6lu

c.! 


\section{ABSTRACT}

This study compares the capabilities of the images obtained from the archives for the satellites of National Oceanic and Atmospheric Administration (NOAA), Defense Meteorological Satellite Program (DMSP), and Earth Resources Technology Satellite (ERTS) systems for displaying information about oceanic currents and circulation features. Although these systems were not designed to collect sea surface data, large scale coastal phenomena have been detected in the imagery of all three. In this analysis of the imagery, the ERTS data proved to be the most useful for displaying coastal processes, especially mixing and sediment transport, because of their availability and sensor abilities to detect sediment. The DMSP archived images proved to be of little value for looking at sea surface features. The NOAA archived images were scarce and only a few of the images requested during this investigation were available. The sensors showed a susceptibility to many atmospheric contaminations, primarily water vapor, which prevented delineation between sea and air phenomena at times. However, special image products were found which displayed sea surface features and flow patterns representative of flow around islands, points of land, and mixing. 



\section{TABLE OF CONTENTS}

I.

INTRODUCTION

II.

BACKGROUND

A. HISTORY

B. SATELIITE SENSORS - 17

1. Introduction - 17

2. The NOAA System --- 18

3. The DMSP System -

4. The ERTS System -----

C. IMAGERY

1. Introduction -

2. NOAA and DMSP Imagery

3. ERTS Imagery -

4. Sunglint -

5. NASA $70 \mathrm{~mm}$ Photography --

III. DETECTION OF SEA SURFACE PHENOMENA -

A. INTRODUCTION

B. PROBLEMS WITH SATELLITE IMAGERY -

C. OBSERVATIONS OF SEPARATED FLOW -

1. Experimental Flows -

2. Conventional Oceanographic Studies ---- 39

3. Observations with Satellite Imagery --- 40

a. Flow Past Islands

b. Flow Past Points of Land -.....- 44

D. WATER MASS BOUNDARIES AND MIXING -

E. SUMMARY 
IV.

CONCLUSIONS

v.

RECOMMENDATIONS

51

APPENDIX A: SATELLITE ORBIT PARAMETERS

53

APPENDIX B : FIGURES

54

LIST OF REFERENCES

87

INITIAL DISTRIBUTION LIST

90 



\section{LIST OF FIGURES}

1. NOAA-3 VHRR Product, 11 Sept. 1974;

visual image of California coast --_-_-_-_-_-- 54

2. NOAA-3 VHRR Product, 11 Sept. 1974;

photographically enhanced infrared image

of California coast -_-_-_- 55

3. DMSP HR Standard Products, 15 March 1973;

visual and infrared images of California coast --- 56

4. DMSP VHR Standard Products, 16 Oct. 1974;

visual and infrared images of California coast --- 57

5. ERTS Standard Products, 20 July 1973;

scene 1362-02481, Bands 4 and 5 of the

Gulf of Tonkin -...... 58

6. ERTS Standard Products, $20 \mathrm{July} \mathrm{1973;}$ scene 1362-02481, Bands 6 and 7 of the

Gulf of Tonkin _- 59

7. NOAA-4 VHRR Infrared Enalargement, showing

sediment transport off Cape Mendocino --.------ 60

8. DMSP HR Enhanced Image, 1 April 1972;

infrared image shows the China Coastal Current --- 61

9. NOAA-4 VHRR Product, 22 Feb. 1972;

infrared image of Gulf Stream flow -...-..-.-.-- 62

10. DMSP HR Enhanced Image, 10 ApriI 1972;

infrared image shows warm currents in

the Sea of Japan and Yellow Sea

11. ERTS Standard Products, 24 April 1974;

scene 1275-18284, Bands 4 and 5 of sediment

transport south of Point st. George

12. ERTS Products; Standard Image 1130-18325,

Band 4 and FSS Enhancement of gyre in

sediment transport off San Francisco -

13. DMSP HR Standard Product, 24 June 1973;

visual sunglint image of California coast ------- 66

14. Gemini V Photograph, 21 August 1965;

image shows von Kármán vortices in clouds

as they flow past Guadelupe Is land 

15. Numerical solutions for the streamline flow past a rectangular obstruction

16. Photographic evidence of tip eddy vortices

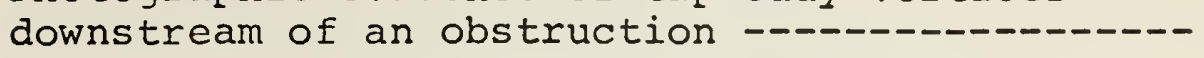

17. Photographs of separated flow around a circular cylinder for various speeds

18. Diagrammatic view of fluid flow past a circular cylinder for various conditions and Reynolds numbers

19. Comparison of observed and theoretical geostrophic flow past Johnston Atoll as shown by R. A. Barclay -

20. ERTS Standard Product, 26 May 1973; scene 1307-18073, Band 4 of atmospheric flow past islands in Santa Barbara Channel -.-- 73

21. ERTS Standard Product , 23 Aug. 1973; scene 1396-18010, Band 4 of atmospheric

flow past islands in Santa Barbara Channel --.- 74

22. ERTS Standard Product, 24 June 1973; scene 1336-17291, Band 4 of atmospheric flow past islands in the Gulf of California -.......-.-

23. NASA $70 \mathrm{~mm}$ Photograph, $22 \mathrm{Jan}$. 1973; this lowaltitude infrared color picture shows many turbulent flow patterns in the surface waters

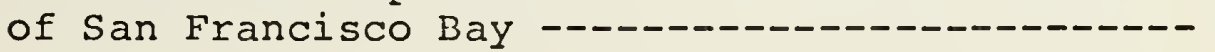

24. ERTS Standard Product, 15 March 1973; scene 1235-18075, Banả 4 of Pt. Conception -.-.-----

25. ERTS Standard Product, 16 March 1973; scene 1236-18134, Band 4 of Pt. Conception -...-.-- 78

26. ERTS Standard Product, 20 April 1973; scene 1271-18075, Band 4 of Pt. Conception --_-----

27. NASA $70 \mathrm{~mm}$ Photograph; oblique infrared color picture of flow past Pt. St. George - 80

28. ERTS FSS Enhanced Image, 22 Jan. 1973; scene 1183-18182 of Kelvin-Helmholtz instability shear flow past Cypress Point, Monterey Bay -..-...-...-

29. ERTS Standard Products, 6 Aug. 1974; scene 1744-18251, Bands 4 and 5 of Cape Mendocino --- 82 

30. ERTS Standard Products, 3 Nov. 1974; scene 1833-18161, Bands 4 and 5 of Cape Mendocino -..- 83

31. NOAA-3 VHRR Product, 3 Nov. 1974;

infrared image of California coast _..._...... 84

32. NOAA-3 VHRR Product, 10 Oct. 1974 ; infrared image of California coast _._._._._. 85

33. DMSP HR Standard Products; 14 June 1973;

visual and infrared image of California coast -- 86 



\section{ACKNOWLEDGMENTS}

A few individuals have been especially helpful in providing satellite imagery and associated information. Special thanks is given to Oscar Huh, Naval Oceanographic Office, for allowing me to use his enhanced DMSP image products. A very special thanks is given to Doug Pirie, U.S. Army Corps of Engineers, for all of his help and time spent in explaining ERTS and NASA image capabilities, and for providing access to his collection of imagery and photographs.

Thanks is expressed to those other persons who helped me to obtain the images and photographs presented herein, specifically:

Larry Braeker, NOAA-NESS, Redwood City, CA.

Lawrence Berry, NOAA-NESS, Washington, D.C.

Sharon Enders, EROS, Menlo Park, CA.

Bob Fett, EPRF, Monterey, CA. 



\section{INTRODUCTION}

The United States Coast Guard has been gathering and using oceanographic data, obtained from ships, to produce surface current charts for coastal waters as part of its search and rescue mission since the establishment of its Oceanographic Unit in 1923. A knowledge of seasonal and weekly surface current trends, both speed and direction, is of great importance to this organization when it comes time to define search areas and probable drifts of ships and persons in distress on the open ocean, lost or missing for hours or sometimes days. Local weather and up-to-date dynamic calculations play an important part in improving predictions of drift rate and direction. Additionally, satellite images of the sea surface present the possibility of obtaining near real-time information on changing surface and wind conditions for inputs into the current predictive numerical models being used. These satellite images might be used in determining the location of turbulent regions which may alter the predicted drift of some vessel or raft in the proposed search area. Not only would this information be helpful for the initial search planning, but it might also be used on scene to modify and up-date existing rescue operations to comply with changing environmental conditions.

Presented here is a comparison of remote sensors now capable of detecting characteristic turbulent flow regions in 

surface waters, with a discussion of those images and enhancement techniques available from each which display such oceanographic features. From this comparison it was found that, although satellite images and associated products are usable for the identification and observation of certain large scale phenomena, the best tool for the detection of surface features in coastal waters is NASA $70 \mathrm{~mm}$ photography taken at altitudes ranging from 5,000 to $65,000 \mathrm{ft}$. A review of this data showed that these more or less conventional aerial photographs were much more suitable for nearshore current analysis than satellite images.

The data from three types of satellites, each type carrying remote sensors capable of obtaining sea surface information in the visual or infrared frequency bands, was available for this work. These types are: i) the National Oceanic and Atmospheric Administration (NOAA) satellites; ii) the satellites of the Defense Meteorological Satellite Program (DMSP); and iii) the Earth Resources Technology Satellites (ERTS). Each type has its unique capabilities and restrictions for detecting dynamic occurrences in ocean waters. Special NOAA and DMSP image products give excellent depictions of the larger scale features, such as oceanic fronts, upwelling, and mixing processes. ERTS imagery shows good results in coastal regions for locating water masses, their boundaries and interactions. The NASA aerial $70 \mathrm{~mm}$ photos, referred to previously, of the West Coast of the United States were also available for this study. These photos cover only the immediate 

coastal regime, but distinct sea surface features are detectable around rocks, islands, and points of land. These features and the resulting surface effects are on a much smaller scale than those depicted in satellite imagery.

The present study began as an attempt to find and classify ocean flow patterns using satellite imagery and to compare these findings with the theoretical and experimental results of classical fluid dynamics. This latter work has shown that, given the right conditions, turbulent regions will form behind objects so as to disrupt steady flow. These areas of motion superimposed on the simpler flow patterns can be located when a foreign substance, acting as a tracer, is present. Starting with the assumption that actual sea surface phenomena, similar to that found in these theoretical experimental studies as well as that previously discovered in cloud pattern images in the vicinity of islands, would be revealed in satellite data, work was begun to catalog characteristic flow patterns about selected geometric shapes approximating actual topographic features occurring in the oceans. Because of sensor limitations, and the confusion involved in interpreting satellite data, clear evidence of these phenomena was not found and the compilation of a catalog has not been possible. An explanation of this failure along with a comparison of satellite images and NASA photographs from these different remote sensors follows. The limited individual and cumulative capabilities of such images and photos for oceanographic purposes are reviewed. This investigation has 

identified more problems, and raised more questions, concerning the oceanographic uses of satellite image products than it has succeeded in answering.

In the study, archived imagery were used to determine if surface phenomena could be detected through this method of looking at the ocean. The preliminary work consisted of looking at random images from all three systems to get an idea of their capabilities. Approximately 50 NOAA and 1000 DMSP and 400 ERTS images from various parts of the world were examined in an attempt to find oceanic features in the images, without enhancement. In the initial investigation, it became obvious that NOAA and DMSP standard images were not useful for obtaining oceanographic information. However, after further research and interviews with other investigators who have found uses for satellite imagery, it was decided to look at specific areas which had demonstrated characteristic coastal processes in ERTS imagery. At the Army Corps of Engineers, San Francisco, over 300 selected ERTS images of the west coast of the United States for 1972-1974 were made available. The images showing sea surface phenomena were selected for closer examination; the DMSP and NOAA archived images were ordered for the same dates, in an attempt to verify the features with the three systems. Unfortunately, the NOAA images for this time period were scarce and DMSP images proved to be incapable of defining sea surface phenomena. 



\section{BACKGROUND}

\section{A. HISTORY}

The first attempts to obtain Earth images from an artificial satellite occurred in 1959 with the launching of VANGUARD 2 and EXPLORERS 6 and 7. These first experiments were designed to observe global cloud cover on a gross scale and, in this, were only partially successful [Stolt and Havanac, 1973]. The primary scientific objective of satellite sensing has changed with the development of the sophisticated multi-purpose platforms being used today, but information about the Earth's atmosphere is still the most important product of remote sensing from space.

The first full-time meteorological satellite was designed using the experience and information obtained during the early experiments. NASA launched this platform on 1 April 1960; it was designated TIROS (Television and Infrared Observation Satellite). Over the years there have been a total of ten TIROS. TIROS 2, 3, 4, and 7 each carried a five channel, scanning, medium resolution, infrared radiometer used to measure Earth-emitted radiation. TIROS 8 was the first to carry a remote system equipped with an automatic picture transmission capability which permitted immediate transmission of cloud cover and infrared data to a ground station within the communication range of the satellite, instead of recording the information on board and eventually transmitting it to a 

data acquisition center at some later date, as was the case for the earlier satellites. This provided a greater capability for collecting meteorological data. In general the TIROS program yielded much information on global cloud cover, cloud formations, and weather systems as well as demonstrating the usefulness of satellites as tools for gathering meteorological data.

Following the deactivation of the TIROS program, the ATS (Application Technology Satellite) series was used to conduct further tests of new concepts in spacecraft design and equipment function. In addition to the testing of camera systems and data relay techniques, scientists were provided with better meteorological information. Some of this data has been used in general large scale temperature profiling of the sea surface, but the major contribution of ATS has been the surveillance and tracking of hurricane and typhoon systems. ATS has also been used successfully in studies concerning upper atmosphere winds and general global circulation.

The NIMBUS satellites, named for the cloud formation, followed with the launching of the first platform on 28 August, 1964 into a near-polar, Sun-synchronous orbit. It was designed as a second-generation meteorological satellite to map cloud cover and atmospheric heat transfer with a real-time data transmission capability. Although ATS platforms produced the first usable images of the sea surface, NIMBUS was really the first which sent back pictures 

with enough detail necessary for oceanographic work [La Violette, 1974]. The high resolution infrared (HRIR) line scan imagery of NIMBUS 2 has been used to produce digital temperature contour charts and direct readout infrared imagery with the capacity for showing large thermal contrasts in surface waters [Szekielda, 1970; Warnecke, et al, 1971].

A more extensive explanation of these early meteorological satellites can be found in the Compendium of Meteorological Satellites, by Stolt and Havanac, 1973.

The ITOS/NOAA (Improved TIROS Operational Satellite) has now become the primary platform for obtaining meteorological information. The DMSP (Defense Meteorological Satellite Program), formerly DAPP (Data Acquisition and Processing Program), is the military version used for obtaining tactical weather data. The ERTS (Earth Resources Technology Satellite) was developed to obtain geological and mineral resource information. The imagery from these three systems is compared to determine the capabilities of each for detecting turbulent coastal effects in surface currents. A further explanation of each system, its sensors and imagery, follows.

\section{B. SATELLITE SENSORS}

\section{Introduction}

The three satellite systems, the products of which are compared in this work, were developed over a period of fifteen years of experimentation and refinement. By no means are these the last step in remote sensing technology (people are 

now aware of strategic spy-satellites capable of a six inch resolution). The three systems studied do carry the best instruments for obtaining unclassified environmental data, including oceanographic information, from outer space. As these systems have benefited from their predecessors, the capabilities and instrument improvement of future satellites will in part be based on data received by the sensors now in use. The ITOS/NOAA series represents the present generation of operational meteorological satellites having the high resolution infrared capability useful for observing sea surface phenomena. The DMSP satellites have improved sensors similar to those of NOAA, with better resolution capabilities and greater potential for oceanographic use. These two platform types were specifically designed to carry sensors for acquiring meteorological data, while ERTS, also having this capability, was designed to monitor land resources involving agriculture, forestry, and mineral interests. Due to the specific nature of the energy spectrums being monitored by the previously mentioned sensors, gross ocean surface processes and related features have been detected in certain images of each type.

\section{The NOAA System}

The NOAA Polar Satellite system is operated and maintained by the National Environmental Satellite Service (NESS). This environmental satellite system is intended to provide global data on the Earth's environment, regularly and reliably, each day [Fortuna and Hambrick, 1974]. The 

fields specified for study have been meteorology, oceanography, hydrology, and the space environment. Oceanographic studies have been minimal and the data has been beneficial only for sea surface temperature detection and ice-field observations. The NOAA system consists of four major parts which are coordinated to gather, process, and disseminate this environmental data: i) an orbiting satellite; ii) an operational system for data acquisition and processing; iii) a direct broadcast service for transmitting raw data; and iv) a central service to disseminate user products.

The NOAA Polar Satellites are ITOS platforms which have been placed in nominal sun-synchronous orbits at an altitude of approximately $1450 \mathrm{~km}$. The satellites cross the equator at the same local time each day, in the afternoon northbound and in the morning southbound (orbit parameters are listed in Appendix A).

The operational system for these satellites includes a Satellite Operations Control Center (SOCC), two Command and Data Acquisition (CDA) stations, a communications network, and a Data Processing and Analysis Division (DAPAD). Scheduling, retrieving, processing, and distributing NOAA environmental and telemetry data is accomplished efficiently with this system. SocC, located in Suitland, Maryland, is responsible for technical direction and engineering assessment of the satellites' status and for coordinating the entire system operation. The two CDA stations, located at Gilmore Creek, Alaska and Wallops Station, Virginia, function 

as relay stations between the satellite and SoCC. DAPAD is the central facility where data is analyzed, processed, and either stored or distributed. The other two major parts of this system are simply electronic links used to transmit data from one place to another.

The real importance of the NOAA satellite system rests with the environmental sensors; the scanning radiometer $(S R)$, the very high resolution radiometer (VHRR), the vertical temperature profile radiometer (VTPR), and the solar proton monitor (SPM). Onlly two of these, the SR and VHRR, are useful for direct oceanographic work. The scanning radiometer is a two-channel instrument sensitive to energy in the visible range of $0.5-0.7 \mu \mathrm{m}$ and in the infrared range of $10.5-12.5 \mu \mathrm{m}$. The very high resolution radiometer is a two-channel sensing instrument sensitive to energy in the visual spectrum at 0.6-0.7 $\mathrm{m}$ and in the infrared region of 10.5-12.5 $\mu \mathrm{m}$. The two sensors record similar information, but the optics of each are different, resulting in different spatial resolutions. Also, the products resulting from these two sensors differ. The information from the scanning radiometer is normally used digitally to produce sea surface temperature contour charts while VHRR visual and infrared thermal contrasts are best shown in image form (Figures 1 and 2). The VHRR sensor has a much better resolution capability than that of the SR. The instantaneous field of view for the visual and infrared channels provides a spatial resolution of approximately $0.9 \mathrm{~km}$ at the satellite subpoint (a point directly below the scanner) 

which almost doubles at the image horizons. For the SR sensor, the best resolution for the visual channel is $3.0 \mathrm{~km}$ at the subpoint; for the infrared channel it is $7.5 \mathrm{~km}$ at the subpoint. The visual channel of the VHRR is helpful in distinguishing clouds and land-water boundaries when interpreting the infrared thermal surface data. The IR channel is used to determine the equivalent blackbody temperature of the radiating surface layer; what is actually recorded is the blackbody energy differential of the target. This data can be useful in dynamic studies of the sea surface. More information about the ITOS/NOAA satellites, the operational system, and the sensors can be found in References 20 and 21 .

\section{The DMSP System}

The Defense Meteorological Satellites are supervised by the United States Air Force Weather Service and are intended to perform two major missions: i) to provide global environmental data for the Weather Service and; ii) to continue the advancement of satellite technology, so as to meet the Department of Defense requirements. The sensors were developed for the specific purpose of obtaining meteorological data for tactical military purposes and have only a limited oceanographic capability. The program is similar to that of NOAA in many ways in that it consists of an operational system for data acquisition and several communication links for the transmission and dissemination of data received from remote sensors in space. 

There is normally a minimum of two Defense Meteorological satellites in operation at any given time. There have been five spacecrafts in all, placed in near-polar, sunsynchronous orbit approximately $840 \mathrm{~km}$ above the Earth. The platform precession rate is about one degree per day. Each satellite orbits in one of two modes; one crossing the equator in the noon-midnight orbit. and the other in the early morningearly evening orbit. Thus a satellite will cross the equator northbound at approximately 1230 Local or 0830 Local and southbound at 00,30 Local or 2030 Local (orbit parameters are listed in Appendix A).

The data relay system consists of a central processing facility, two acquisition and data relay sites, and several mobile tactical readout sites, all of which support DOD needs for weather information. The central processing facility, located at the Air Force Global Weather Central (AFGWC), Offutt AFB, Nebraska, receives and prepares data from each spacecraft twice daily. This information is used for numerical prediction models, space environmental support systems, and many other related tasks. Selected data is forwarded to the Navy Fleet Numerical Weather Center and the Pentagon. There are three readout sites; Vandenburg AFB, California is a full time site, Kessler AFB, Mississippi provides "hurricane hunter" support, and McClellan AFB, California (which is also the intermediate maintenance shop for ground equipment). The two data and tracking sites for 

this system are located at Fairchild AFB, Washington, and Loring AFB, Maine. There are several Air Force and Navy mobile tactical sites located around the world for local data collection. The information is transmitted throughout the system over special wide band communications lines.

The spacecraft sensors of the DMSP are scanning radiometers operating in the infrared spectral range of 8.0-13.0 $\mu \mathrm{m}$ and the visual region of $0.4-1.1 \mu \mathrm{m}$. There are two different sensing devices. The first is a two-channel high resolution (HR) instrument for visual and mode infrared energy detection. This sensor is capable of a maximum spatial resolution of approximately $3.7 \mathrm{~km}$ at the subpoint. The second sensor is a two-channel very high resolution radiometer (VHR) with visual and infrared detection, capable of a best resolution of about $0.6 \mathrm{~km}$, expanding to more than $4.0 \mathrm{~km}$ at the image horizons. The expanded infrared region of these sensors was selected so the field of view could be narrowed to obtain this good spatial resolution while maintaining an acceptable signal-to-noise ratio at the detector. This is an asset for meteorological purposes, allowing for the detection of thin fog and haze, but it causes many problems for oceanographic studies because of image contamination due to water vapor and other substances in the atmosphere. Figures 3 and 4 show a comparison of images from both sensors. More information about DMSP satellites and images can be found in Reference 7. 



\section{The ERTS System}

The Earth Resources Technology Satellite program is administered by the National Aeronautics and Space Administration (NASA). It is similar, operationally, to the other systems used for space-borne sensing of the environment; there are two remote sensors and a system for obtaining and processing the raw data. The six specific application areas defined by NASA for this system are: i) agriculture; ii) land use; iii) geology; iv) environment; v) water resources; and vi) marine resources. Some oceanographic uses have been found for ERTS images, such as, tracing sediment transport and coastal current drift and determining water depth.

ERTS has two satellites in near-polar, Sun-synchronous orbit at an altitude of $865 \mathrm{~km}$, circling the Earth on the average of fourteen times per day and covering the same area every eighteen days. ERTS/LANDSAT-1 was launched on July 23, 1972 and ERTS/LANDSAT-2 was launched on January 22, 1975 (orbit parameters are listed in Appendix A).

The operational system for ERTS is simple, similar to that of DMSP and NOAA. The sensors transmit data to three NASA receiving stations located at Fairbanks, Alaska, Goldstone, California, and Greenbelt, Maryland. This data is forwarded via wide-band communication links to the data processing facility at Goddard Space Flight Center, Greenbelt, Maryland, where the digitized information is stored on tapes and transferred into useful photographic products. 

The two sensors of the Earth Resources Technology Satellite program give a different representation of the sea surface and ocean than that of the visual and infrared DMSP and NOAA sensors. The Multi-Spectral Scanner (MSS) is a line scanning device producing four synchronous images, each with a spatial resolution of approximately $80 \mathrm{~m}$ and each of different wave length (Figures 5 and 6 ). The images from the Return Beam Vidicon (RBV) camera have not been used for oceanographic studies because of the lack of thermal resolution. More information about ERTS/LANDSAT data can be found in Reference 9.

C. IMAGERY

\section{Introduction}

All three satellite systems have been used in studies to detect large scale ocean features such as boundaries between water masses and general surface movement. These studies have included interpretation and description of sea surface phenomena observed in selected imagery, and in coordinating surveys with the use of imagery to direct conventional data collection by ships.

2. NOAA and DMSP Imagery

The NOAA and DMSP sensors have much in common;

i) both sense nearly the same region of the spectrum to produce images showing the relative thermal differences of the sea surface on a near real-time basis; ii) both have electronic enhancement procedures for providing improved images for oceanographic use; iii) both have remote processing 

units capable of collecting data and producing usable products of a survey area within minutes of sensor detection; and iv) both have night-time sensing capabilities.

NOAA archives only VHRR data ( $1 \mathrm{~km}$ resolution) as 10 in by 10 in negative or positive prints (Figures 1 and 2). The thermal range recorded by NOAA images is broad, $185-315^{\circ} \mathrm{K}$. Infrared data, relayed from the satellite, is displayed as a black and white image of 32 gray shades, providing a $4^{\circ} \mathrm{K}$ resolution which is not good for all oceanographic studies, but can be sufficient for some. NOAA images and other data are archived at:

Satellite Data Service Branch NOAA Environmental Data Service (EDS) NOAA-NESS World Weather Building Room 606 Washington, D.C. 22033 (301) 763-8111.

The DMSP sensors record both visual and infrared radiation data over a much broader range than that of NOAA sensors. Standard products archived by the Air Force are positive transparencies produced form the digital data received by the satellite sensors. DMSP images and tapes are archived at:

Satelite Data Library Space Science and Engineering Center The University of Wisconsin 1225 W. Dayton street Madison, Wisconsin 53706 (608) 262-5335. 

The high resolution visual and infrared images $(3.7 \mathrm{~km}$ resolution) are 9.5 in wide and from one to eight feet long. The very high resolution visual and infrared transparencies (0.6 $\mathrm{km}$ resolution) are also 9.5 in wide but range from one to four feet in length. The thermal range monitored by the DMSP infrared sensors, recorded on the transparencies, is $100^{\circ} \mathrm{K}\left(210-310^{\circ} \mathrm{K}\right)$. Displayed as a black and white product, with 16 shades of grey for visual contrast, a temporal resolution of $6.4^{\circ} \mathrm{K}$ is achieved in the imagery (see Figures 3 and 4).

Several computer enhancement techniques have been perfected which result in improved imagery, for oceanographic studies, from both NOAA [Ia Violette, Stuart and Vermillion, 1975] and DMSP [Huh, 1975] satellites. The NOAA data is seldom enhanced for oceanographic work, but the capability does exist to improve the normal visual and IR imagery. One example is given in Figure 7, a simple enlargement of the mixing occurring north of Cape Mendocino. This is a NOAA-4 image (note the streaking and the roughness of the photo, primarily due to the enlarging process). Although some special digital and photographic processing has been used with NOAA imagery to get a more distinct picture, very little has been done for oceanographic work and few good examples could be found for presentation. While NOAA enhancements are limited, many enhancements of DMSP imagery have been performed. The DMSP has the use of three separate temperature ranges. With the expansion setting of $x I$, during data acquisition, 

the entire $100^{\circ} \mathrm{K}$ range is covered. At X2 the range becomes $50{ }^{\circ} \mathrm{K}$ and at $\mathrm{X} 4$ further reduction of range to $25^{\circ} \mathrm{K}$ is accomplished, giving a thermal resolution of $1.6^{\circ} \mathrm{K}$. This is much more desirable for oceanic studies. By knowing local conditions, a base temperature (warmest of a display) can be selected to give the best image for a specific area [Huh, 1973]. "Thresholding" has been another technique employed, but it offered no real benefit to this study. With this process, the entire range of temperatures sensed is presented in four shades of grey, for example; everything below $275^{\circ} \mathrm{K}$ would appear white, between $275-285^{\circ} \mathrm{K}$ would be grey, between 285-292 ${ }^{\circ} \mathrm{K}$ would be dark grey, and everything above $295^{\circ} \mathrm{K}$ would be black. Huh has determined that the best DMSP imagery for detecting oceanic features is the high resolution inversion mode infrared (MI) imagery with a temperature range (X4) of $25^{\circ} \mathrm{K}$. This gives a very good thermal presentation of the sea surface with a temperature resolution of $1.6^{\circ} \mathrm{K}$ and a spatial resolution of 0.6 or $3.7 \mathrm{~km}$ (Figure 8). These images cover an area of almost $3,000 \times 5,700 \mathrm{~km}$ and are transverse mercator projections at scales of $1: 15,000,000$ or $1: 7,500,000$. The sensor "window" of the NOAA satellite has provided images for identifying and monitoring strong thermal features of the ocean [Rao, Strong, and Koffler, 1971]. Studies using these images have been successful in locating large scale surface phenomena, such as seasonal upwelling and mixing between coastal and bottom waters. An example of such an occurrence along the California coast is shown in Figure 2. 

The large scale eddies of the Gulf Stream have been observed in VHRR images of NOAA-4 (Figure 9). The best oceanographic uses for DMSP imagery have been in detecting mesoscale type sea surface thermal contrasts, current directions, thermally distinct water masses, and oceanic fronts (Figure 10).

These different types of image products have been used as integral parts of oceanographic surveys and, because of the remote processing capability available for both systems, certain images have actually been used to direct the later stages of an expedition. For example, during the Sahara Upwelling Experiment (SUE), 18-28 August, 1973, NOAA visible and infrared images were used to "pinpoint the location of principal sea surface thermal features" [La Violette, Stuart, Vermillion, 1975]. Also, during Operation NUGGET RANCH (10 October-10 November 1972), "the synoptic HRIR (of DMSP) data were used over the sea of Japan to supplement simultaneous surface measurements, for making decisions on spacing and positioning of ship tracks, to detect and position water masses, and to measure water mass boundary movements" [Huh, 1973] .

APT (Automatic Picture Transmission) stations are capable of receiving satellite radiation data when within the line of sight of the spacecraft. These portable stations can be located anywhere in the world; they are relatively expensive and produce accurate, usable images in near realtime [La Violette, Stuart, and Vermillion, 1975]. Digital and analog (used to produce images) data are receivable by 

such a station from only the scanning radiometers of the NOAA satellites. The DMSP has similar remote facilities, capable of producing near real-time synoptic HRIR images, for use during an oceanographic survey [Huh, 1973]. There have been as many as nine mobile land-receiving stations in operation at any one time. The Navy has had a mobile-van unit placed on the USS CONSTELLATION during its Pacific cruises for weather observations and now maintains such a system on the USS ENTERPRISE.

These two satellite systems have the capability of recording night-time radiation from the Earth. Description and use of this data is not attempted here because of the unavailability of visual and other supporting information. One interesting use of the night-time capability has been to identify fishing fleet activities in the sea of Japan with DMSP imagery [Fett, 1975].

\section{ERTS Imagery}

The ERTS sensors, operating in the visible range of the spectrum, have produced imagery capable of detecting water movements. ERTS imagery is archived at:

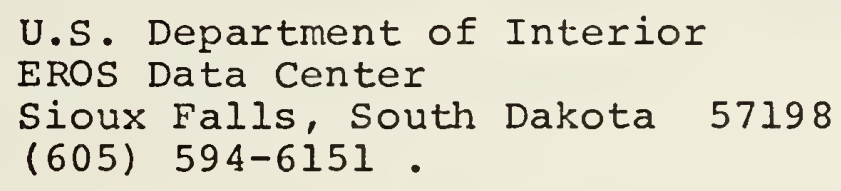

These images have been used most successfully in coastal studies [Magoon, 1973; Charnell and Maul, 1973]. The standard images come in 7.3 in negative or positive prints with a scale of $1: 1,000,000$. The best images for looking at ocean phenomena 

are Bands 4 and 5 [Pirie and Steller, 1974; Edmisten, 1974] (see Figure 5). Sediment transport and current direction have also been studied using these images (Figure 11). MSS Band 4 (green), 0.5-0.6 $\mu \mathrm{m}$ qualitatively discriminates turbidity in water; Band 5 (lower red), 0.6-0.7 $\mathrm{m}$, is best for showing topographic features; Band 6 (red), 0.7-0.8 $\mu \mathrm{m}$, shows tonal contrasts that reflect various land use products; Band 7 (near infrared, $0.8-1.1 \mu \mathrm{m}$, is best for land-water discrimination. The Return Beam Vidicon camera has produced only a limited amount of data because of sensor malfunctions. This device was designed to transmit data in three bands:

1) Band 1 (green), 0.460-0.600 $\mu \mathrm{m}$; 2) Band 2 (red), 0.569-0.680 $\mu \mathrm{m}$; and 3) Band 3 (near infrared), 0.660-0.820 $\mu \mathrm{m}$.

The most outstanding and impressive enhancement of any satellite derived imagery is accomplished with ERTS data; color composite prints are produced for land-use and landmanagement purposes. However these are not useful in oceanographic studies. Several enhancement attempts have been made using computerized digital techniques, such as flying spot scanner (FSS) enhancements. These have been used successfully to improve detection of near-shore sediment transport and current trends, as can be seen in Figure 12.

4. Sunglint

When the satellite is oriented in such a way as to receive an intense reflection of the sun from the surface, a bright spot appears in the imagery. This phenomenon has 

been referred to as sunglint and is apparent in most daytime imagery when the angle between the sun and sensors is correct. The effect will be minimized for a Northern Hemisphere site at the Winter Solstice, increasing to a maximum as the sun approaches the summer solstice. The intensity and frequency of this effect is also dependent on the latitude of the image. Associated with this bright area are several dark zones of reversed tone representing minimum surface reflectance caused by calm regions and areas of dryness [Fett and Rabe, 1973]. Photos demonstrating these types of effects have been used to locate atmospheric and ocean surface perturbations in the lee of islands. An example of a typical sunglint pattern is shown in Figure 13.

A difference of opinion exists as to what is actually visualized in satellite photos. Some say certain phenomena observed are sea surface features, some say they are visible effects in the air column immediately above the water, and some argue they may be both. Using Apollo photographs, Stevenson [1970] noted calm areas in the lee of the Cape Verde Islands and concluded that the effects were turbulent wakes resulting from wave refraction around the island. Strong, et al [1974] observed the same effects in the lee of the islands in NOAA-2 photos, concluding they were caused by wind-shadow resulting in differences in sea surface roughness. Fett and Rabe [1975] attribute island barrier effects observed in this type of imagery (DMSP) to sea state and low-level 

atmospheric moisture changes. The same confusion exists to a greater degree in the interpretation of perturbations apparent in the sunglint patterns.

5. NASA $70 \mathrm{~mm}$ Photographs

Several other types of photographic products, useful for looking at sea surface phenomena were found during this investigation. The NASA $70 \mathrm{~mm}$ and $\mathrm{U}-2$ photographs demonstrated the ability to show current trends and turbulent features at the sea surface. These features were similar to those found in satellite imagery, but on a smaller scale. Not only was nearshore sediment transport obvious in these photos, but so also were surface disturbances caused by obstructions to flow (see Figures 23 and 27). A detailed explanation of the camera systems used to obtain these products is not given. These photographs are presented here to show that remote sensing from aircraft also has potential uses in studies of oceanic and coastal processes.

The photographs of this type were normally taken with a camera and filter system, with a lens focal length of 6 in, from altitudes between 5,000 and $65,000 \mathrm{ft}$. This resulted in picture scales of $1: 10,000$ and $1: 130,000$, respectively. Presented here are those color and color infrared photographs archived by NASA at:

U.S. Department of Interior EROS Data Center Sioux Falls, South Dakota 57198 (605) 594-6151. 

The cameras are passive sensors, as are the satellite sensors, which produce both vertical and oblique views of the Earth's surface. The vertical photos have a constant scale which is dependent on the altitude of the aircraft and increases in distortion toward the periphery of the scene. The oblique photos are distorted over the entire picture, but are useful in finding surface features. 



\section{DETECTION OF SEA SURFACE PHENOMENA}

\section{A. INTRODUCTION}

During the Gemini manned space flights, the astronauts were able to capture on film evidence of atmospheric turbulence from altitudes of approximately $240 \mathrm{~km}$. Photographs of this type (Figure 14) demonstrated the potential of remote sensing of the Earth and they stimulated investigation into the future uses of instrumented sensing platforms in space. Since satellite studies have shown that large scale synoptic flow patterns do exist in the atmosphere and can be observed from space, it is reasonable then to assume that similar phenomena exist in the ocean.

A preliminary investigation of satellite imagery and theoretical and experimental work led to the assumption that sea surface effects resulting from islands and other obstructions, such as points of land or seamounts, might be observed and distinguishable flow patterns could be put into some sort of catalog. Images of the West coast of the United States, which showed characteristic eddy and gyre formations, were selected for presentation in this work. These images are representative of the characteristic flow patterns found in four areas which were examined closely. They were: i) Cape Mendocino $\left(38^{\circ} \mathrm{N}-42^{\circ} \mathrm{n}, 123^{\circ} \mathrm{W}-127^{\circ} \mathrm{W}\right)$ off which occurs a submarine escarpment which appears to influence deep currents; ii) the Monterey Bay area $\left(36^{\circ} \mathrm{N}-38^{\circ} \mathrm{N}, 121^{\circ} \mathrm{W}-123^{\circ} \mathrm{W}\right)$ which shows some interesting surface current effects; iii) the santa 

Barbara Channel $\left(32^{\circ} \mathrm{N}-35^{\circ} \mathrm{N}, 117^{\circ} \mathrm{W}-121^{\circ} \mathrm{W}\right)$ in which several examples of turbulent flow were observed with ERTS imagery; and iv) the Gulf of California $\left(26^{\circ} \mathrm{N}-30^{\circ} \mathrm{N}, 111^{\circ} \mathrm{W}-115^{\circ} \mathrm{W}\right)$ in which a few sunglint photo patterns picked-up interesting effects near islands. The three particular flow situations which were looked for are: i) flow around islands; ii) flow around points and extensions of land; and iii) water mass boundary interactions and mixing.

Qualitative deductions have been given for the phenomena observed in these images because of the lack of ground truth data. However these explanations are based on this author's experience, having looked at hundreds of photographs and on information obtained during interviews with investigators, such as Doug Pirie, Bob Fett, and Oscar Huh, who have had much experience in using satellite images. With an understanding of the regional oceanography, and after examining a great many images, one can make acceptable conclusions as to the causes of the flow patterns observed.

\section{B. PROBLEMS WITH SATELLITE IMAGERY}

Satellites offer oceanographers a new dimension for examining sea surface properties and structure. Their uses thus far have been limited because problems exist which prevent the sensors, in most cases, from obtaining true sea surface information. Only the archived data were available for this study and the formulation of a catalog was found to be unfeasible; it was determined that the spectral ranges of 

the sensors were generally unsatisfactory for detecting many sea surface phenomena.

The NOAA and DMSP sensors offer the best potential for oceanographic use, especially for locating distinct large scale surface phenomena with specially enhanced imagery. The characteristics of these systems which make them versatile also inhibit their ability to record ocean phenomena at times. The DMSP sensors record both visual and infrared radiation over a much broader range than that of the NOAA sensors. This wide range has provided a better image resolution capability for standard and enhanced products, however, this greater sensor "window" makes the data more susceptible to atmospheric contamination $\left(\mathrm{CO}_{2}\right.$, ozone, water vapor). Cloud cover, fog, and haze interfere noticeable with imagery from both satellite types, distorting the IR products until delineation between ocean features and atmospheric phenomena is neither certain nor realistic (this is most obvious in Figures 3 and 4). The archived imagery, due to the above limitations and the fact that the thermal resolutions of the sensors are too large, is restricted in its use for oceanic studies. As a matter of fact, the DMSP archived products were not at all useful in this investigation.

The ERTS sensors, operating primarily in the visual part of the spectrum, have produced imagery capable of detecting coastal water movements using sediments as a tracer. The images from this system have been extremely informative and useful although several drawbacks exist. First, coverage of 

an area repeats only every eighteen days, hardly sufficient for use in detecting sea surface changes on an operational basis, but usable. Second, the system presently has no remote processing facility capable of a near real-time use of the imagery. Third, the system has only been useful in nearshore current studies when a tracer has been present in the water. Even when sediment is present, several different enhancing techniques, augmenting the contrasts at the sea surface, are often necessary to produce a usable image for detecting currents. For this study sediment laden waters were found to occur year round in Northern California coastal areas because of the plentiful river discharge, while along the Southern California coast the presence of sediment was a seasonal occurrence. Rivers and streams south of San Francisco discharge during the winter and spring. A minor amount of sediment in the water is attributed to cliff erosion which is greatest in the winter. Hence, detection of coastal currents and nearshore processes with satellite imagery was found also to be seasonal, being best in the spring months.

Although coastal studies using satellite imagery are limited, surface information about the open ocean is even much more limited. In the open ocean, seaiment is virtually nonexistent and the surface thermal structure is more homogeneous.

\section{OBSERVATIONS OF SEPARATED FLOW}

1. Experimental Flows

A wake is formed downstream of an obstruction in a fluid flow. Many methods have been developed to calculate 

and record such flow fields; mathematical explanations, numerical solutions (Figure 15), and experimental results (Figure 16) have been used to describe and demonstrate the boundary-layer effects and potential flow of a fluid past objects of differing geometry, under special conditions. The most studied shape, that of a circular cylinder oriented vertically in the flow (Figure 17), makes a good first approximation to the plan view of many islands. It is assumed that the results of these numerical and experimental studies can be used to identify similar flow patterns, which might occur in the oceans, using a similitude hypothesis.

The Reynolds number, which relates the inertial forces to the viscous forces acting within the fluid, is often used to parameterize various flow conditions. For different fluid speeds, various Reynolds numbers can be associated with flcw patterns about a particular object whose dimensions remain constant. An example of classifying fluid flow with the Reynolds number is presented in Figure 18. The magnitude of the Reynolds number in the ocean is generally greater than $10^{8}$, hence flow patterns in the ocean would be expected to resemble Figure $18(e)$.

\section{Conventional Oceanographic Studies}

Several oceanographic surveys using standard hydrographic, drogue, and current meter techniques, have indicated that wake effects and vortex development can occur in oceanic flow, around islands in particular, under the proper conditions. Barclay [1972], using current meters and hydrographic data, 

showed the presence of a wake in the ocean downstream of Johnston Atoll $\left(16^{\circ} 45^{\prime} \mathrm{N}, 169^{\circ} 31^{\prime} \mathrm{W}\right)$. In this study an attempt was made to compare a theoretical analysis of the flow around this island with the observed flow field (Figure 19). The observations showed that the flow pattern strongly resembled that of a von Kármán vortex wake. Barclay concluded:

Wakes in nature probably resemble those on a much smaller scale in the laboratory because dissipation of energy by friction is similar, in some significant sense, on both scales. Thus the island-wake problem reduces to the well-known problem of the nature of large scale energy dissipation in turbulent fields.

Hendy and Wunsk [1973] found a wake effect downstream of Jarvis Island $\left(0^{\circ} 23^{\prime} \mathrm{S}, 160^{\circ} 00^{\prime} \mathrm{W}\right)$ from a survey of the density field. The flow was characterized by a high Reynolds number of $10^{9}$. A study by Hogg [1972], using drogues, current meters, and hydrographic casts to study the steady flow past Bermuda $\left(32^{\circ} 20^{\prime} \mathrm{N}, 64^{\circ} 45^{\prime} \mathrm{w}\right)$, revealed an anamolous area downstream of the island which appeared to be a turbulent wake effect; theoretical calculations and laboratory measurements of fluid flow about a circular island on a rotating plane seemed to be in good agreement with the actual results.

3. Observations with Satelite Imagery

a. Flow Past Islands

Several atmospheric investigations of flow around islands have been done which would indicate further that laboratory observations have applications to the real world. It has been shown that island topography is a major cause of wind variations and eddy formations in the lee of islands. Patzert [1969] found this to be the case in his study of the 

Hawaiian Islands. Numerical methods have shown that island barriers under certain conditions of low-level inversions can cause drying effects in their lee [Lavoie, 1974]; examples of DMSP sunglint imagery have been presented by Fett and Rabe [1975] showing this effect. Vortex wake developments have been observed in the satellite imagery of cloud patterns [Chopra and Hubert, 1965].

Although vortex wake development seems to be a common occurrence in atmospheric flows, none of the satellite images used in this study showed definitely identifiable sea surface effects resulting from similar separated flow around islands. It was not apparent whether the features which were observed were oceanic or atmospheric. With the standard DMSP products obtained, it proved to be impossible to detect ocean flow patterns, even though some atmospheric phenomena were apparent. The resolution of the NOAA sensors prevented any sea surface features from being detected, even the distinction between the islands and the surface of the ocean was difficult with the infrared imagery. ERTS imagery proved to be useful even though there was no evidence that what was observed was caused by currents flowing past the islands. Rather it is conjectured that generally the images are recording energy reflected from the surface and that the observed features are mostly atmospheric, being the result of air flowing over and around the island barriers. Cram and Hanson [1974], using ERTS-1 imagery in a study of the Lesser Antilles $\left(12^{\circ} \mathrm{N}-16^{\circ} \mathrm{N}, 60^{\circ} \mathrm{W}-63^{\circ} \mathrm{W}\right)$ found similar turbulent zones 

in the lee of these islands. However, ground truth analysis proved that these features were not oceanic eddy formations. Fett and Rabe [1975], using enhanced DMSP imagery, have also concluded that these occurrences are primarily atmospheric. They state that these features are visible in sunglint images due to reflection differences of the surface air layer; as the air flows past an island barrier it experiences a drying effect which becomes visible in satellite imagery as a grey shade of a different tone than that of the surrounding moist air. This hypothesis seems to be consistent with what was found in the imagery of the Santa Barbara Channel, obtained for the present study. Figure 20 depicts this kind of phenomenon very well. The dark area in the lee of Santa Cruz Island occurred during a time when the wind was from $310^{\circ} \mathrm{T}$ at a constant speed of 16 knots. Santa Cruz has tworather large peaks ( $660 \mathrm{~m}$ and $740 \mathrm{~m}$ above MHW) at the western edge of the island, as well as a single peak (550 $\mathrm{m}$ above MiHW) at the eastern edge, each of which would act as an obstacle to air flow past: The position of the dark areas correlates well with the location of the peaks. Figure 21 shows similar effects for other islands in the channel for the date of 23 August 1973. San Nicholas has a maximum elevation of $280 \mathrm{~m}$, Santa Catalina is a broad obstruction of $650 \mathrm{~m}$ elevation, while San Clemente is $600 \mathrm{~m}$ high. The wind direction for this and the previous day was steadily from $310^{\circ} \mathrm{T}$ at approximately 20 knots. Another example of the same type of effect is evident in Figure 22 which shows this streaming and calming 

effect behind all four islands in the region of the Gulf of California.

Surface effects on the sea surface also occur in the lee of islands which would tend to mask the streaming action of the general flow. If the wind blows steadily for a period of time, seas and local currents would be established at the surface due to frictional stress. Not only might the wind decrease in magnitude in the lee of a barrier and the air experience the drying effect just discussed, but a calming effect should occur in the seas and surface current, thereby amplifying the lessened reflectance in the area behind the island. Stronger reflected energy would be picked-up by the sensors from the rough sea areas away from the calmed regions. Thus, although it appears that this phenomenon is detected because of atmospheric conditions, it is likely that the sea surface is experiencing similar effects.

The most interesting photograph found during this investigation was a NASA infrared color photograph of San Francisco Bay (Figure 23) which shows the capabilities of such low-altitude sensing of the coastal environment. Not only are flow patterns past islands obvious, but the photograph also shows the boundaries of the water masses in the Bay and their interactions. The sea surface phenomena caused by disrupted flow are clearly visible. They are: i) the flow past Alcatraz Island, showing an eddy downstream;

ii) the bow wake and the lee effect of Treasure Island; and iii) wakes behind the Bay Bridge abutements which are similar 
to the high Reynolds number flow demonstrated in Figure $18(e)$ for circular cylinders.

\section{b. Flow Past Points of Land}

Several examples of turbulent effects forming on the sea surface due to extensions of land into a flow field were found which were definite oceanic phenomena. The boundary-layer spearation caused by fluid flow past points can be observed with ERTS images. This particular phenomenon could not be attributable in NOAA and DMSP imagery because the thermal and spatial scales of their sensors were too great to define the nearshore flow regime.

Figure 24 shows turbulent flow about Point Conception for 15 March 1973. A counterclockwise gyre resembling tip vortices similar to those forming the eddies depicted in the experimental flows of Figure 16, is demonstrated. The major sediment transport is to the south and has obviously been influenced by the land extending into the nearshore flow. Figure 25 shows this same gyre, in the image taken of Point Conception one day later as the satellite progressed to the west, away from the coast. The feature appears to have moved further south and dispersed with the flow. Figure 26 shows a small gyre forming off Point Conception during the same time of the year (20 April 1973). At other times of the year, this phenomenon has not been picked-up by ERTS imagery because of insufficient sediment to act as a tracer, or the currents being weak or non-existent. 

Conventional aerial photographs are also very useful in locating separated flow patterns. Figure 27 is a U-2, NASA flown $70 \mathrm{~mm}$ oblique color photograph, taken of Cresent City and showing a gyre downstream of Point st. George. The similarity between this flow pattern and those of Figure 16 (experimental flows) is outstanding.

Another type of gyre formation is shown in Figure 28. The image is an ERTS FSS enhancement showing the turbulent flow caused as the current tends south past Cypress Point near Monterey Bay. This phenomenon is characteristic of a Kelvin-Helmholtz flow instability and is caused by the water shearing along the land boundary of the current system.

\section{WATER MASS BOUNDARIES AND MIXING}

Determination of the synoptic coastal circulation has been the most fruitful use of present satellite imagery because of the presence of tracers in the water. The large scale oceanic phenomena and an explanation of their probable causes as interpreted from satellite imagery is given below. Eddies and gyres associated with mass transport can be found along oceanic fronts and continental shelves [Fett and Rabe, 1975]. These features are observed with satellite imagery when the isolines of the "contaminants" (sediment and thermal contrasts) tend to align themselves with the streamlines and the flow can be examined.

Dispersion of the coastal sediment is obvious in ERTS imagery. Figure 29 shows the sediment transport in the ocean off Cape Mendocino for 6 August 1974. Figure 30 shows the 

transport in the area three months later ( 3 November 1974).

A greater quantity of sediment is observed in the latter image. A gyre, possibly caused by a northward flow of cool upwelled water, is apparent in both images; this would account for the dark zone of sediment-free nearshore water in the presence of the southerly flowing sediment transport. The northerly Davidson Current is prevalent in the area during this time of the year (winter). As the water flows north it encounters a ridge off Punta Gorda and may be forced to the surface creating thermal contrasts in the ocean similar to those observed in these as well as Figure 7. The NOAA image for 3 November 1974 (Figure 31) does rot show these surface features. The difficulties of interpreting the phenomena in these images again points out the need for ground truth information for verification of the surface structure.

Figures 2 and 32 show the capability of the NOAA satellite images for locating general circulation patterns and large scale oceanic fronts. A strong thermal contrast is apparent in Figure 2, which is a photographic enhancement of a standard infrared image. Figure 32 is a standard product showing upwelled coastal water being mixed seaward by an interaction between the southerly California current and the coastal water.

DMSP archived imagery proved to be incapable of revealing any surface phenomena. Figure 33 is presented to show again the futility of attempting to use these standard images for oceanographic studies. It is typical of the DMSP products received during this study. 



\section{E. SUMMARY}

The difficulties of explaining sea surface phenomena with satellite imagery have become obvious during this investigation. The study began with two general assumptions, neither of which has been proven conclusively: that sea surface processes could easily be detected on a regular basis using the presently available imagery; and, that by using the imagery from all three types of systems, a better understanding could be obtained of any observed flow phenomena. It is concluded, however, that the phenomena cannot be satisfactorily explained without direct supporting atmospheric and oceanic data. This ground truth information is necessary before a substantive description and analysis of sea surface processes are attempted. Because of the lack of supporting data, many of the effects observed in the imagery presented in this paper have been hypothetically and qualitatively described.

There has been some extensive research, done in specific ccean areas, which has demonstrated the utility of satellite information. Huh [1973 and 1975] has shown the real-time capability of the DMSP for obtaining specially enhanced images of the Yellow sea and the Sea of Japan, and Braeker and Jurick [1975] have recommended real-time use of NOAA images for locating favorable fishing areas. Most researchers presently are not able to obtain access to the kind of special processing equipment required. Only standard available images were compared here and this examination has illustrated their limited oceanographic usefulness. 



\section{CONCLUSIONS}

Satellites and airplanes offer an observer the ability to see the Earth from a remote viewpoint. The images produced with data returned from sensors carried by these platforms give an instantaneous picture of a large area. The satellites produce these images at specific periodic intervals, enabling the observer to monitor changes over the same area. Meteorologists have found many uses for such imagery and improvement in the sensors and processing techniques over the years has enabled workers in this area to increase their knowledge of weather phenomena. Although problems arise when using these systems to obtain information of an oceanographic character, the capability presently exists for limited uses of satellite imagery in marine studies. This usage should greatly increase with the development of sensors, designed specifically to gather oceanographic data.

A catalog of oceanic surface flow patterns detected by present satellite sensors has not been possible to anything near the extent originally anticipated. A serious restriction is the spectral ranges which these sensors monitor. The sensors carried by NOAA and DMSP satellites were designed to detect cloud cover and other atmospheric conditions; their particular susceptibility to water vapor in the atmosphere prevents a continuous or complete survey of the 

sea. The sensors of ERTS are dependent on sediment being present in the surface waters and are also restricted by cloud cover. The lack of thermal contrast or sediment content further limits or inhibits the use of present imagery in the open ocean.

However, even with the above drawbacks present satellite imagery does have the capability to detect and show several coastal sea surface processes. Other than the fact that ERTS does not have a real-time processing capability, the images from this system produced the best results for this investigation. Not only were the standard products excellent, but the FSS enhancement proved to be beneficial in bringing out perturbations in the surface flow regime. The following coastal processes have been detected using ERTS imagery: i) sources and distribution of sediment transport; ii) monthly and seasonal current patterns [Pirie and Steller, 1974]; iii) regions of water mass boundaries and areas of mixing and shearing; and iv) flows disturbed by obstructions, wind, and bottom topography. Although the ERTS imagery proved to be most useful, the NOAA and DMSP images do have the ability to detect certain mesoscale sea surface structures such as: i) oceanic fronts [Huh, 1975]; ii) water mass boundaries and areas of mixing and shearing; iii) zones of convergence and divergence; and $i v)$ upwelling [Braeker and Jurick, 1975]. As yet quantitative work using available satellite imagery has not proved effective because of the lack of ground truth, but qualitative use of this information is important. 

The most valuable attribute of present satellite systems is their ability to obtain images in near real-time with remote computerized processing facilities. Real-time images give the oceanographer the ability to control his conventional survey and consequently obtain more useful information about the entire water column; this in itself makes the satellite an extremely useful tool.

Satellite images have the capability to observe synoptically, turbulent regions at boundaries between oceanic fronts and currents, as well as in areas of separation due to the obstruction of fluid flow. This information could be beneficial in coastal search and rescue operations since it could be used to up-date the data obtained from the present seasonal and weekly predicted surface current charts. Along with the general environmental data obtained on scene through conventional means, satellite imagery offers the search planner additional information to compute drift direction and to find anamolous current patterns. 



\section{RECOMMENDATIONS}

1. More ground truth studies must be conducted to determine the actual phenomena being observed in satellite imagery.

2. NOAA and ERTS archived imagery could be used for postsurvey evaluations of any conventionally obtained oceanographic data whenever additional information about the sea surface could benefit the researcher. The imagery could add synoptic information to the survey.

3. Any institution or individual planning a detailed coordinated environmental survey should attempt to use the realtime capability of the NOAA and DMSP satellite systems whenever possible. Thus data collection could be directed, using the imagery, to obtain information about prominent transitory features of the general current flow.

4. Although certain large scale surface phenomena are observed in present satellite imagery, better resolution is necessary for detailed ocean studies. Researchers should continue working on the design of sensors with better thermal and spatial resolution. More multi-spectral sensors with smaller spectral ranges to eliminate atmospheric contamination from the data should be used for oceanographic work.

5. The Coast Guard Oceanographic Unit has been using NOAA images to check the quality of its predicted weekly sea surface current charts of the Gulf stream. For this purpose, 

the DMSP special products could offer much more information. In addition to a higher repetition rate of coverage, better resolution of the surface structure can be obtained $\left(0.6-3.7 \mathrm{~km}\right.$ and $\left.1.6^{\circ} \mathrm{K}\right)$. Inquiries should be made to the U.S. Air Force as to the possibility and cost of obtaining, on a regular basis, their specially enhanced high resolution imagery. These should be used to check the quality of the present predicted current charts.

6. A study should be conducted as to the feasibility of using satellite images to locate, in a search area, local turbulent surface disturbances which might affect the predicted drift of a distressed vessel or craft. 



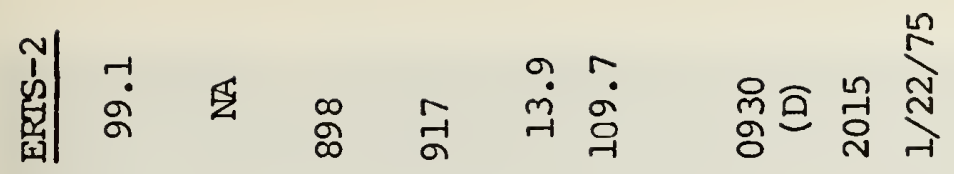

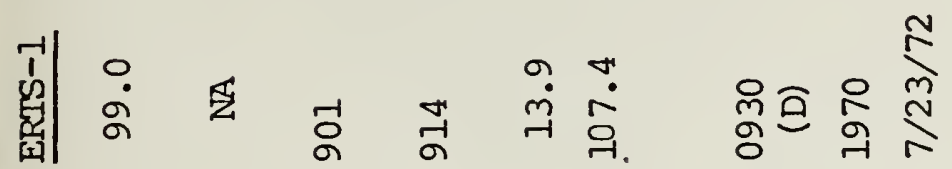

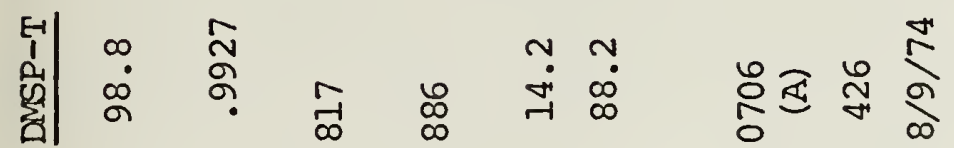

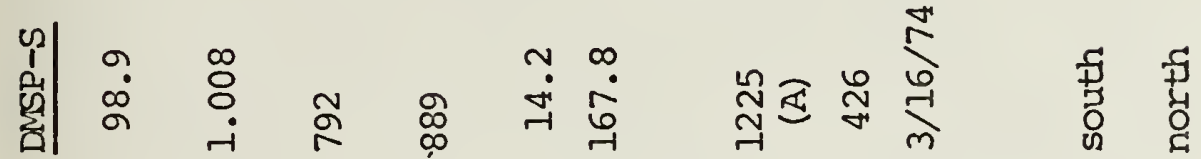



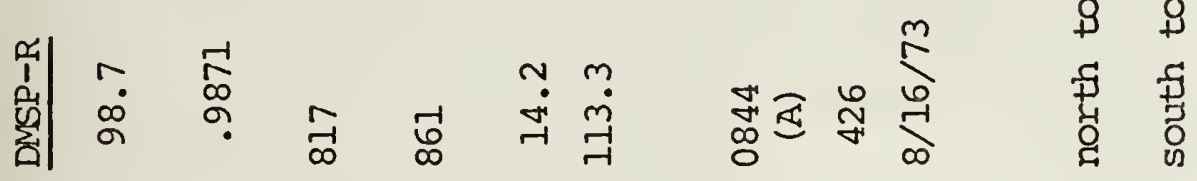

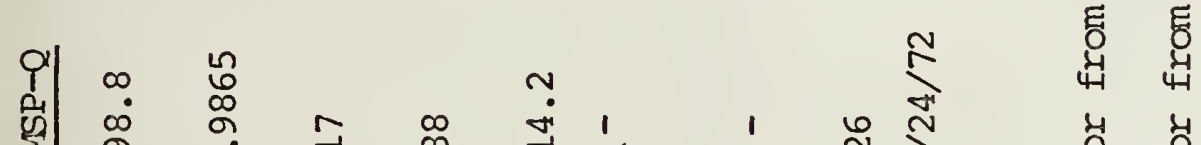

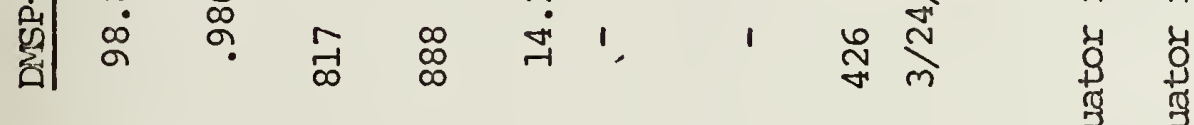

4

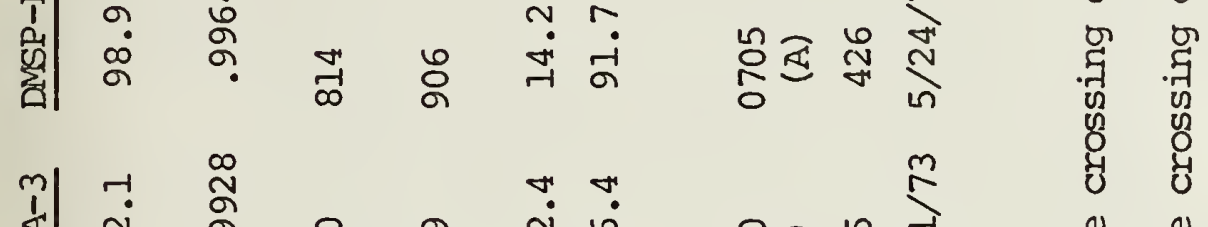

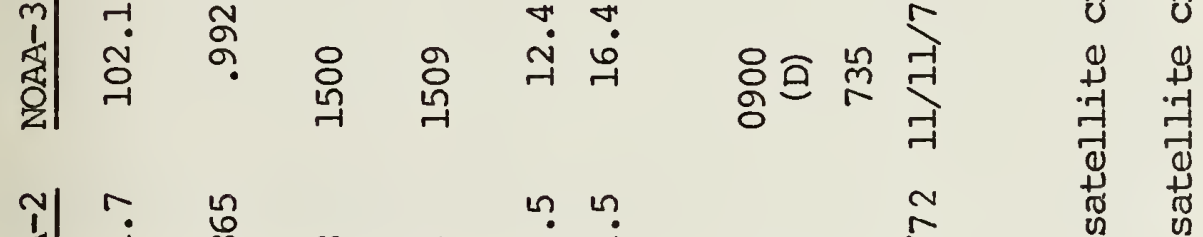

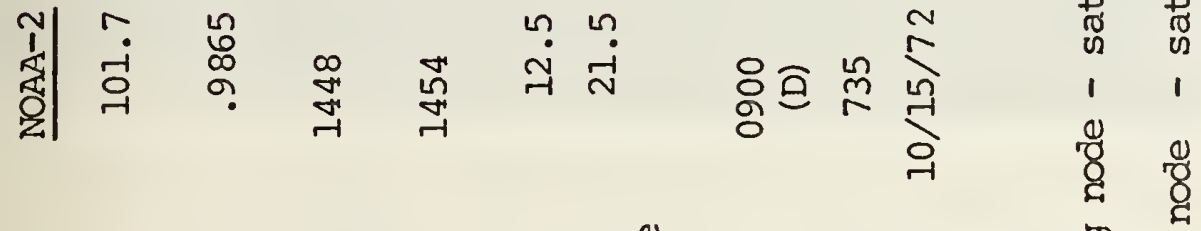

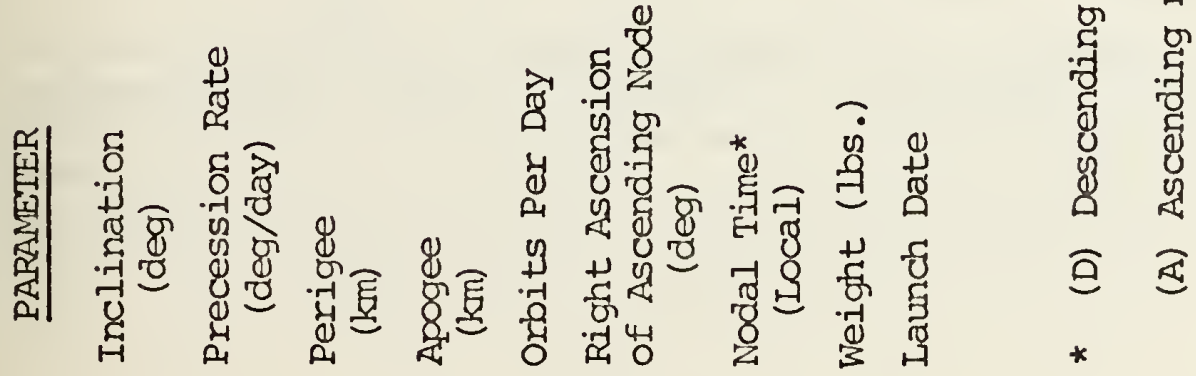





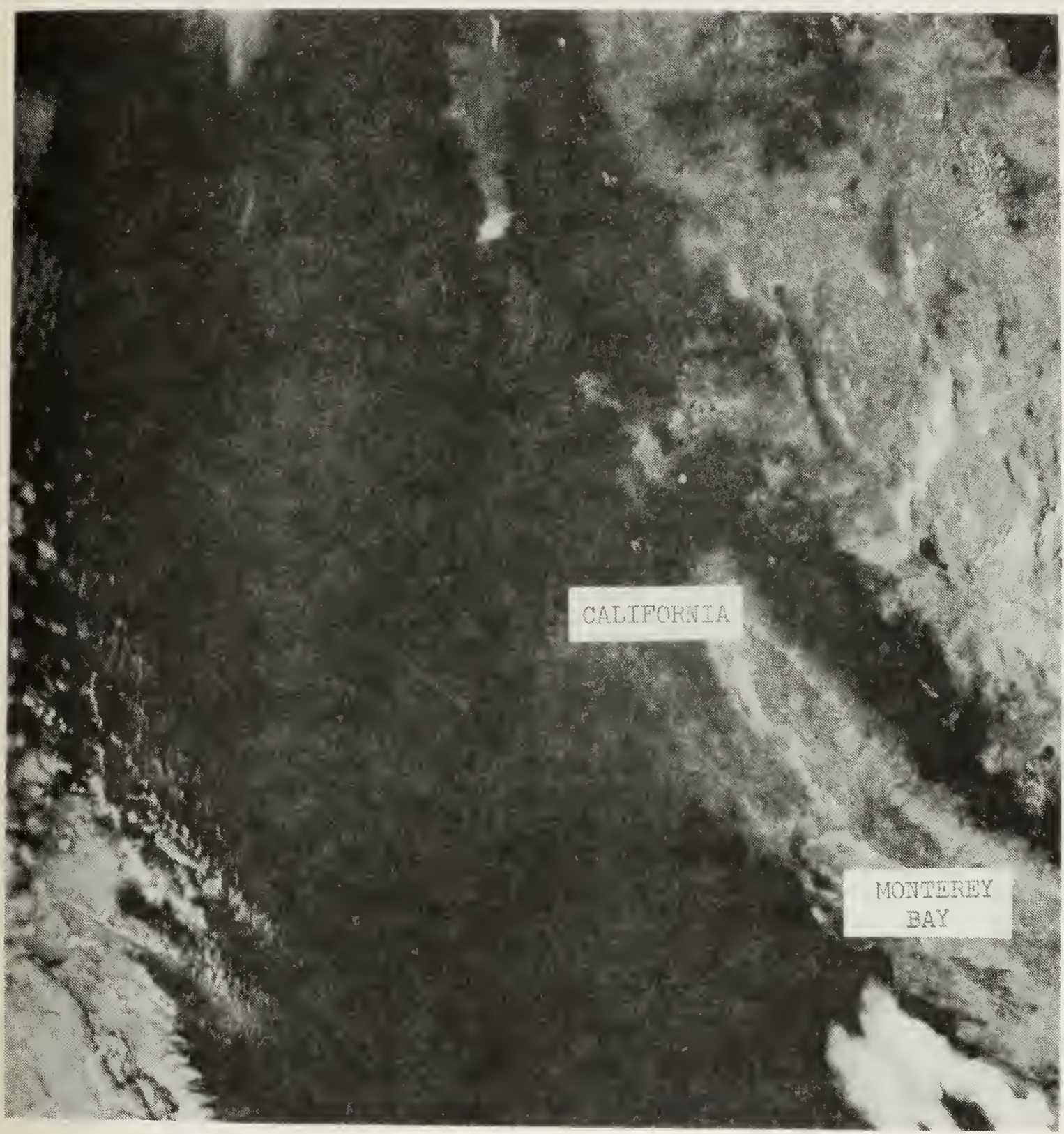

Figure 1. NOAA-3 VHRR Standard Archived Product, 11 sept. 1974.

This is the visual image produced, in conjunction with the infrared image shown in Figure 2. This image is useful for differentiating between the sea surface, coastline and cloud cover.

Provided by Larry Braeker, NOAA-NESS Redwood City, CA. 



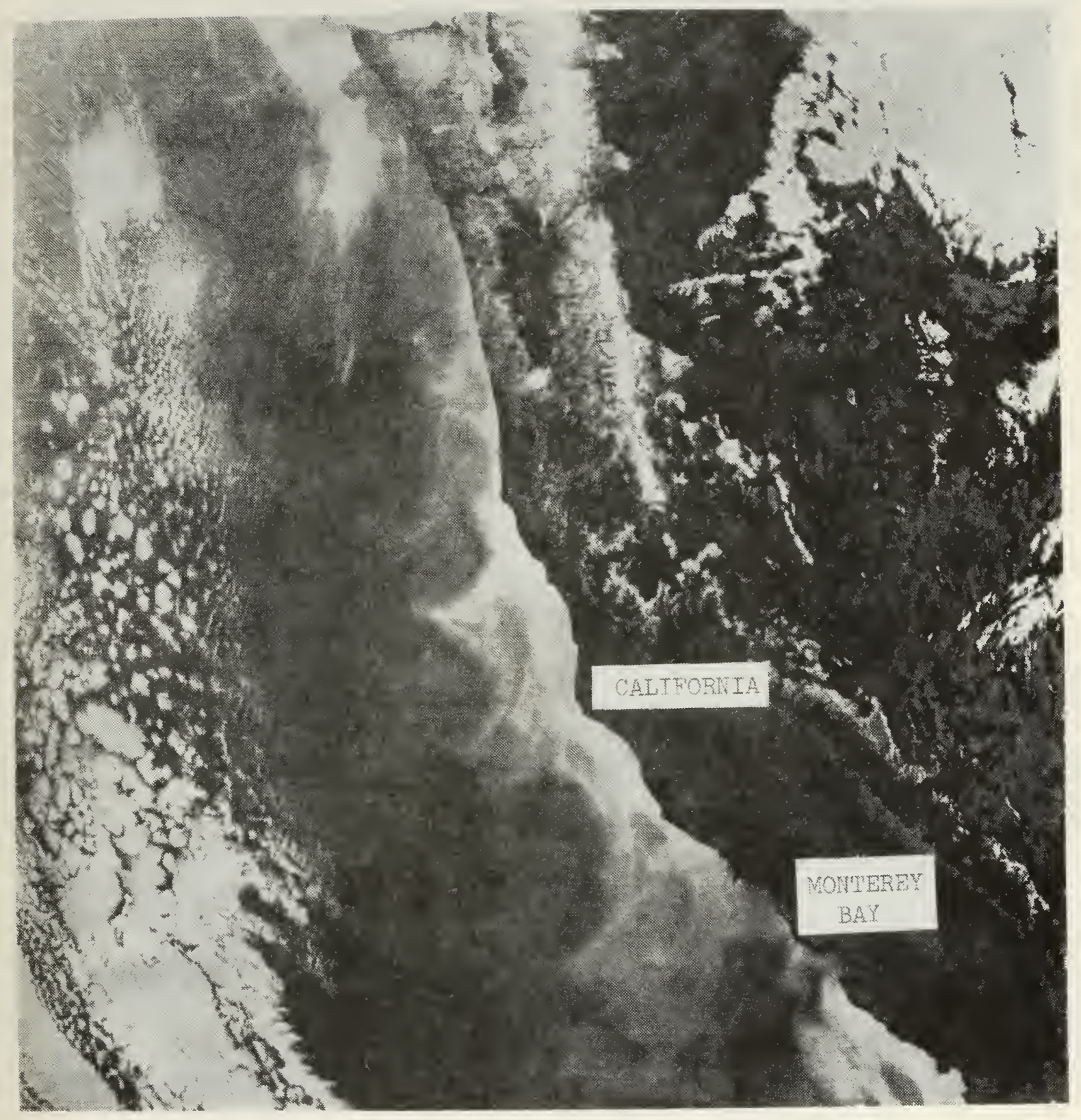

Figure 2. NOAA-3 VHRR Product, 11 sept. 1974.

This is a photographic enhancement produced from the infrared image. This image shows many gyre formations due to the mixing between the nearshore and upwelling water masses and the southerly moving Oceanic Current off the Pacific coast. A fog wedge was present near Monterey Bay (bottom right) but is not distinguished from the sea surface features without the supporting visual image shown in Figure 1.

Provided by Larry Braeker, NOAA-NESS Redwood City, CA. 



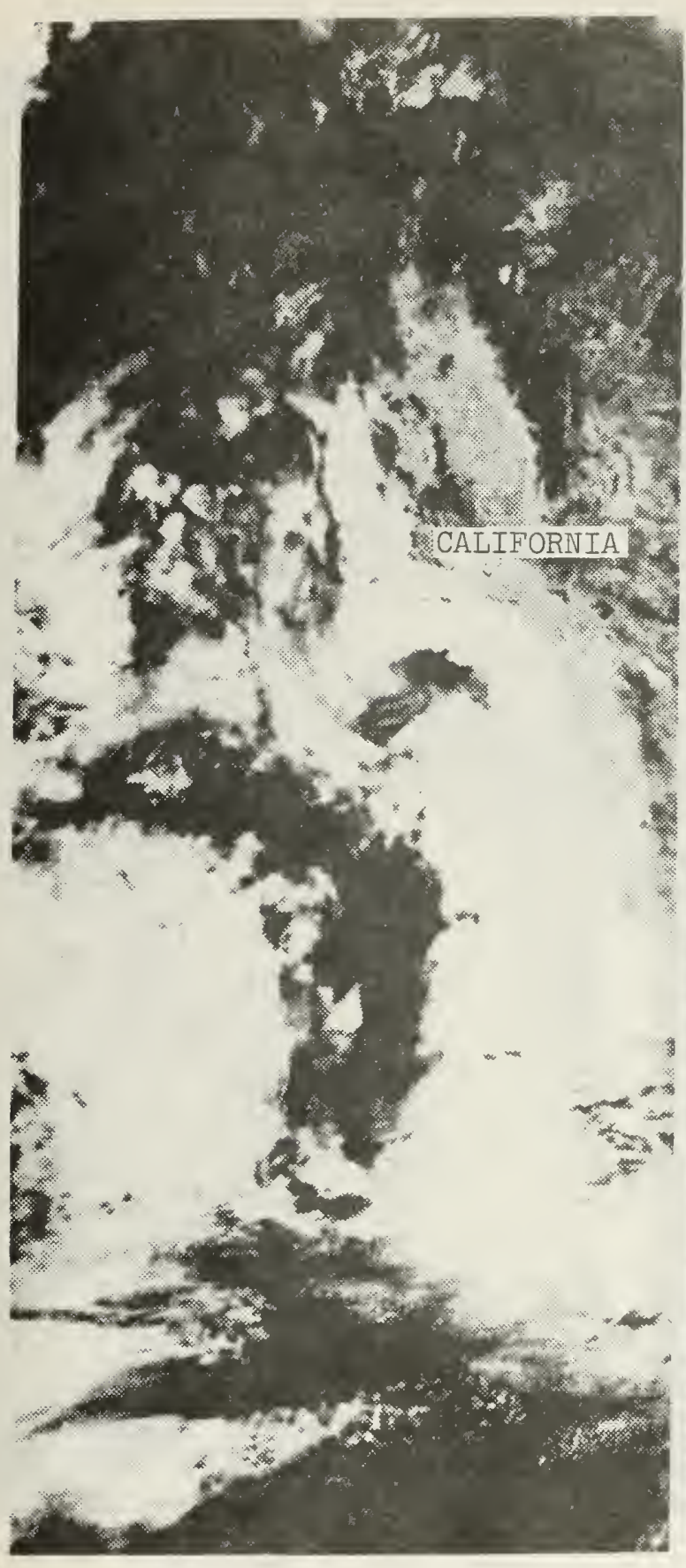

(a)

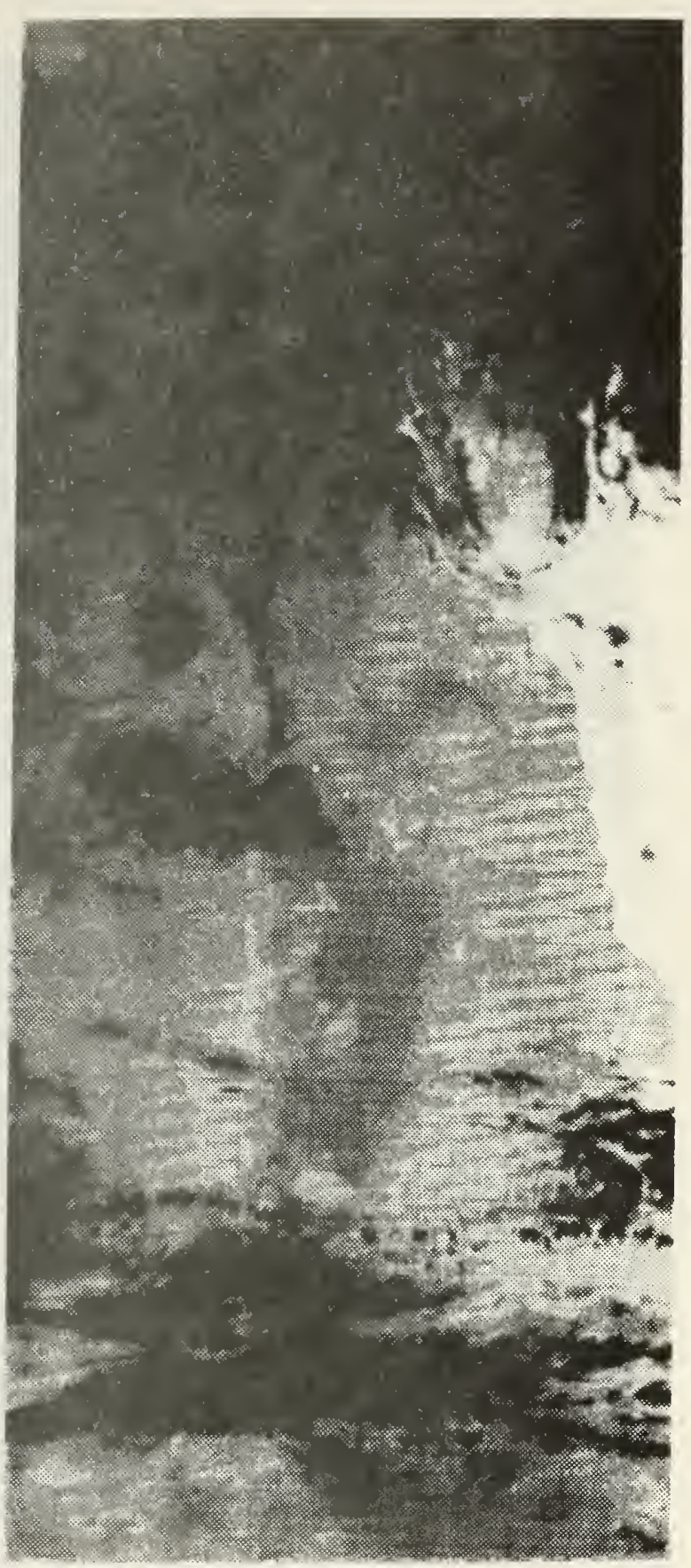

(b)

Figure 3. DMSP Standard Archived Products, 15 March 1973.

(a) Portion of a high resolution visual image of the California coast.

(b) Portion of a high resolution infrared inage of the California coast, showing the same area.

Both images were taken at the same time by the same sensor, the scanning radiometer (SR). Again notice the usefulness of the visual image for differentiating between the ocean and clouds.

Received from the University of Wisconsin, Madison. 


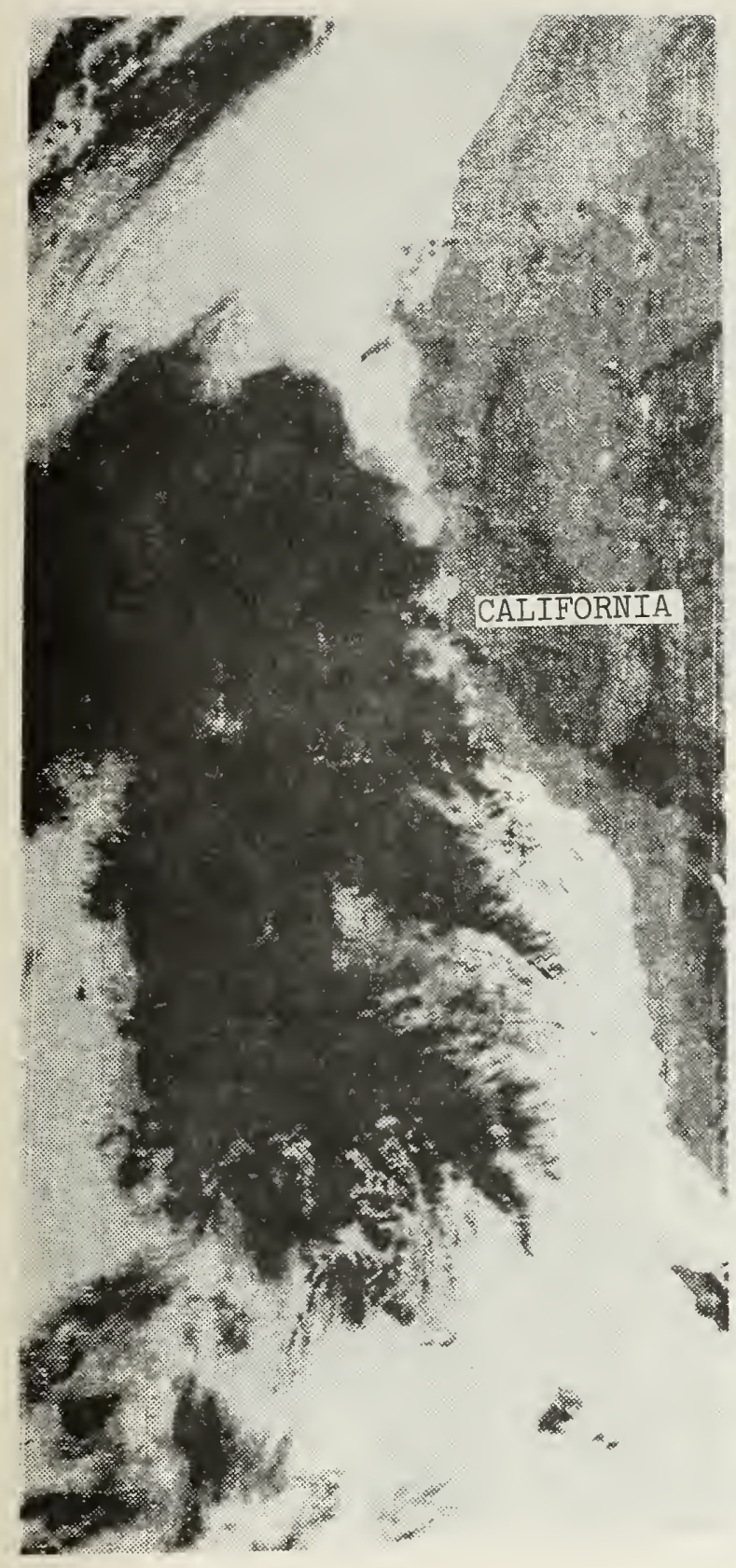

(a)

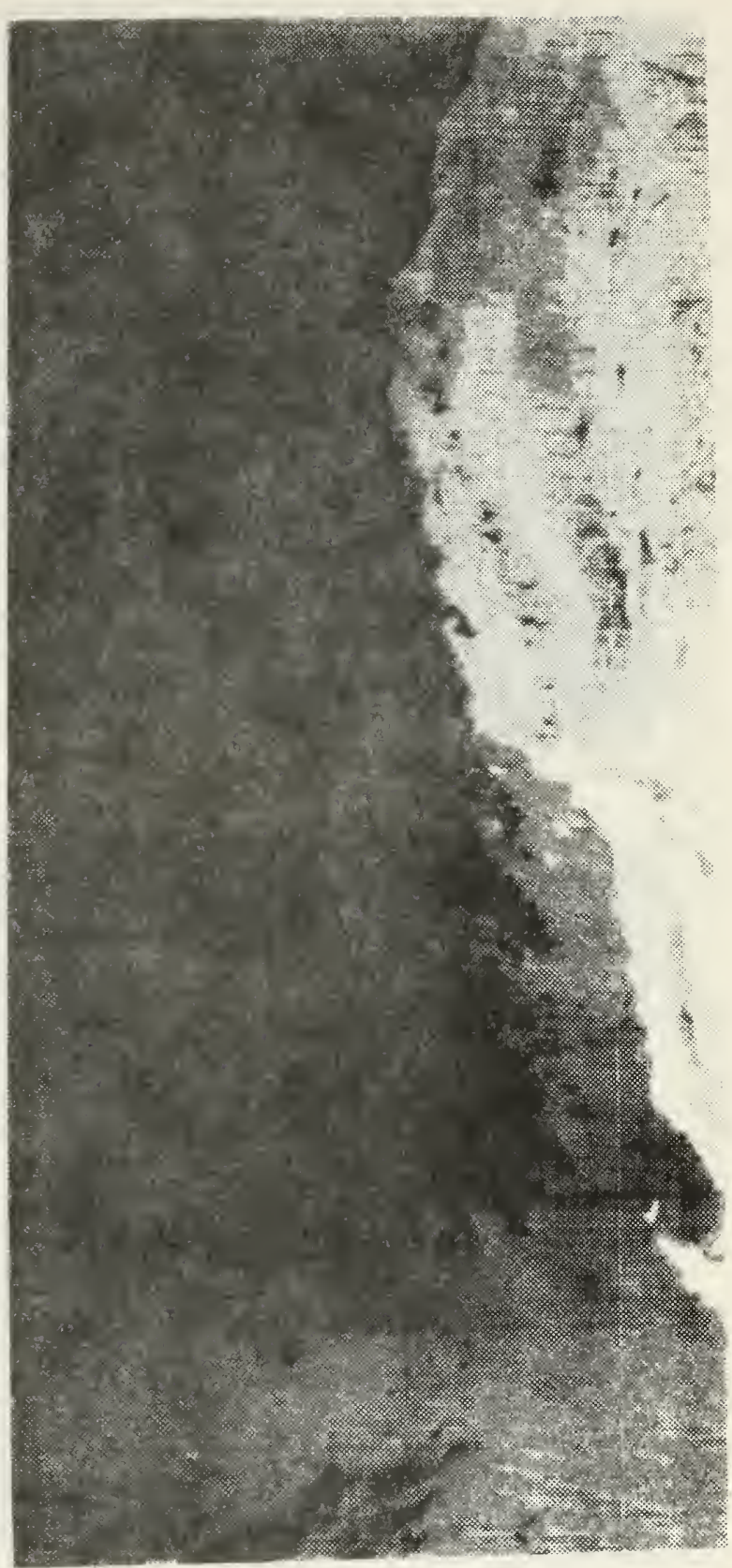

(b)

Figure 4. DMSP Standard Archived Products, 16 october 1974.

(a) Portion of a very high resolution visual image of the California coast.

(b) Portion of a very high resolution infrared image of the California coast - the same area.

These images show the poor quality imagery, which is not useful for oceanographic work, although meteorologists have found several uses for it.

Received from the University of Wisconsin, Madison. 



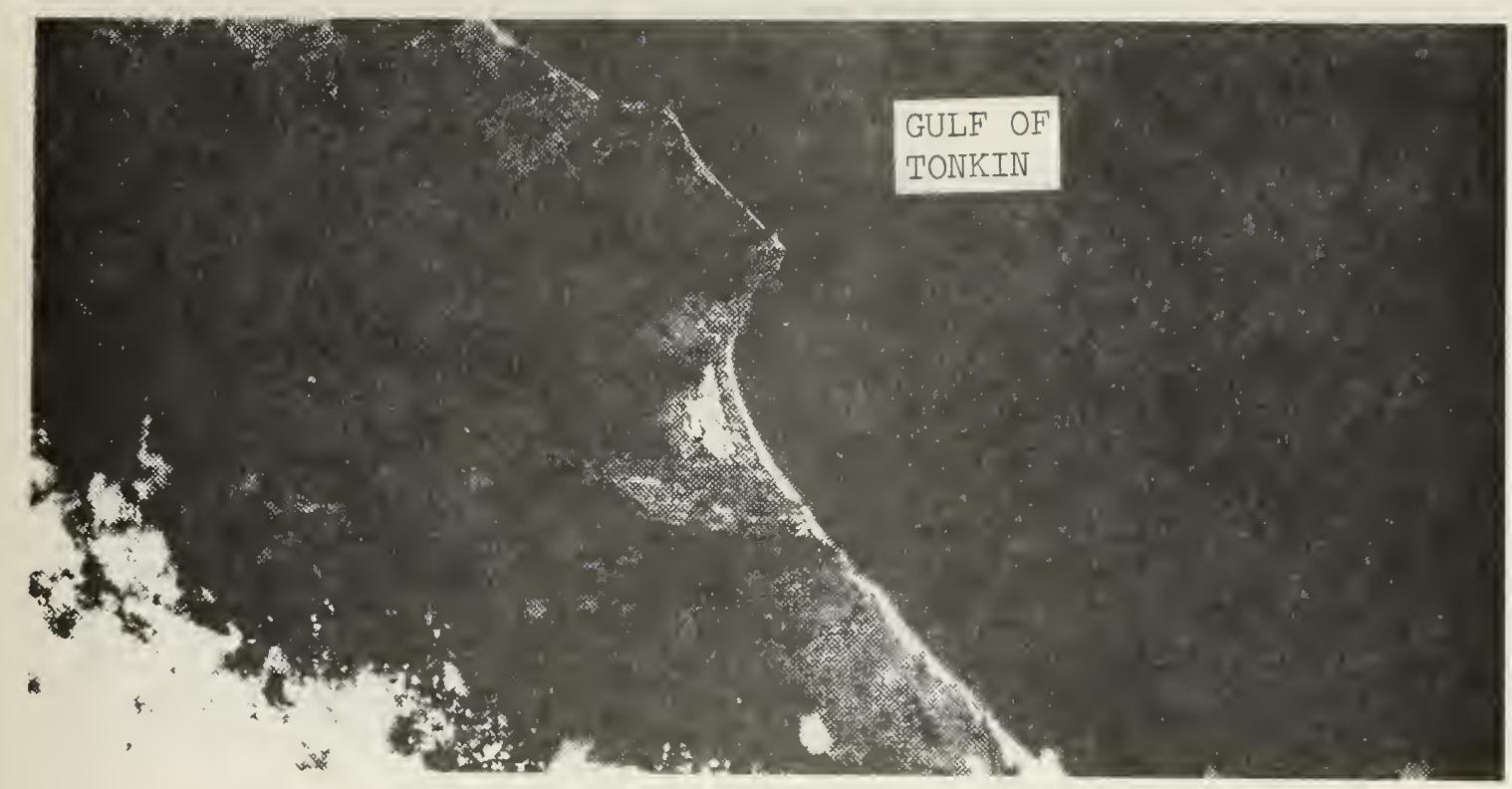

(a)

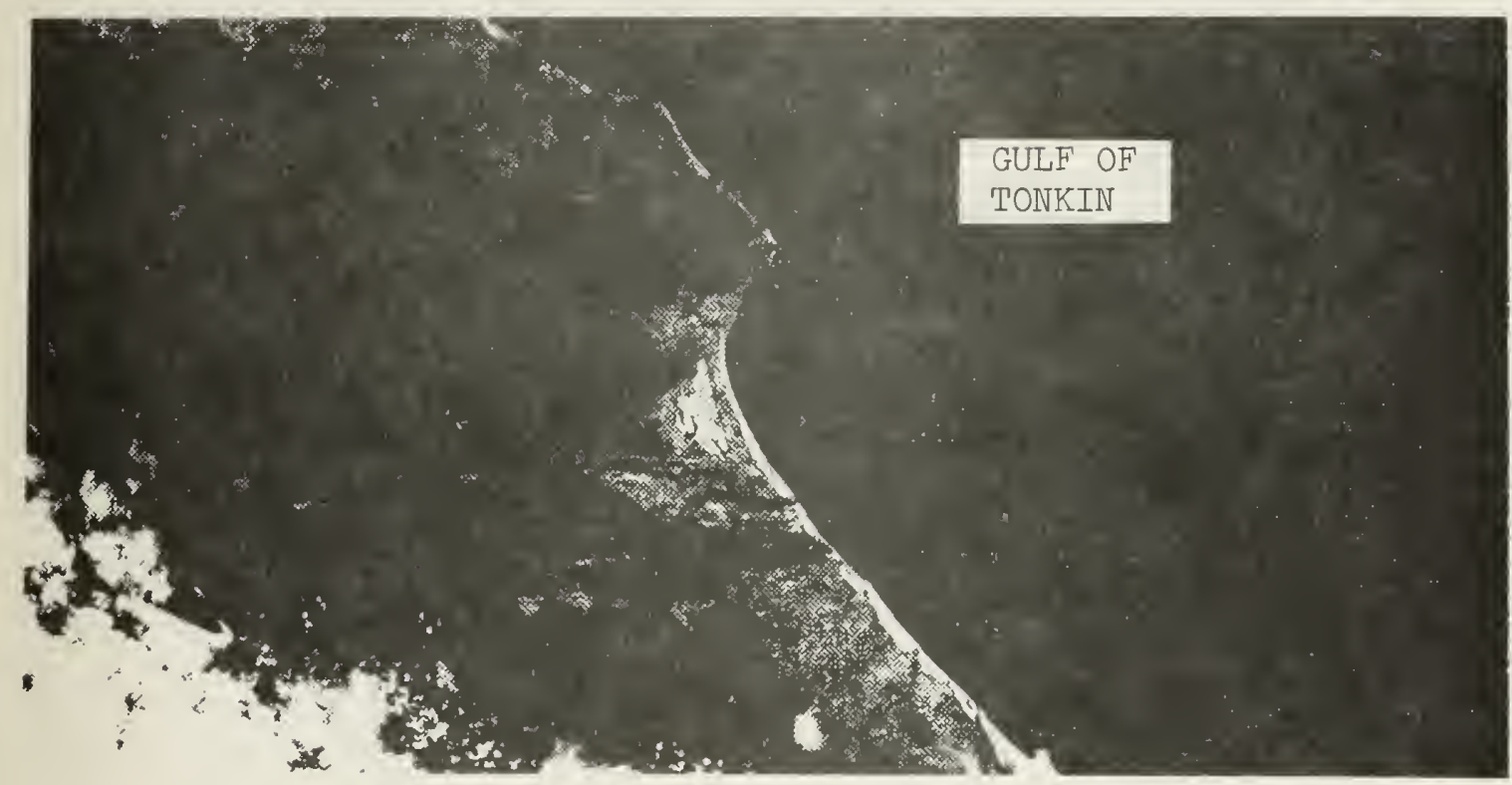

(b)

Figure 5. ERTS Standard Archived Products, 20 July 1973.

(a) 1362-02481, Band 4 .

(b) $1362-02481$, Band 5 .

Both images were taken at the same time as were those in Figure 6, which shows Bands 6 and 7. This image shows the sediment in the surface waters off Vietnam in the Gulf of Tonkin, and is only visible in Bands 4 and 5.

Received from EROS Data Center, Sioux Falls, South Dakota. 



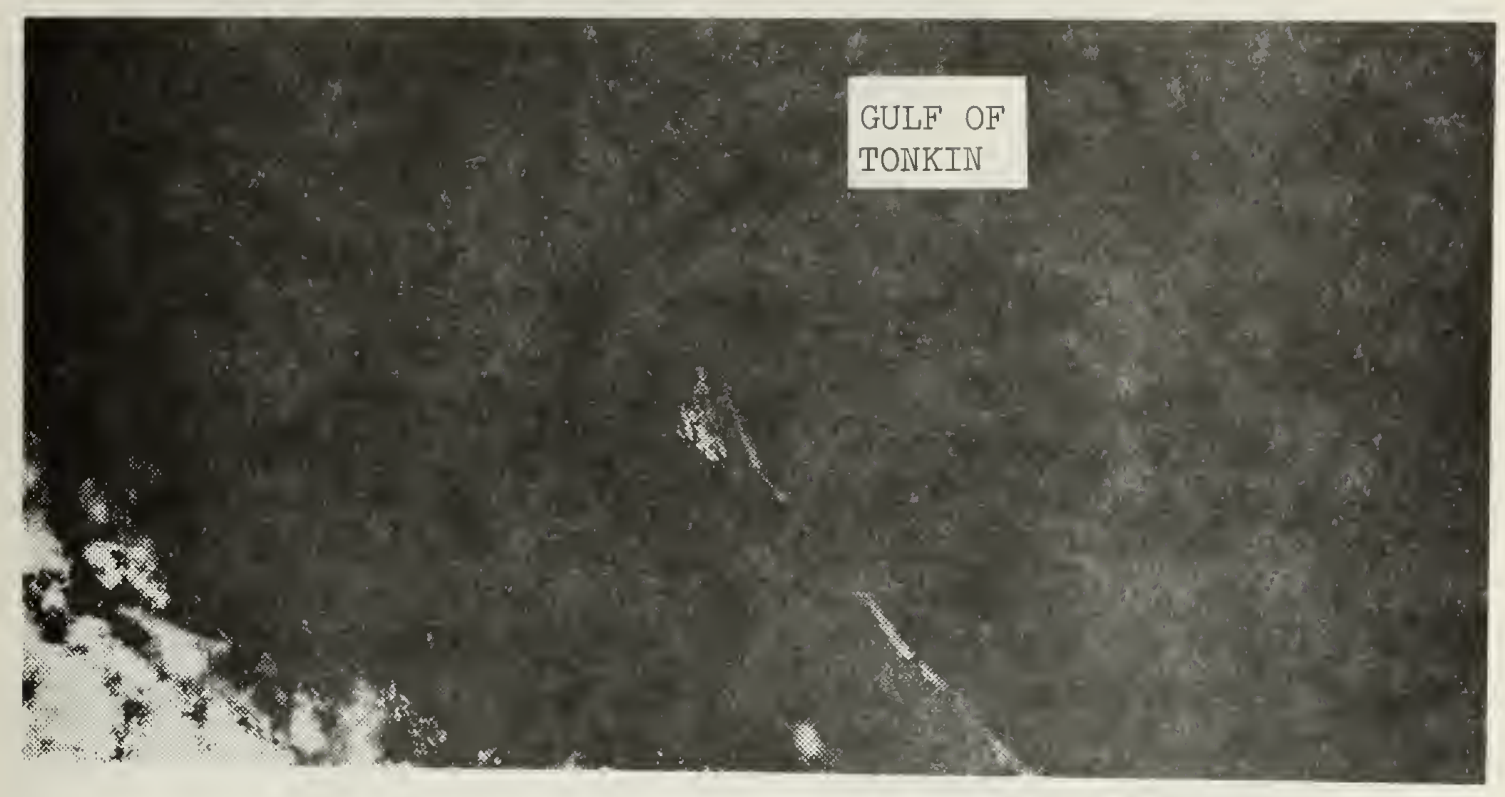

(a)

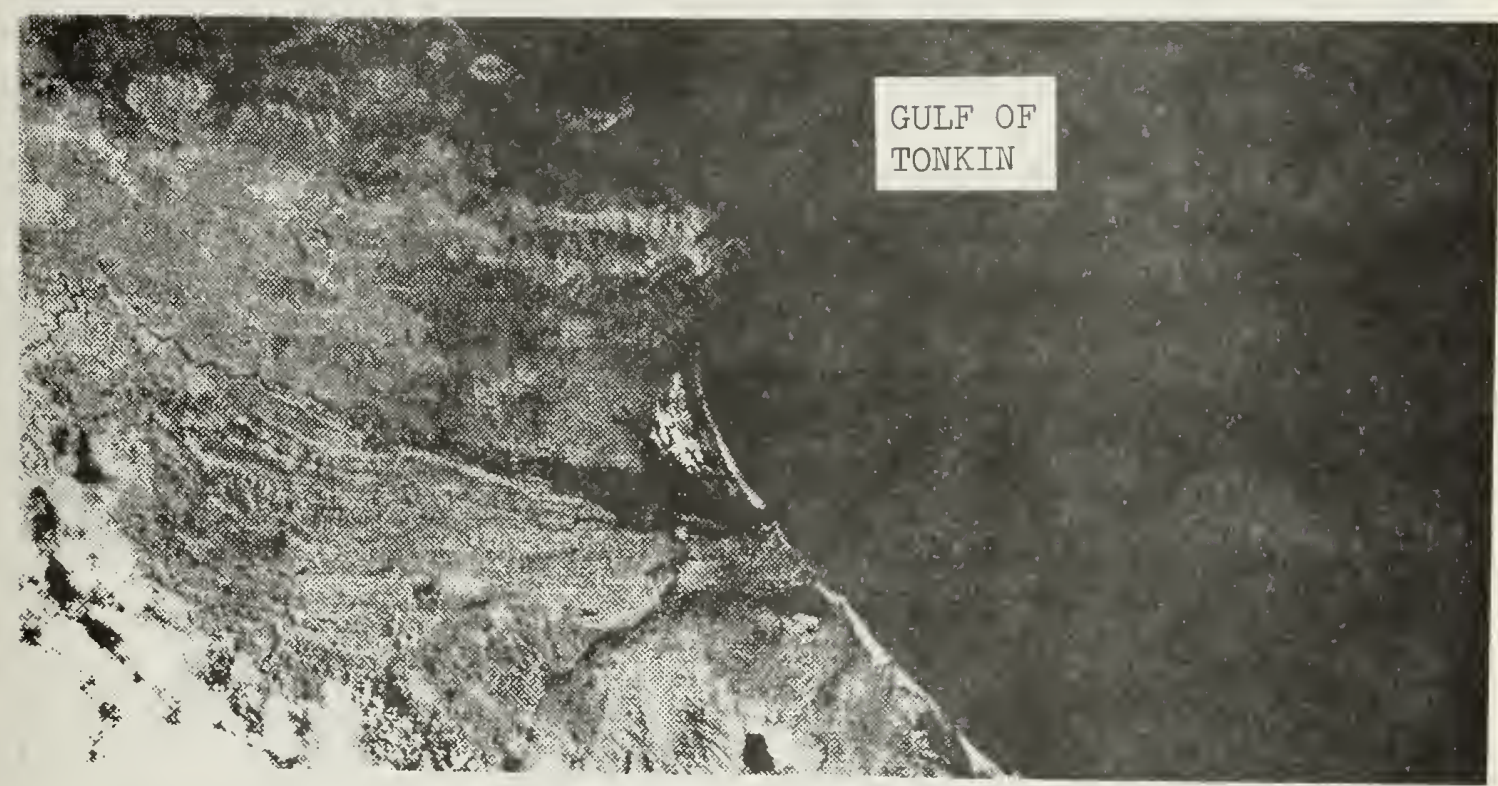

(b)

Figure 6. ERTS Standard Archived Products, 20 July 1973. (a) 1362-02481, Band 6 . (b) $1362-02481$, Band 7 .

Both images show the same scene depicted in the images of Figure 5. These images are not capable of recording the sediment in the surface.

Received from EROS Data Center, Sioux Falls, South Dakota. 



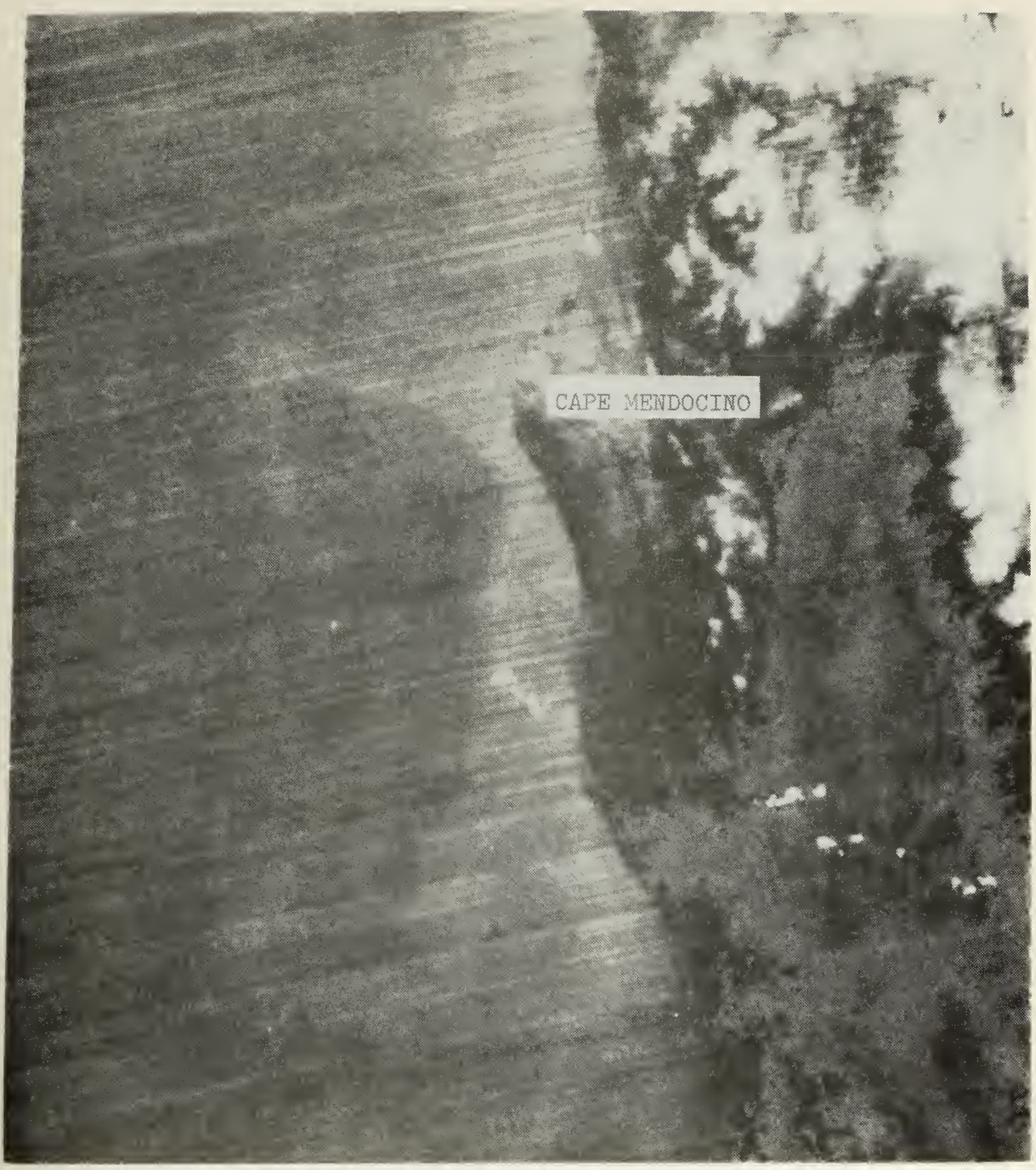

Figure 7. NOAA-4 VHRR Infrared Enlargement.

Image shows an upwelling off Cape Mendocino with the formation of several gyres, resulting from the mixing and shearing between water masses.

Warm areas appear dark; cool areas appear grey. Provided by Larry Braeker, NOAA-NESS Redwood City, CA. 



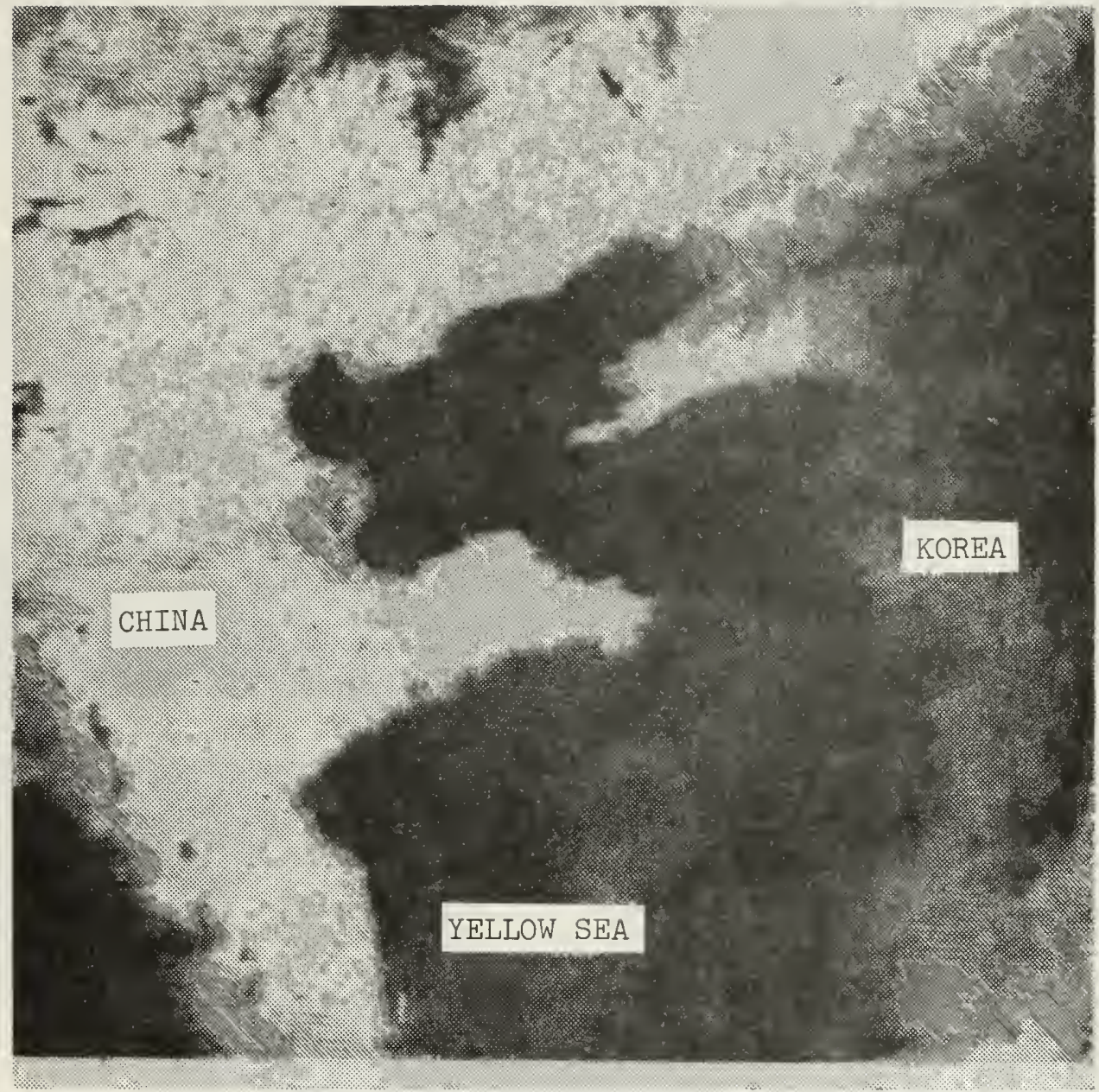

Figure 8. DMSP HR Infrared Image, 1 April 1972, 4527/2405, center expanded, setting $\mathrm{MI}_{1}, \mathrm{X}_{4}, 291^{\circ}$.

Image shows the China Coastal Current as a cold water tongue moving southerly in the Yellow Sea.

Warm areas appear white; cool areas appear dark since print was originally made using the film product (positive transparency) as a negative.

Provided by Oscar Huh, Naval Oceanographic Office, Washington, D.C. - Technical Report \# 241. 


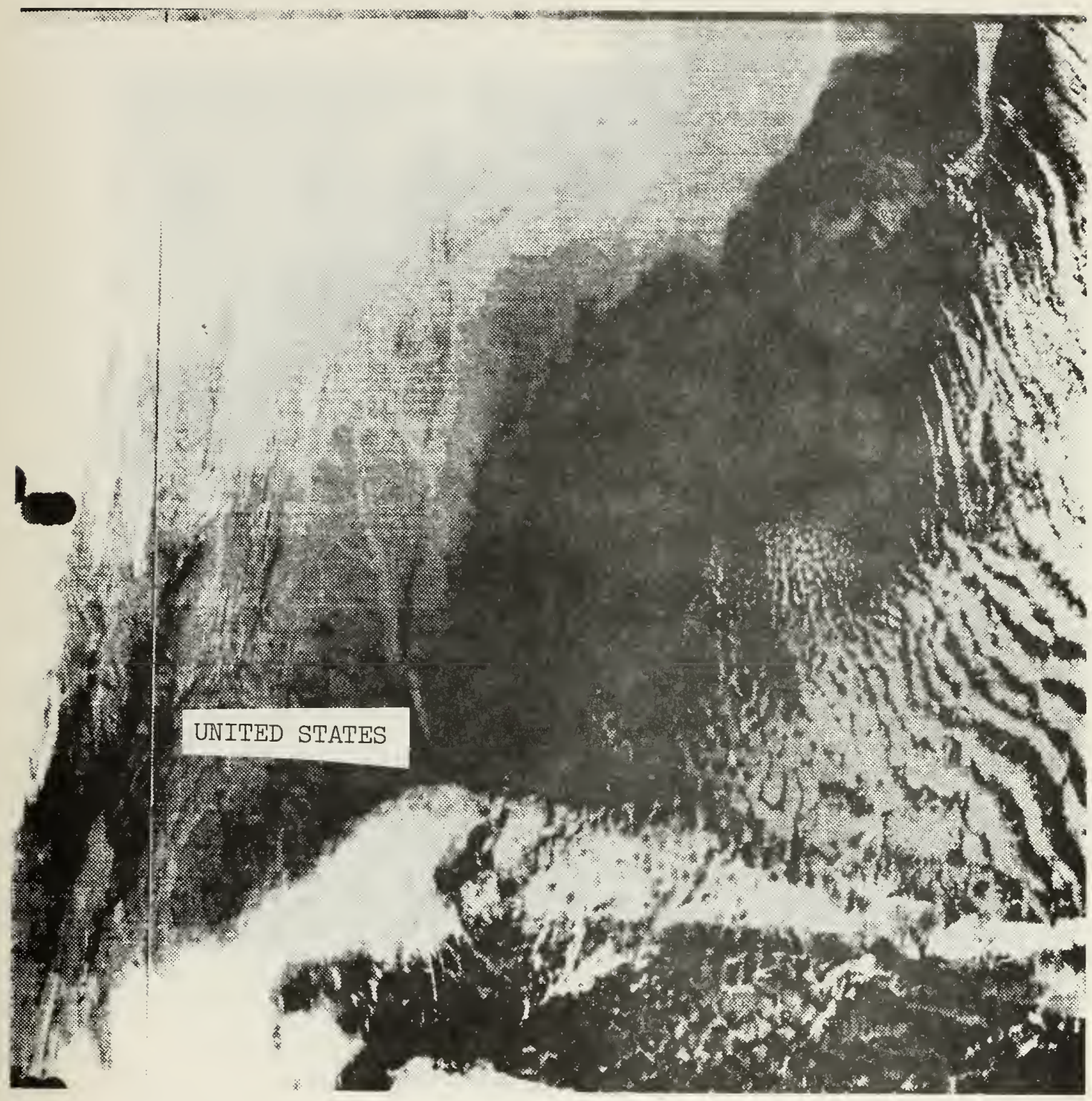

Figure 9. NOAA-4 VHRR Infrared Product, 22 Feb. 1975.

Image shows the formation of large scale gyres in the sea surface at the boundaries between the Gulf stream, as it flows north, and the nearshore and oceanic water masses as they interact and $\mathrm{mix}$.

Warm areas appear dark; cool areas appear grey.

Provided by Larry Braeker, NOAA-NESS Redwood City, CA. 



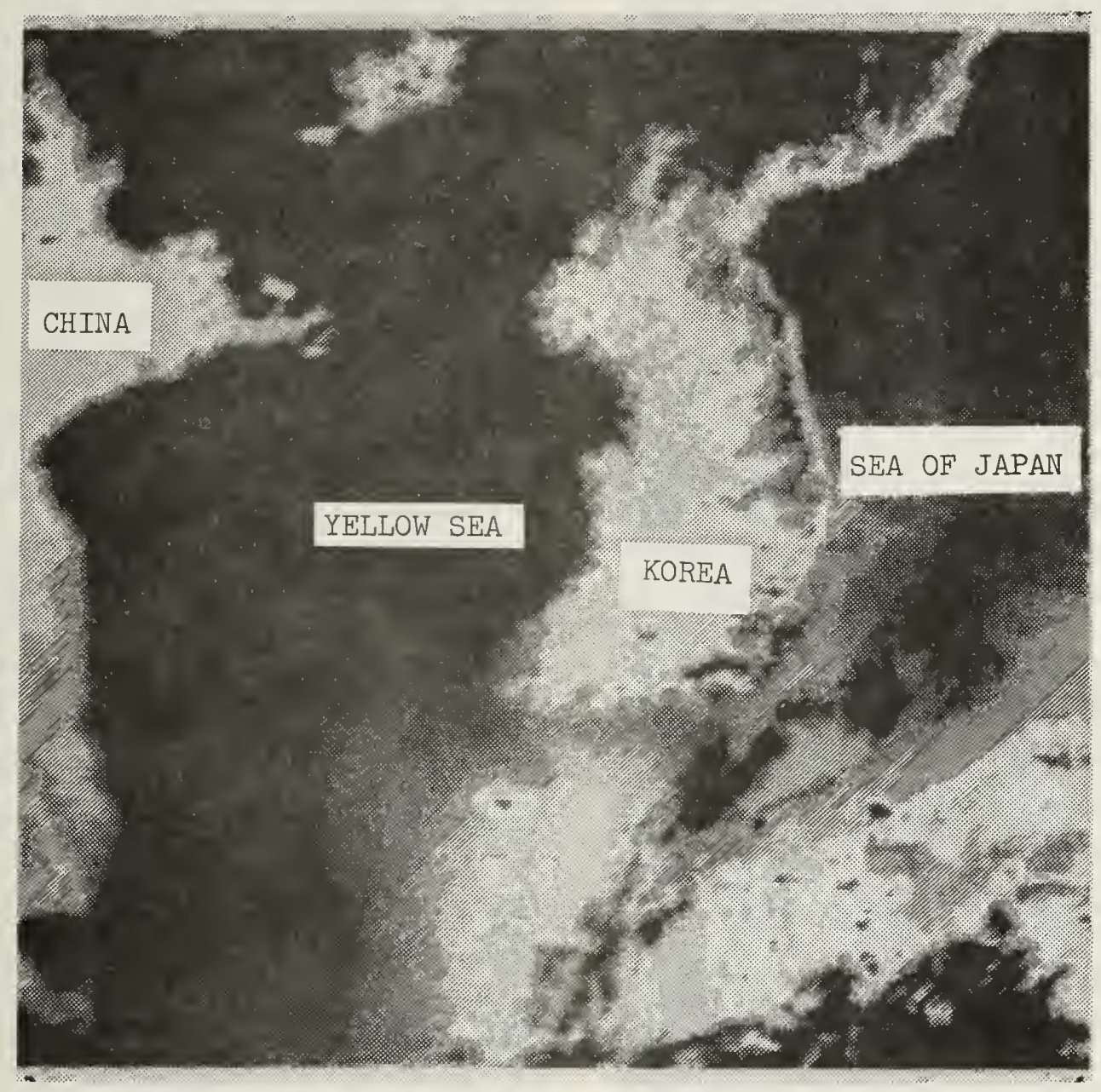

Figure 10. DMSP HR Infrared Image, 10 April 1972, 4527/2532, right expanded, setting $\mathrm{MI}_{1}, \mathrm{X}_{4}, 291^{\circ}$.

Image shows thermally distinct water masses and the warm currents in the sea of Japan and Yellow sea are noticeable due to the strong gradients.

Warm areas appear white; cool areas appear dark.

Provided by Oscar Huh, Naval Oceanographic Office, Washington, D.C. - Technical Report \# 241. 

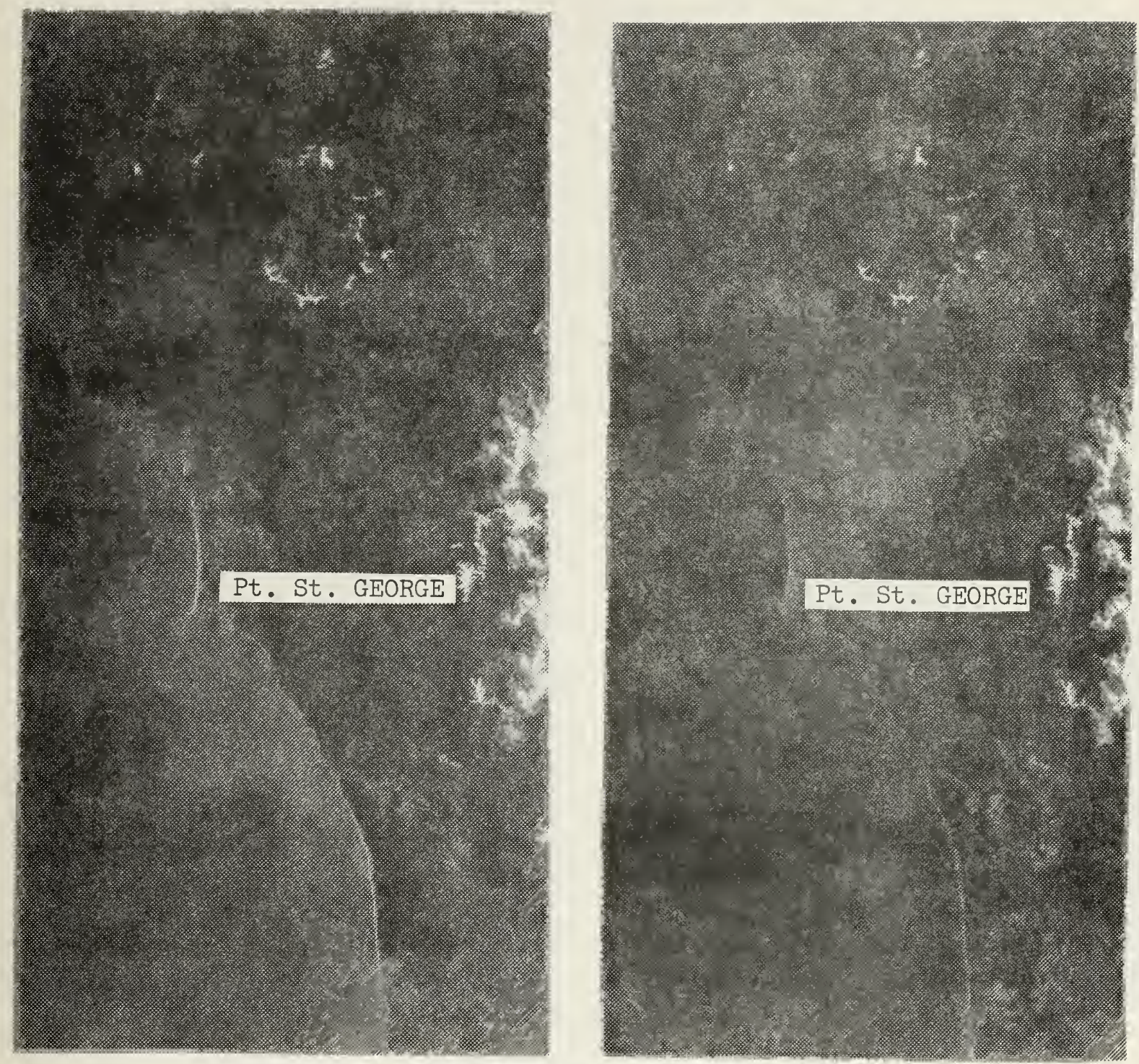

(a)

(b)

Figure 11. ERTS Standard Archived Products, 24 April 1974,

(a) $1275-18284$, Band 4,

Images show the extent of sediment being deposited by the rivers along the coast of California south of Point St. George. Received from ERos Data Center, Sioux Falls, South Dakota. 



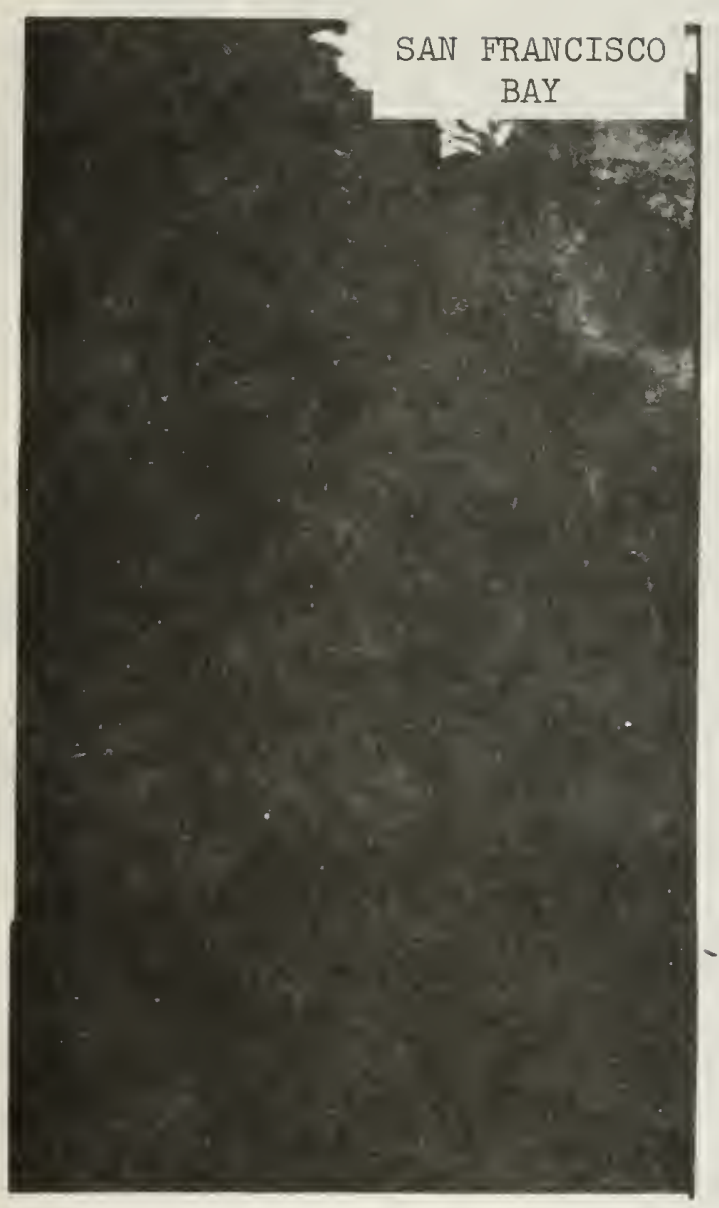

(a)

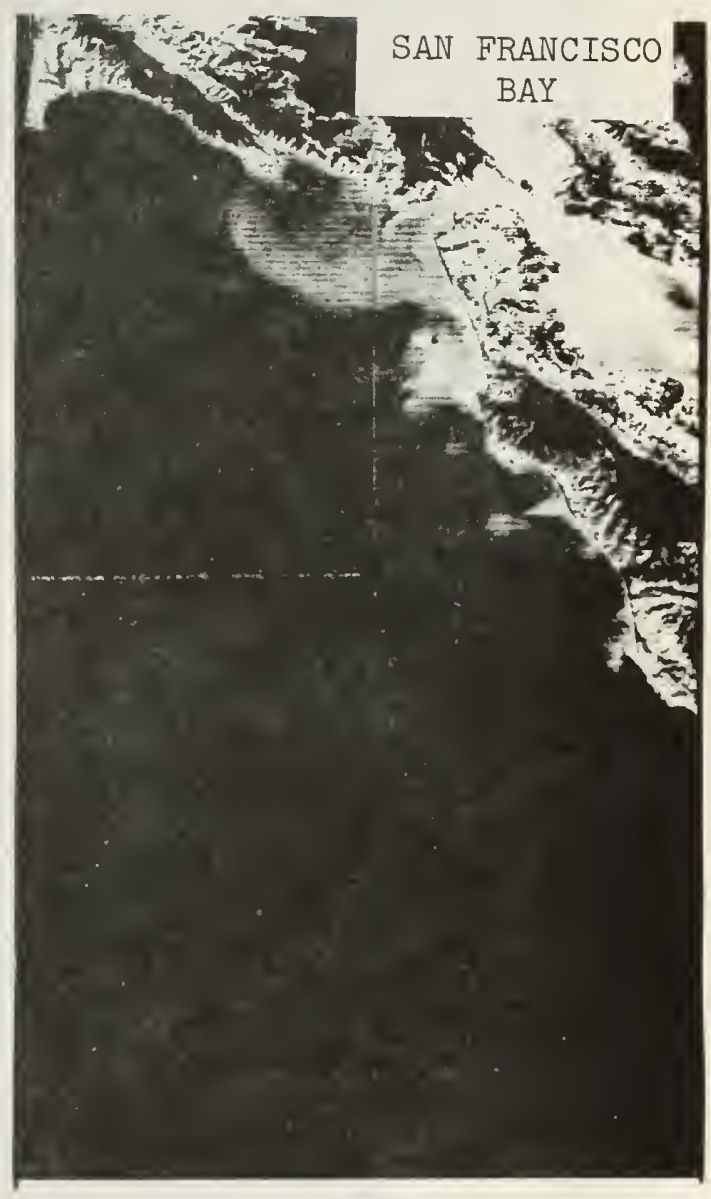

(b)

Figure 12. ERTS Products.

(a) ERTS Standard Imagery, 1130-18325, Band 4.

(b) ERTS Flying Spot Scanner (FSS) Enhancement.

Images show coastal sediment being transported from San Francisco Bay. In this case the sediment is clearly visible in the FSS Enhancement, while it is difficult to see in the standard Band 4 image. A counterclockwise gyre seems to have formed south of the Bay near the Gulf of Farallones. Provided by Doug Pirie, Army Corps of Engineers, San Francisco, CA., [Pirie and Steller, 1974]. 



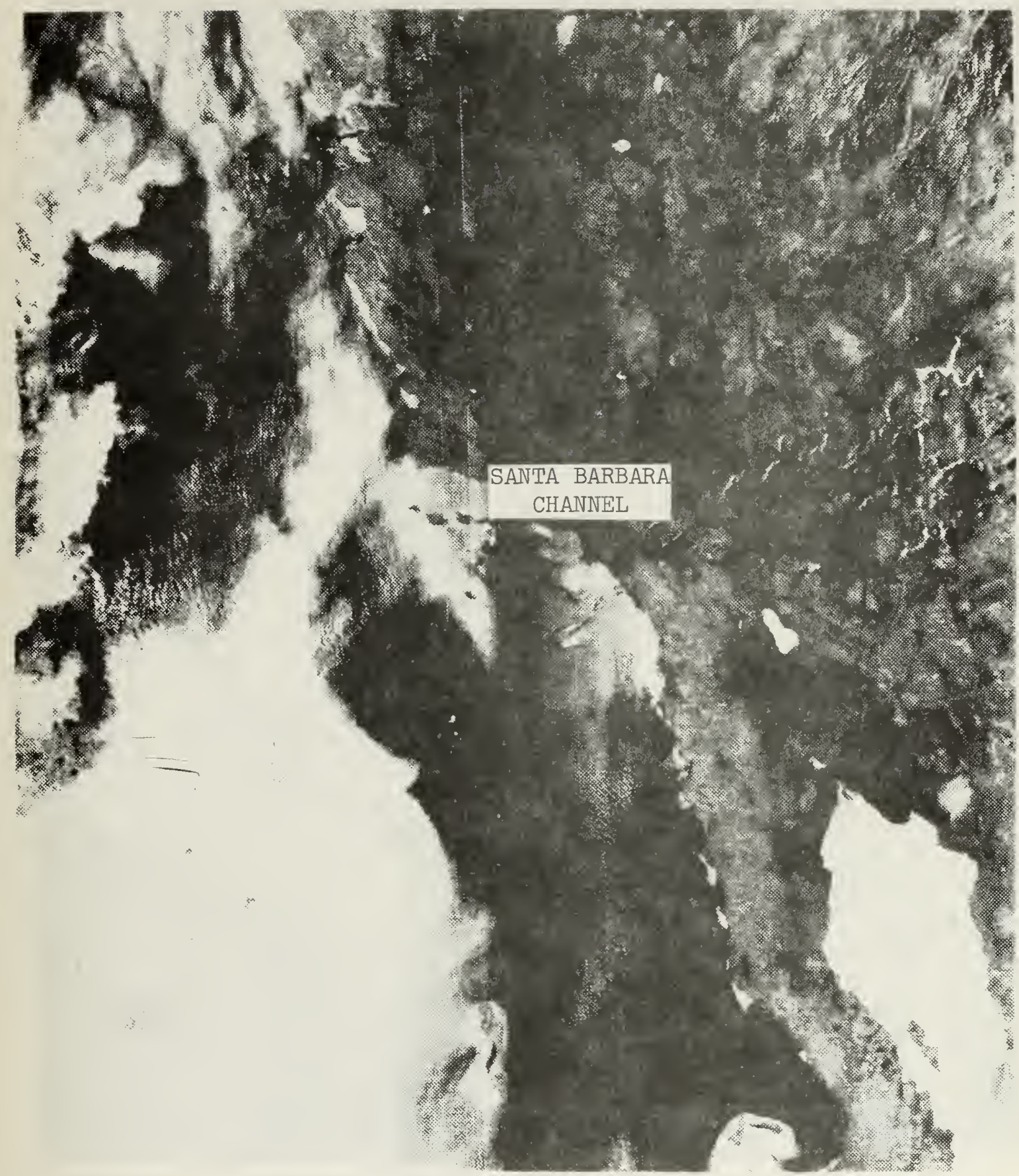

Figure 13. DMSP Standard Archived Product, 24 June 1973.

Portion of a high resolution visual image which shows a common sunglint effect; the sun light energy is reflected directly into the sensor from the Santa Barbara area.

Received from the University of Wisconsin, Madison. 



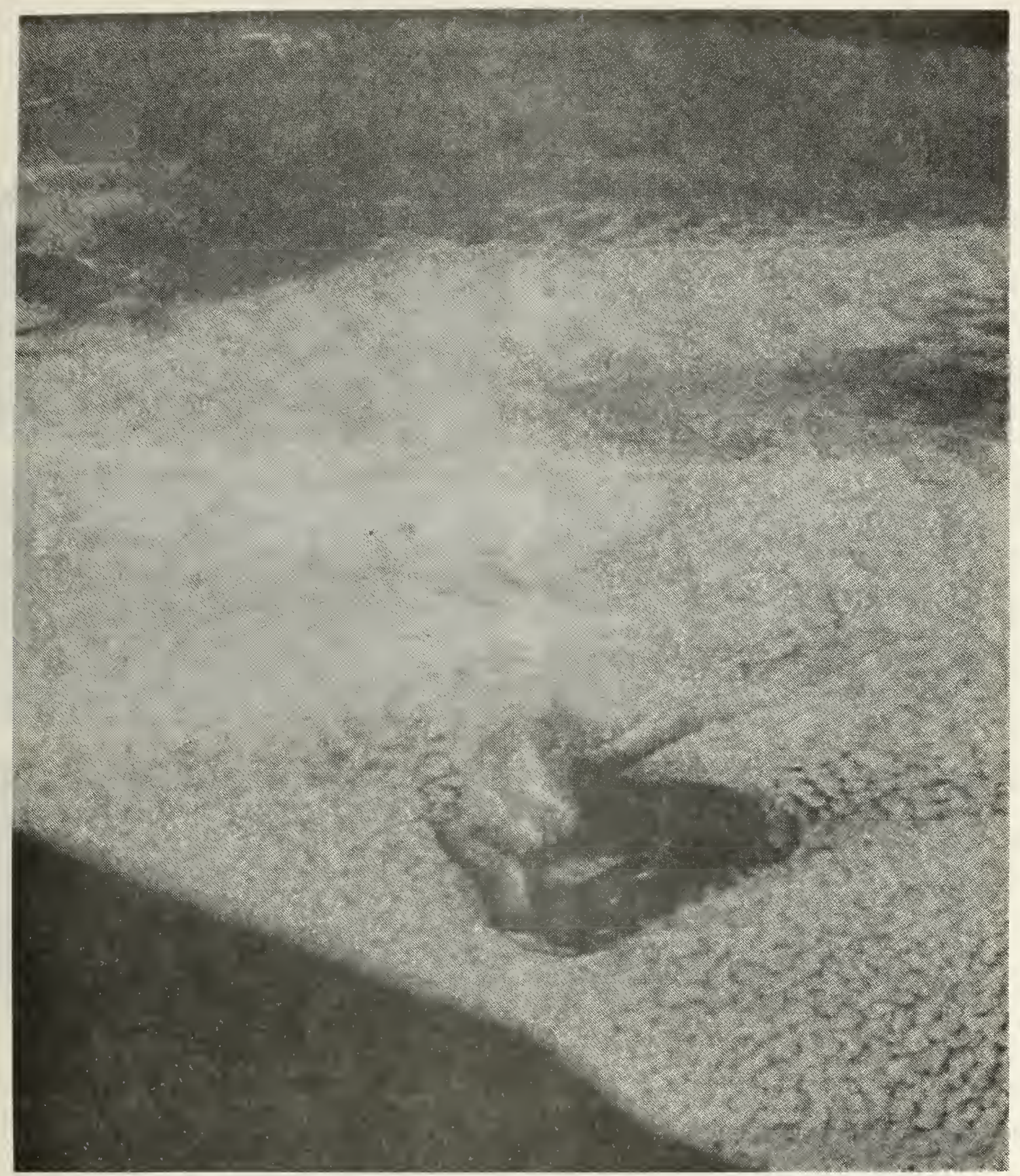

Figure 14. Gemini V Photograph, 21 August 1965, taken by Astronauts Cooper and Conrad.

Photograph shows the cloud formation over Guadelupe Island off Baja, California. Note the von Kármán vortices and bow wake in the cloud layer.

NASA Photograph, from EROS, Sioux Falls, South Dakota. 



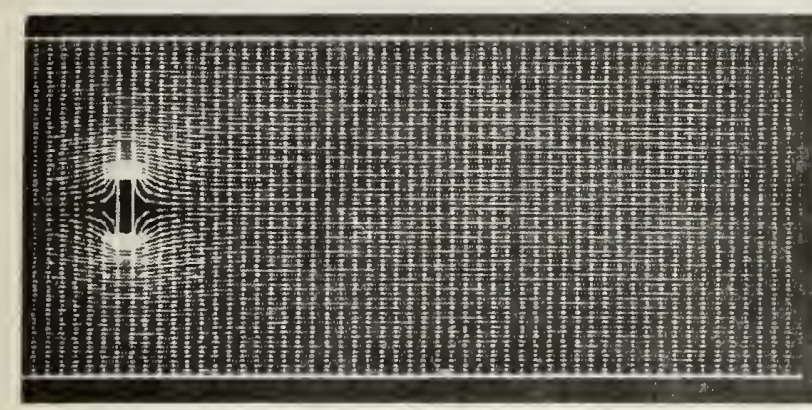

a

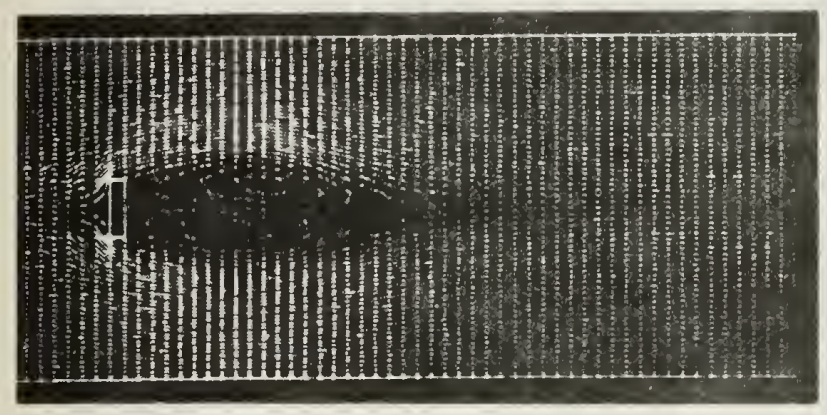

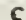

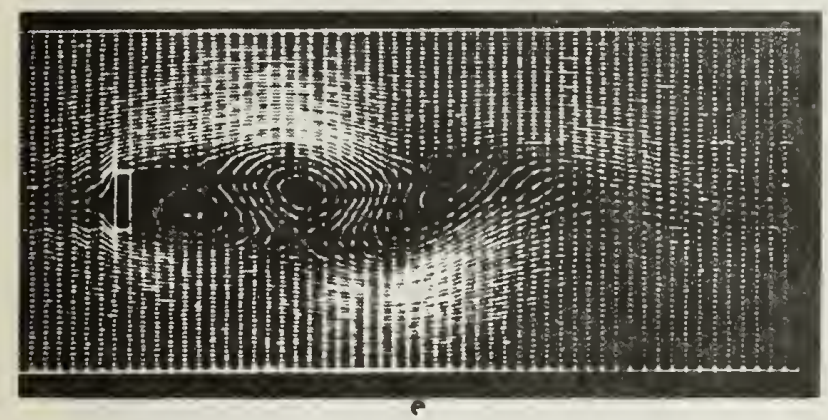

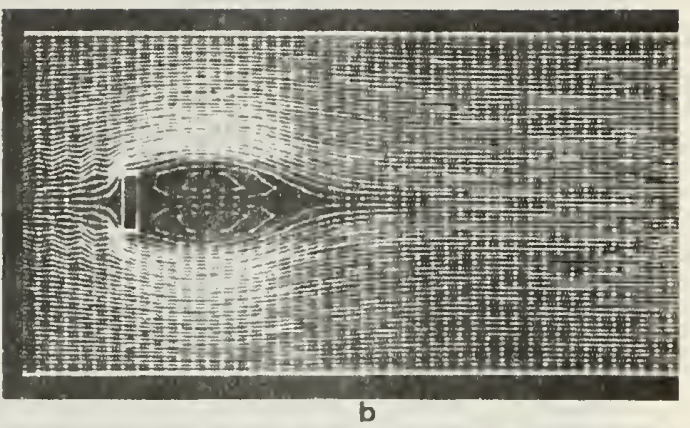

b

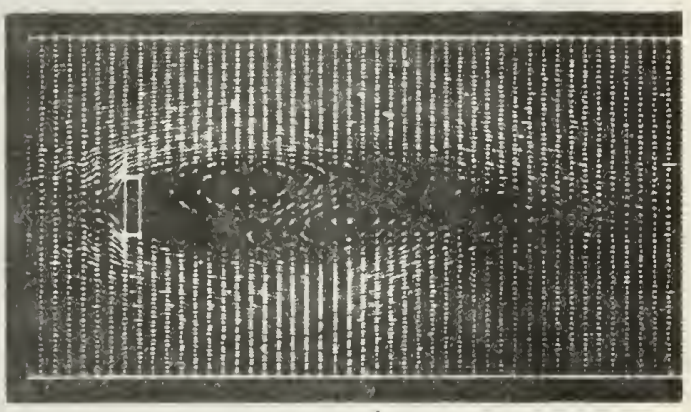

d

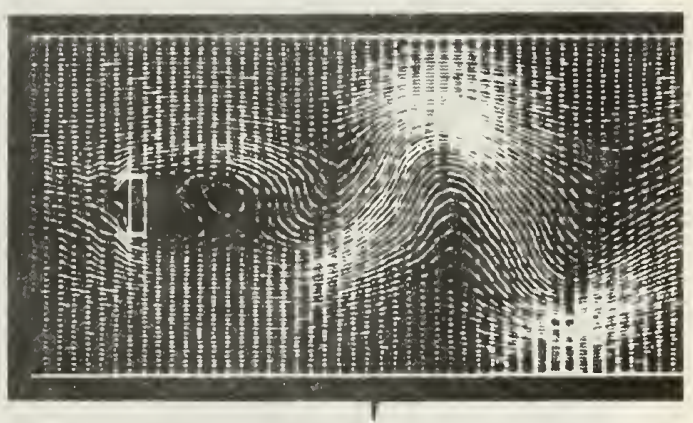

Figure 15. Numerical solutions for the streamline flow past a rectangular obstruction.

(a) the laminar flow pattern.

(b) the development of a turbulent symmetric eddy pair.

(c) vortex shedding of different degrees.

From J.E. Fromm and F.H. Harlow, "Numerical Solution of the Problem of Vortex Street Development." 


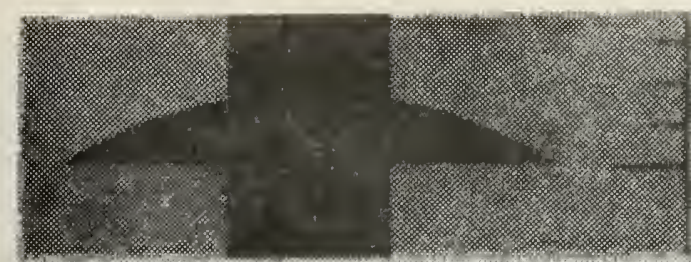

3.
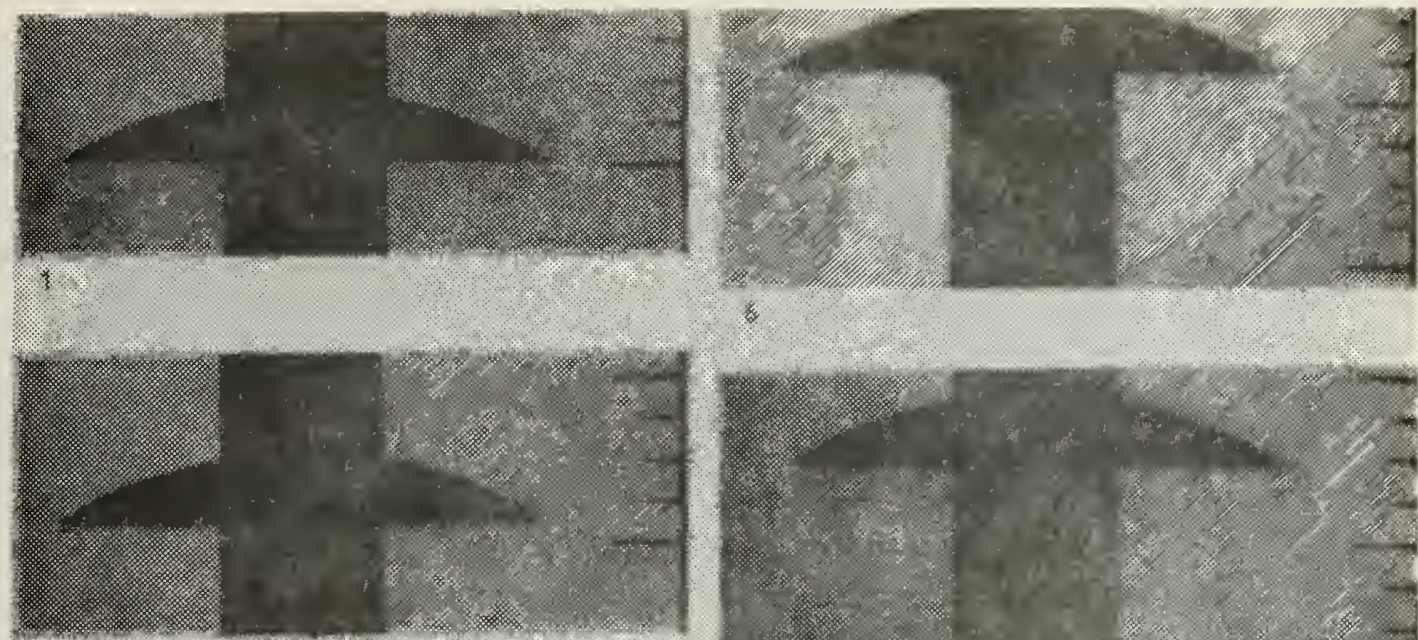

i.
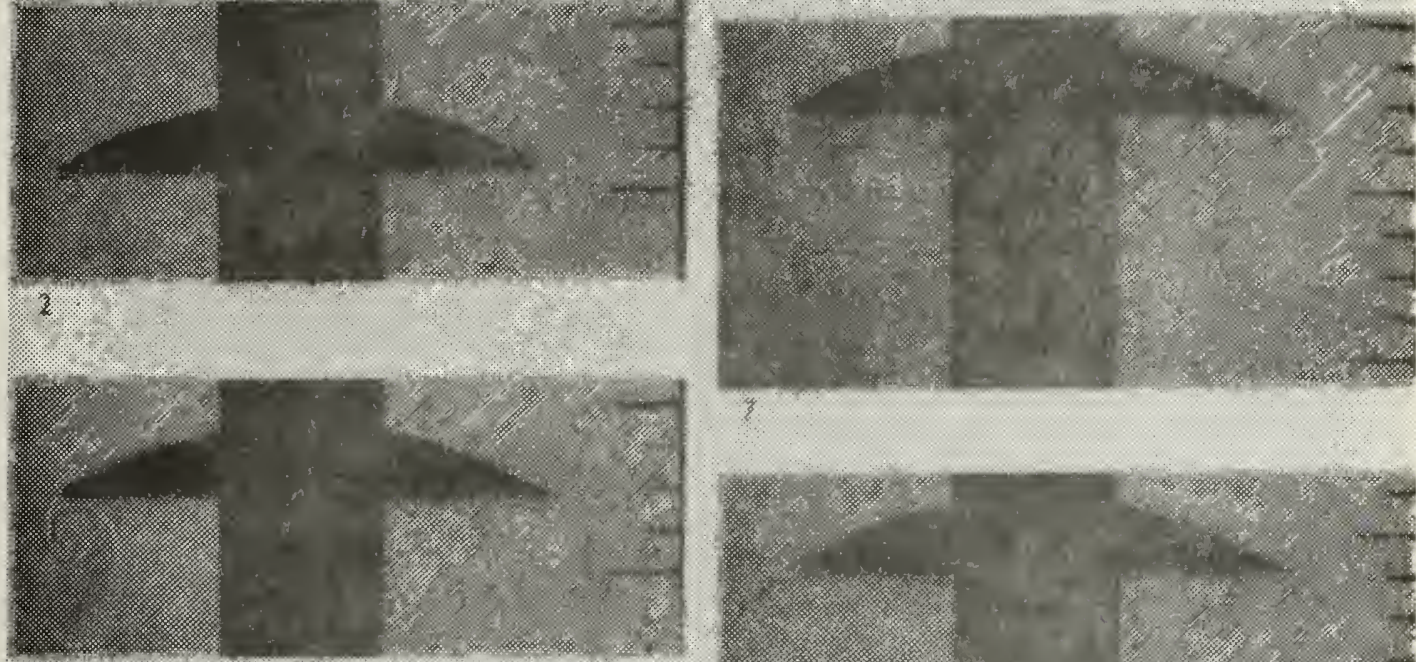

2.

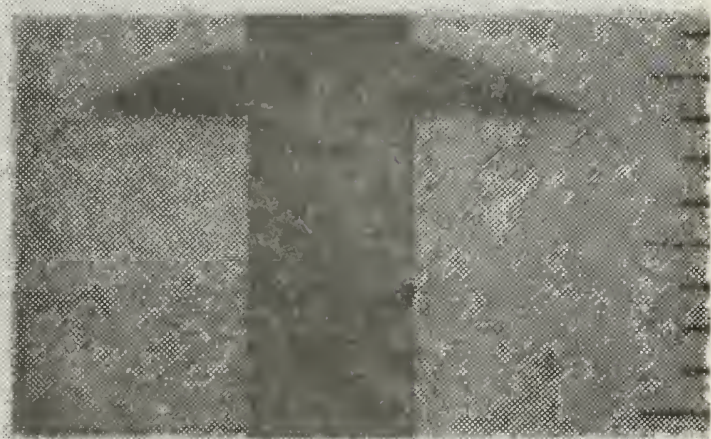

婉

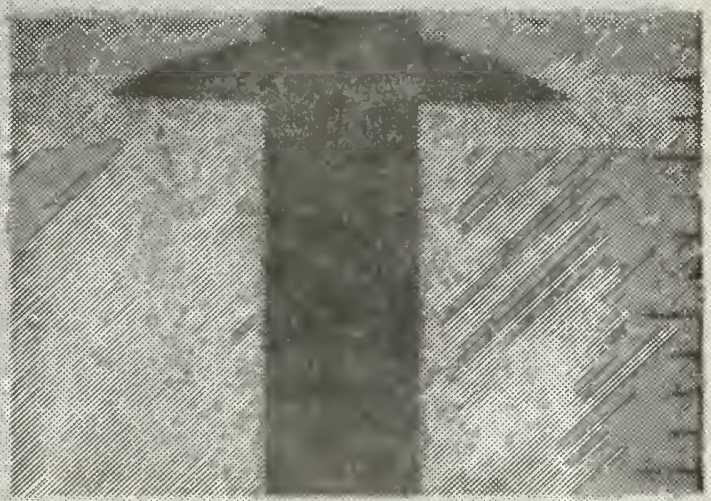

3.

Figure 16. Photographic evidence of the characteristic eddy formations created downstream of an obstruction in an accelerated flow.

From D. Pierce, "Photographic Evidence of the Formation and Growth of Vorticity Behind Plates Accelerated from Rest in Still Air." 



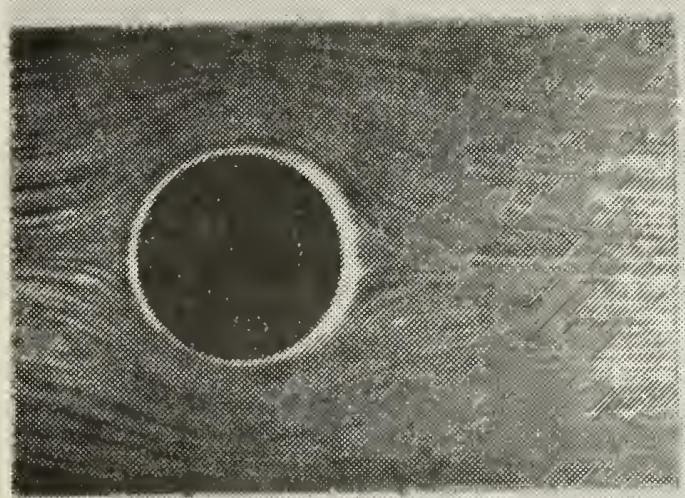

3

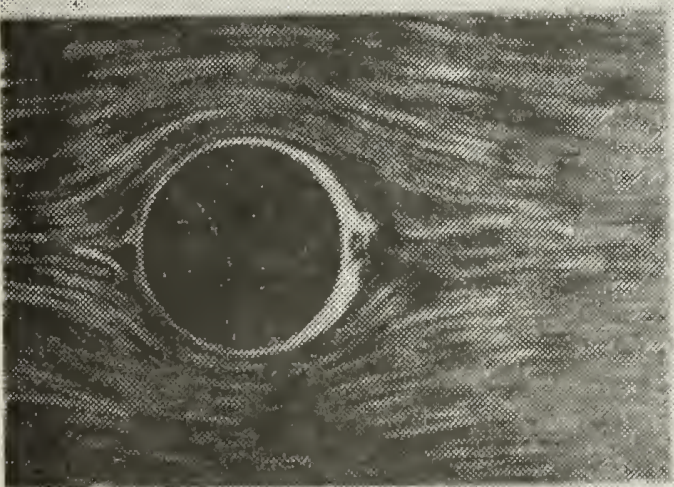

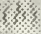

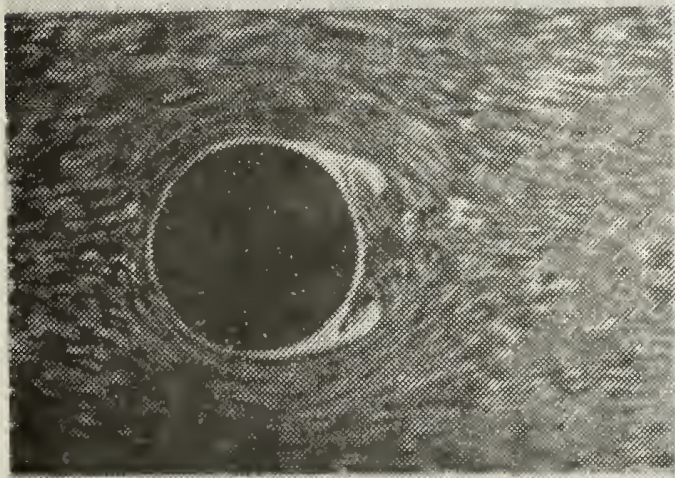

3

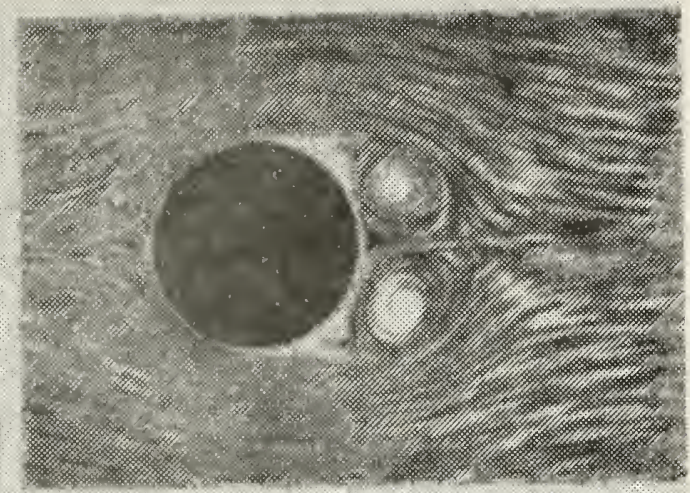

\%

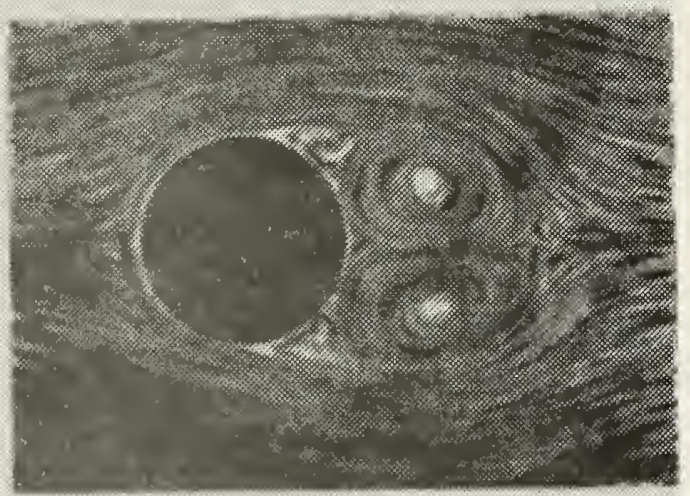

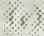

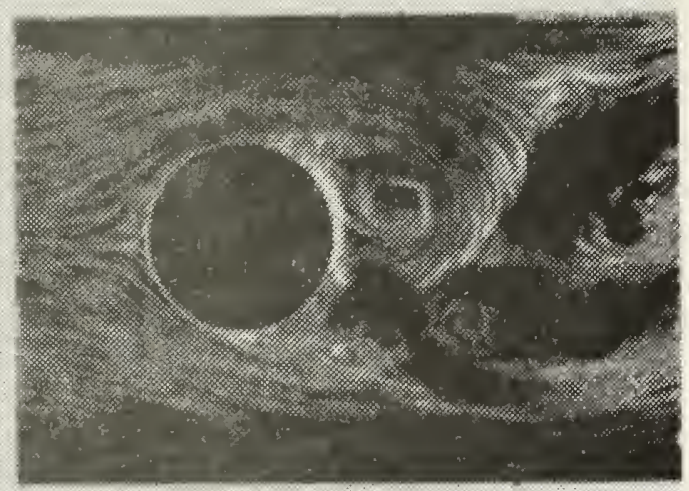

3

Figure 17. Photographs taken of flow around a circular cylinder and the turbulent features created as the flow accelerates.

From G.K. Batchelor, An Introduction to Fluid Dynamics, 1967. Originally from Applied Hydro- and Aerodynamics, 1937,

L. Prantl and O.G. Tietjens. 



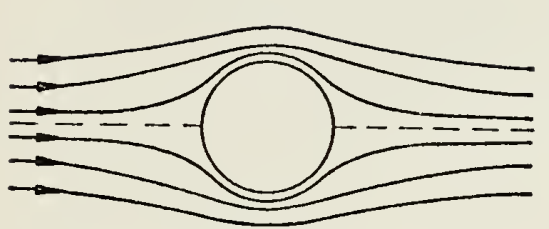

(a)

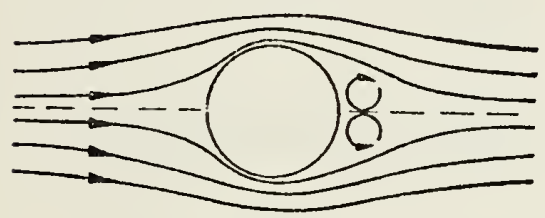

(b)

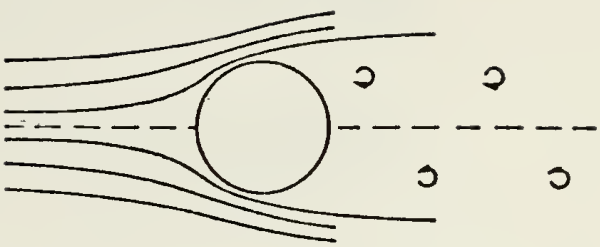

(c)

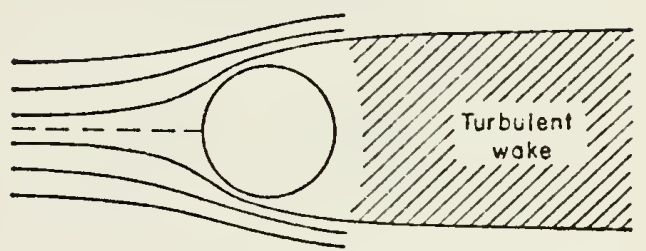

(d)

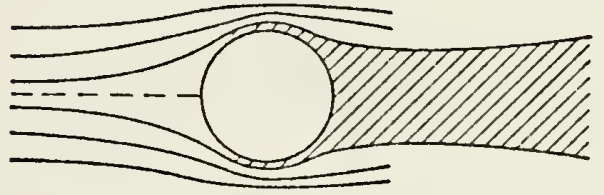

(e)

Figure 18. Diagrammatic view of several characteristic turbulent patterns of fluid flow past a circular cylinder defined in terms of the non-dimensional Reynolds number:

(a) $R>1$, Flow symmetrical.

(b) $1<\mathrm{R}<30$, Eddies.

(c) $40<\mathrm{R}<30$, Ordered wake.

(d) $10^{3}<\mathrm{R}<10^{5}$, Chaotic turbulent wake.

(e) $R>10^{5}$, Boundary-layer turbulent flow.

From N. Curle and H.J. Davies, Modern Fluid Dynamics, 1968. 


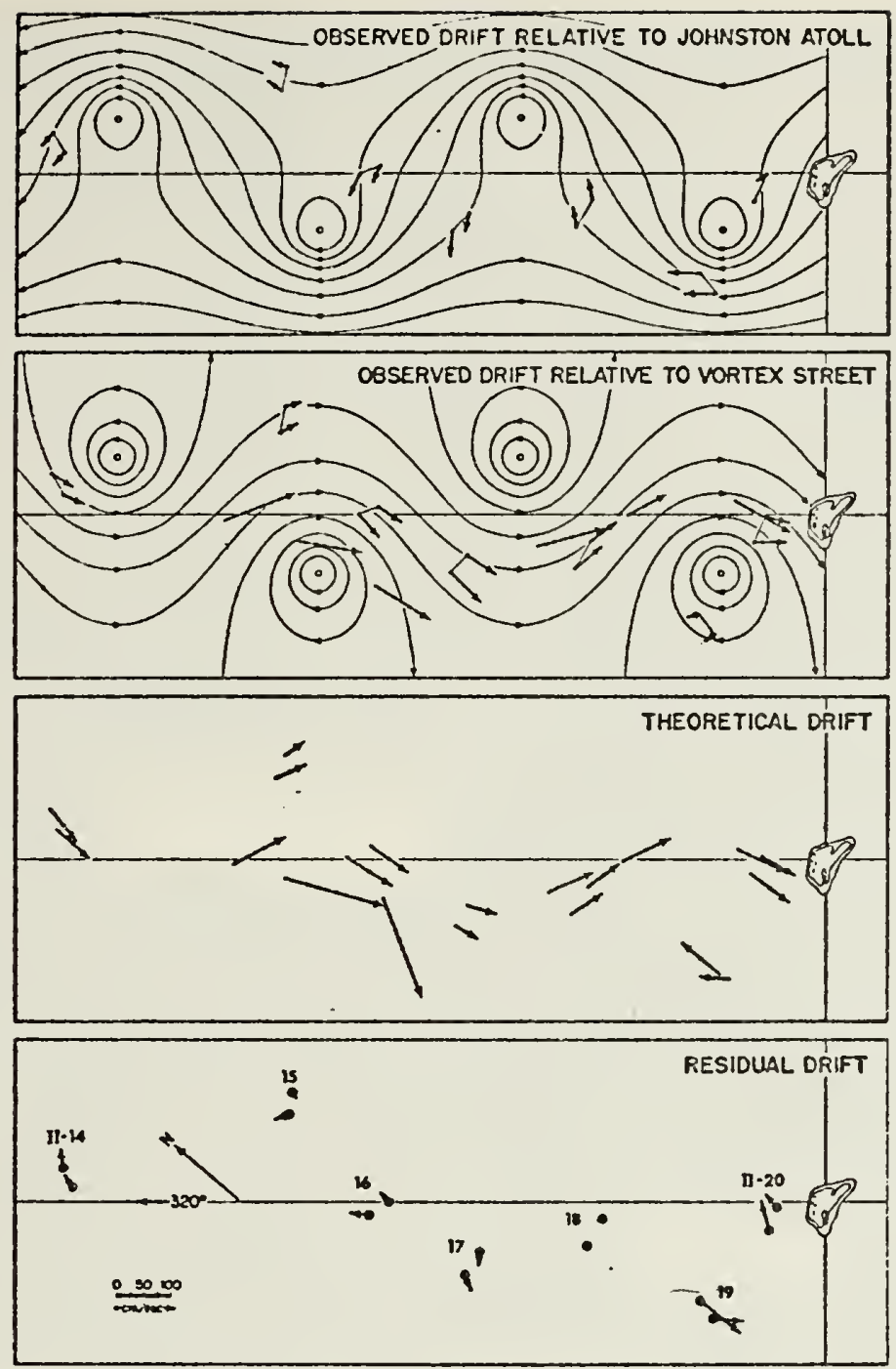

Figure 19. A comparison of the observed and theoretical current drift past Johnston Atoll for Feb. 1968.

Surface current observations show a von Kármán vortex street downstream of the atoll which resembles the theoretical drift. From R.A. Barclay, "Johnston Atoll's Wake." 



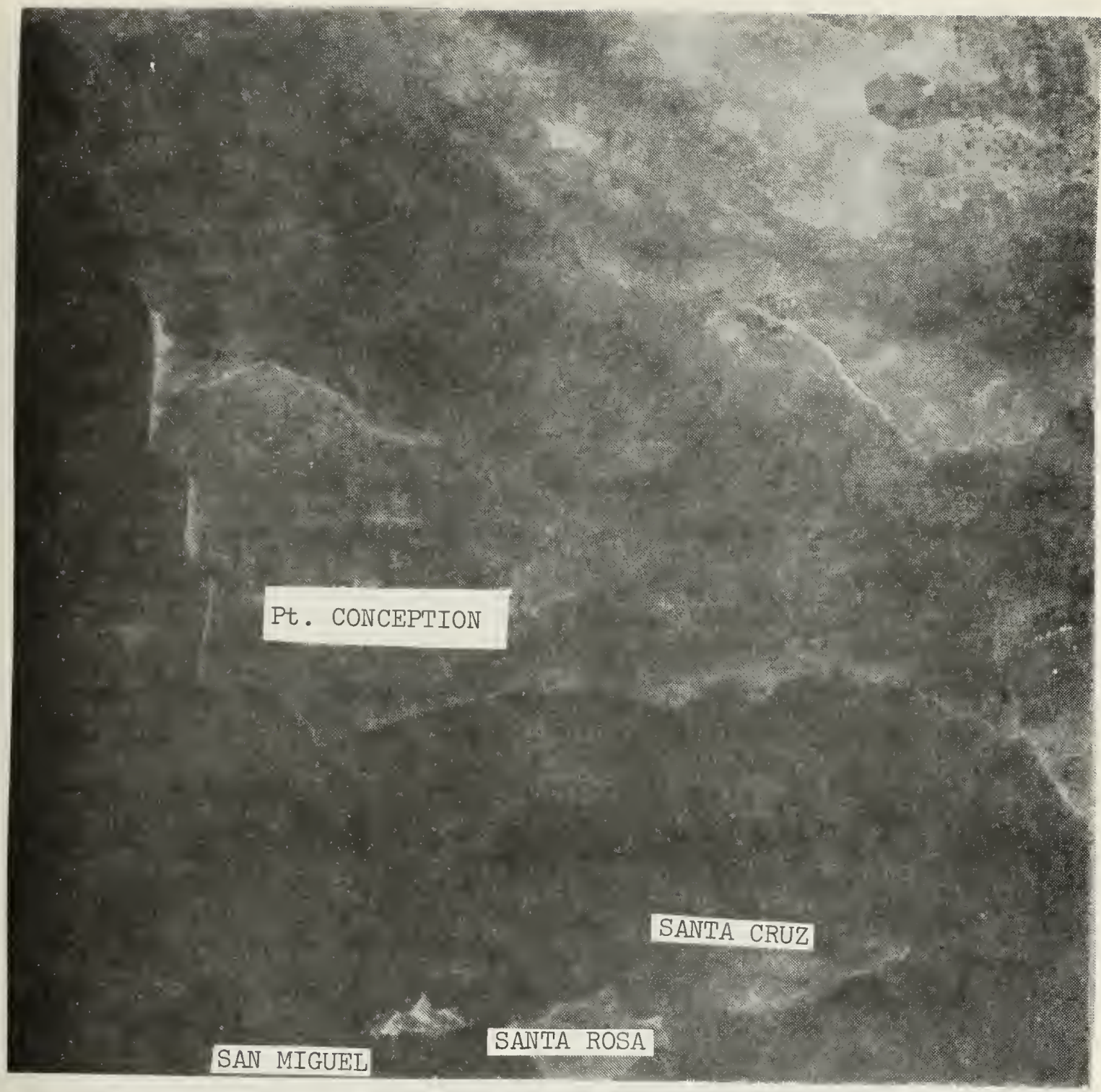

Figure 20. ERTS Standard Archived Product, 26 May 1973, 1307-18073, Band 4 .

Image shows atmospheric effects caused by air flow over land and island topographic anomalies. In this sunglint photo of the Santa Barbara Channel, the dark areas are indicative of calmed winds and drying air.

Received from EROS Data Center, Sioux Falls, South Dakota. 



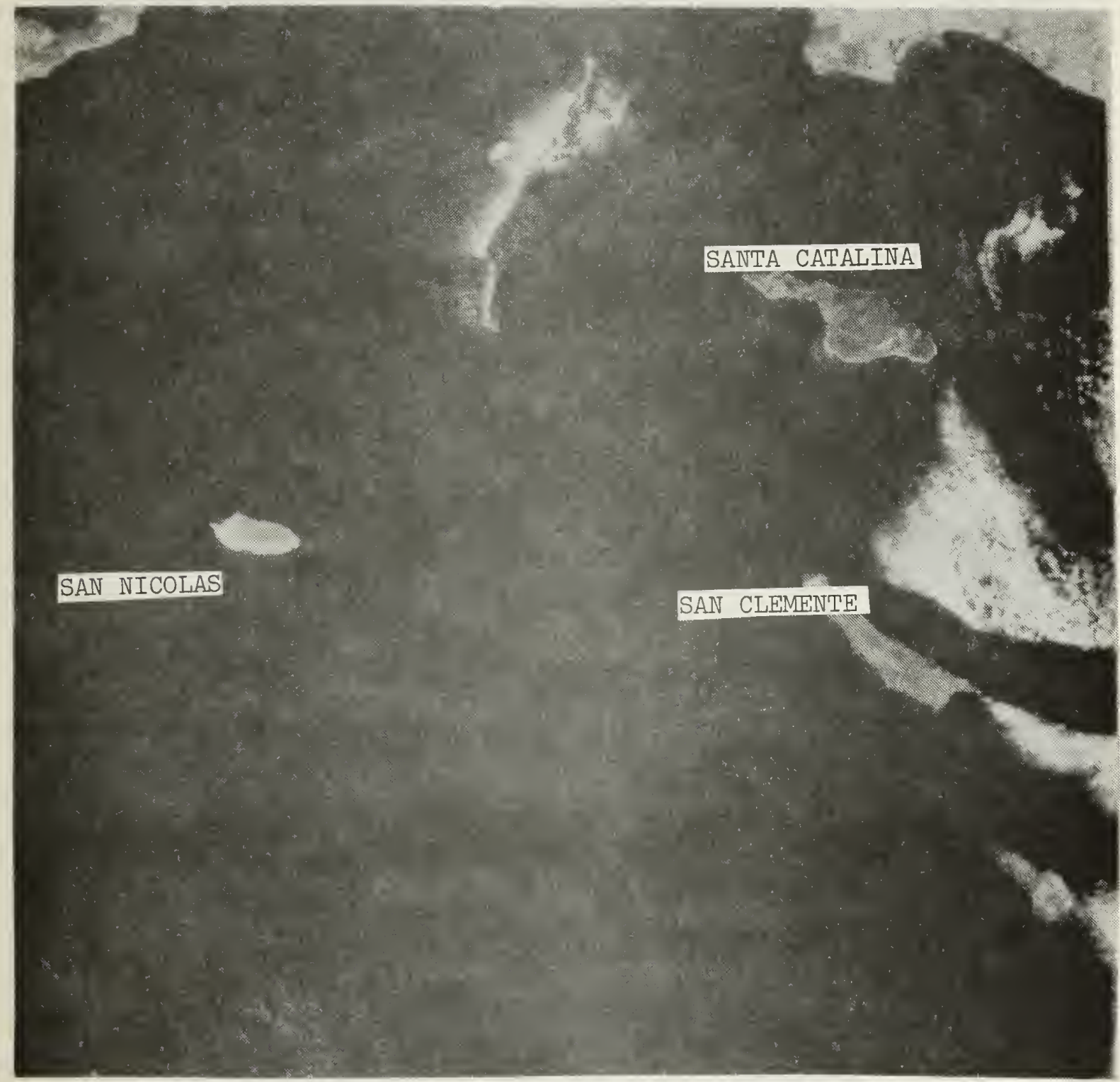

Figure 21. ERTS Standard Archived Product, 23 Aug. 1973, 1396-18010, Band 4 .

Image shows the same type of features recorded in Figure 20 for other islands in the Santa Barbara Channel at a different time of the year. The images seem to indicate that this assumed drying effect can extend some distance downstream. Winds from $310^{\circ} \mathrm{T}$ (top left corner) in excess of 20 knots were recorded for this time period.

Received from EROS Data Center, Sioux Falls, South Dakota. 



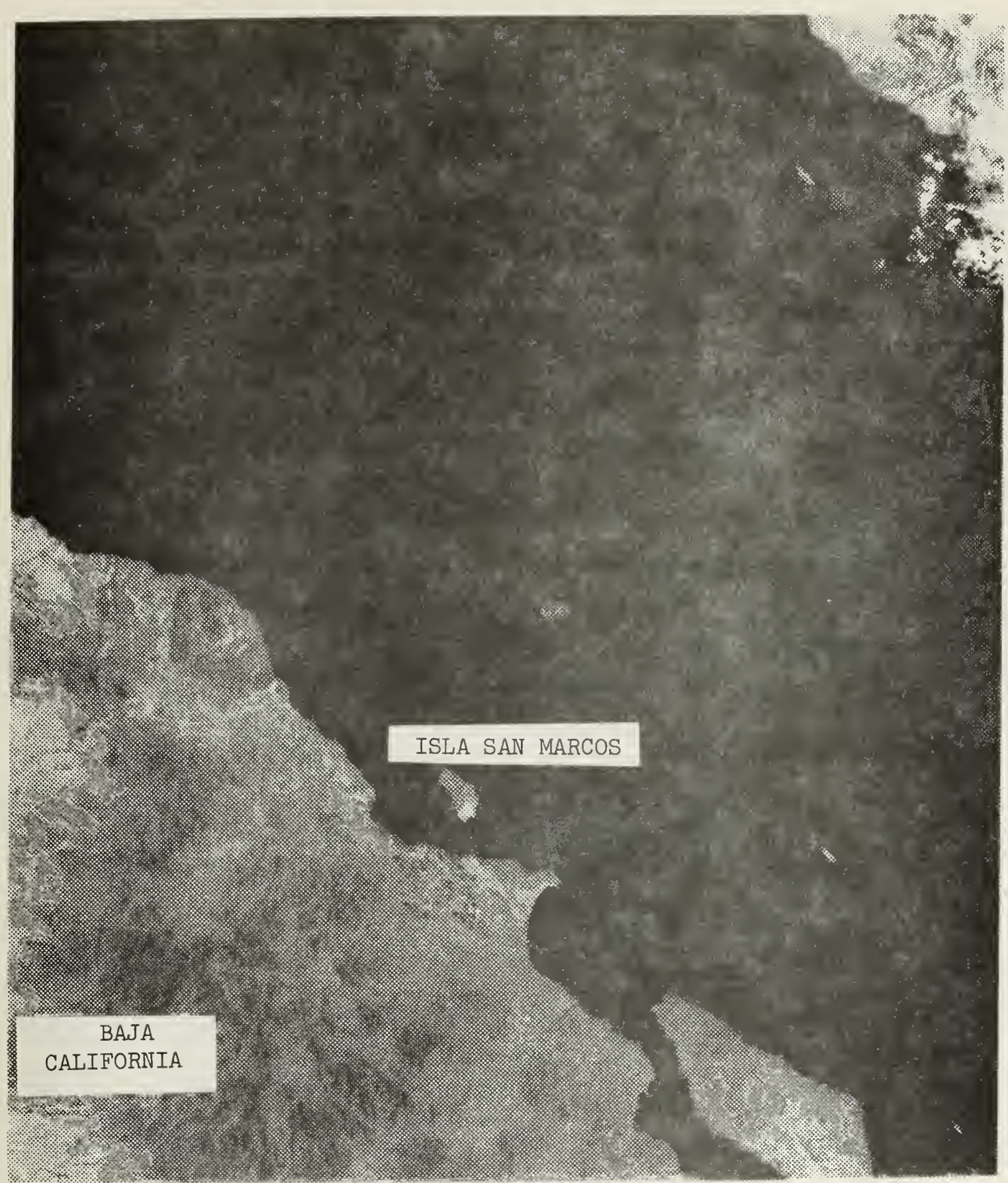

Figure 22. ERTS Standard Archived Product, 24 June 1973, 1336-17291, Band 4.

Image shows dry, calmed air flow over high topographic features on the islands in the Gulf of California. Notice the cloud (white) and its reflection (black) at the bottom right of the image. This same effect was visible in all four Bands, which supports evidence that these are atmospheric effects.

Received from ERos Data Center, Sioux Falls, South Dakota. 



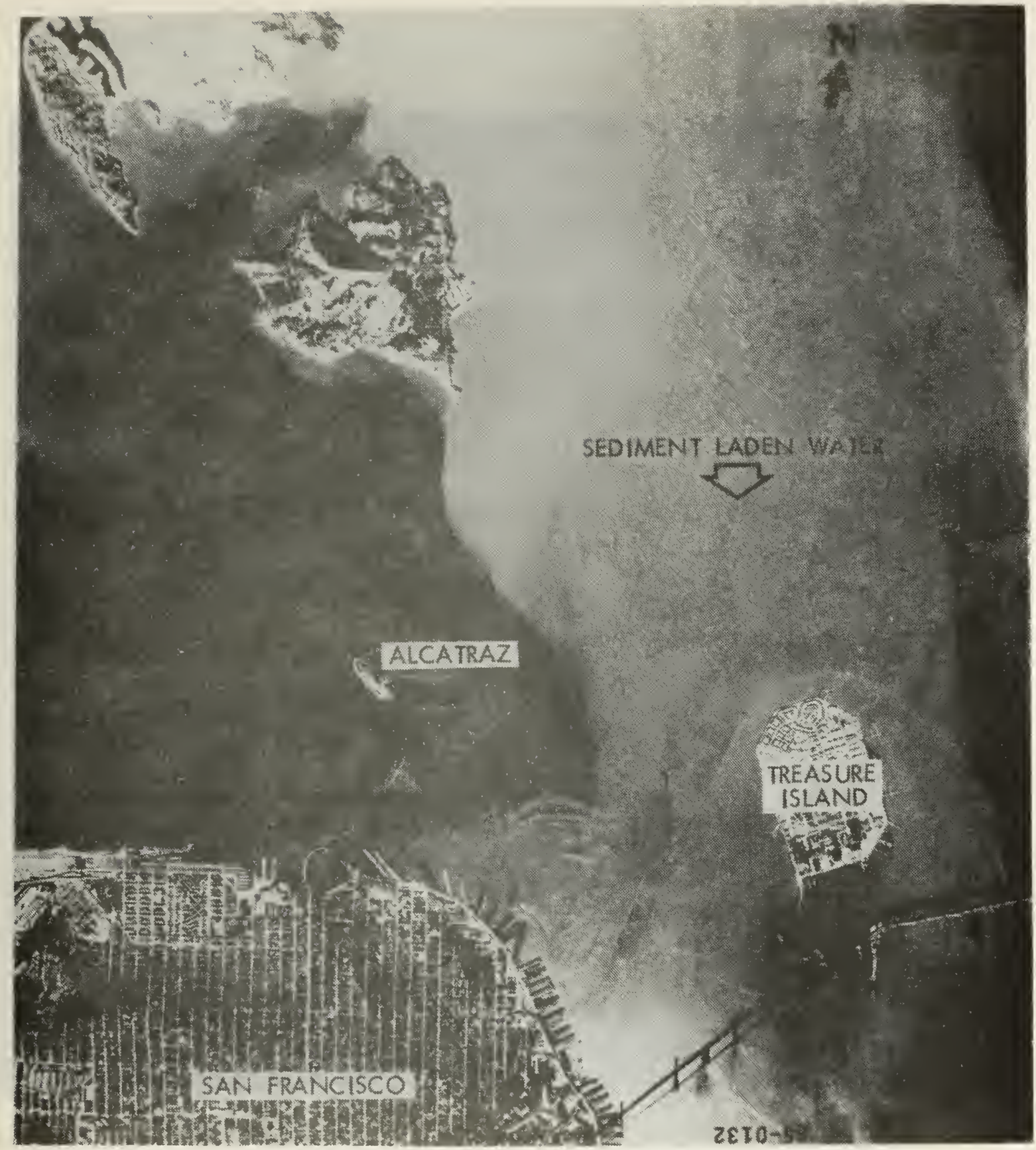

Figure 23. Low-altitude NASA Flown Infrared Color Photo. Picture, taken 22 Jan. 1973, shows in great detail the different kinds of flow looked for in this investigation of satellite imagery.

(a) Eddy downstream of Alcatraz - see Figure 16.

(b) Bow wake and lee effect around Treasure Island.

(c) Lengthy streamers behind bridge supports, indicating a swift current - see Figures 20,21, and 22.

(d) Boundaries and mixing between coastal and Bay water masses. Provided by Doug Pirie, Army Corps of Engineers, San Francisco, CA., [Pirie and Steller, 1974]. 



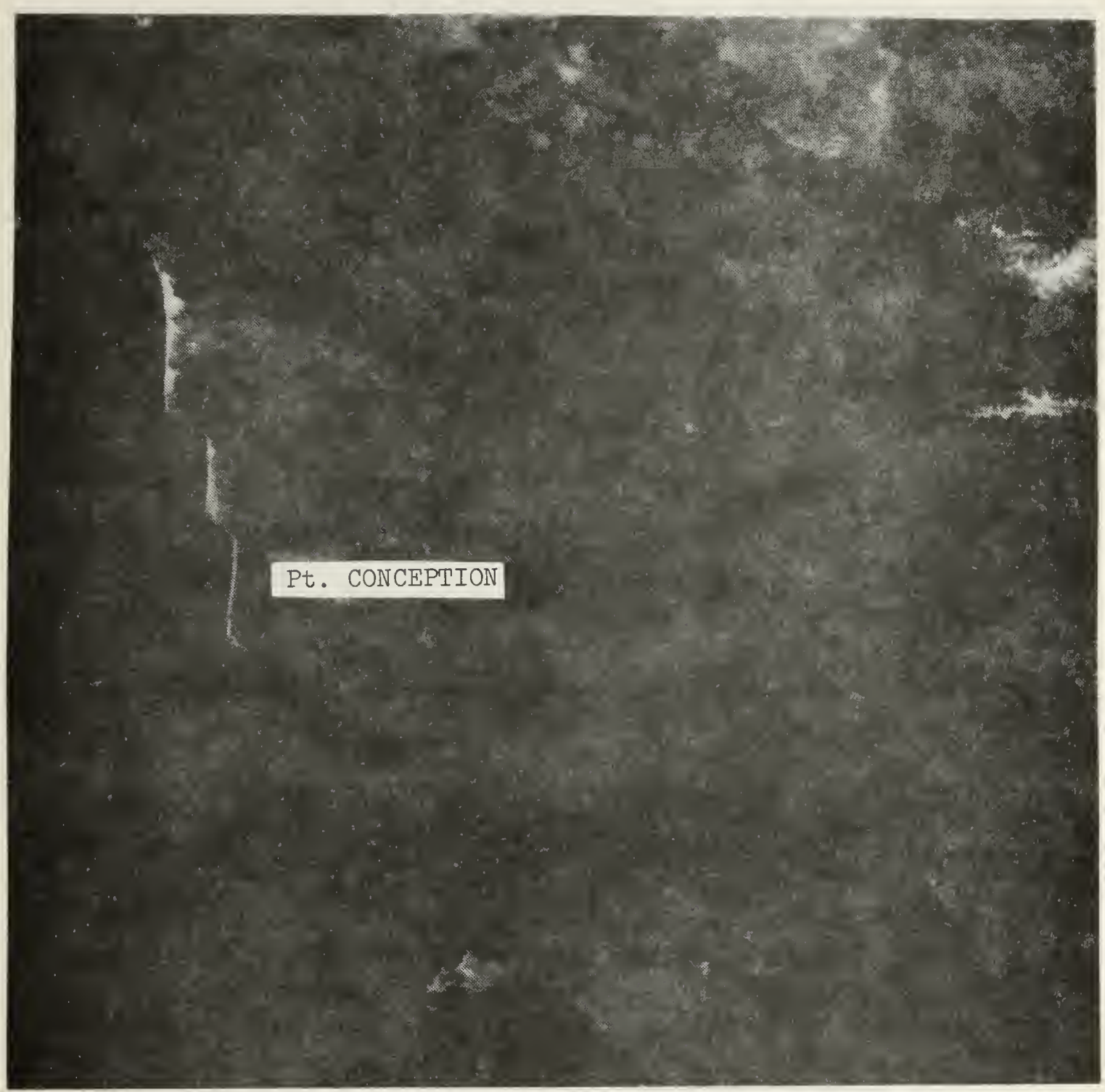

Figure 24. ERTS Standard Archived Product, 15 March 1973, $1235-18075$, Band 4 .

Image shows coastal sediment transport along southern California coast. The formation of a counterclockwise gyre is seen clearly in the sea surface flow past point conception. The gyre resembles those shown in Figure 16 (photographs of laboratory flows).

Received from EROS Data Center, Sioux Falls, South Dakota. 


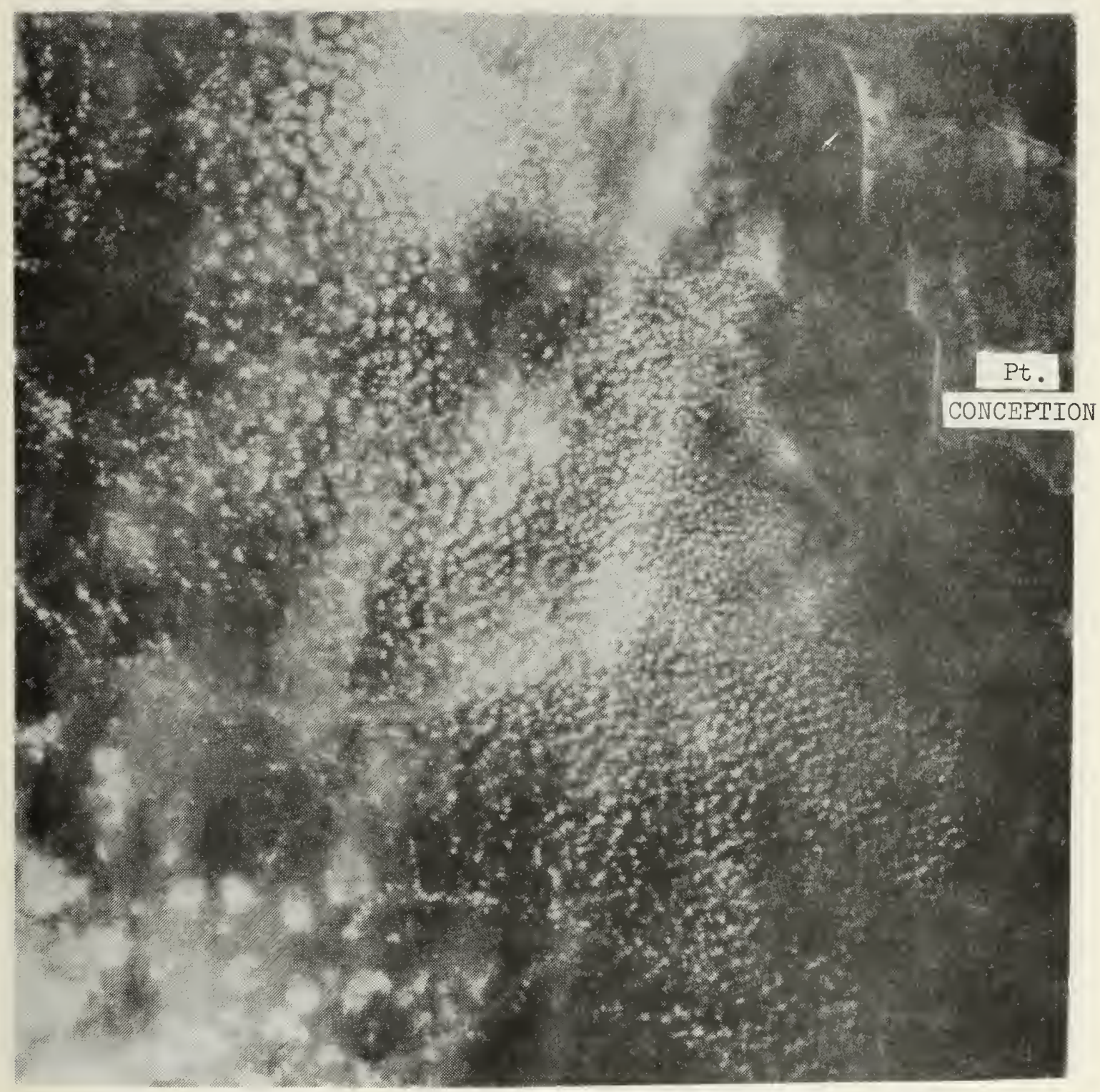

Figure 25. ERTS Standard Archived Product, 16 March 1973, 1236-18134, Band 4.

Image shows coastal sediment transport along southern California coast. The gyre, shown in Figure 24 and viewed from a different angle, seems to have dispersed as it was carried further downstream past Point Conception.

Received from ERos Data Center, Sioux Falls, South Dakota. 



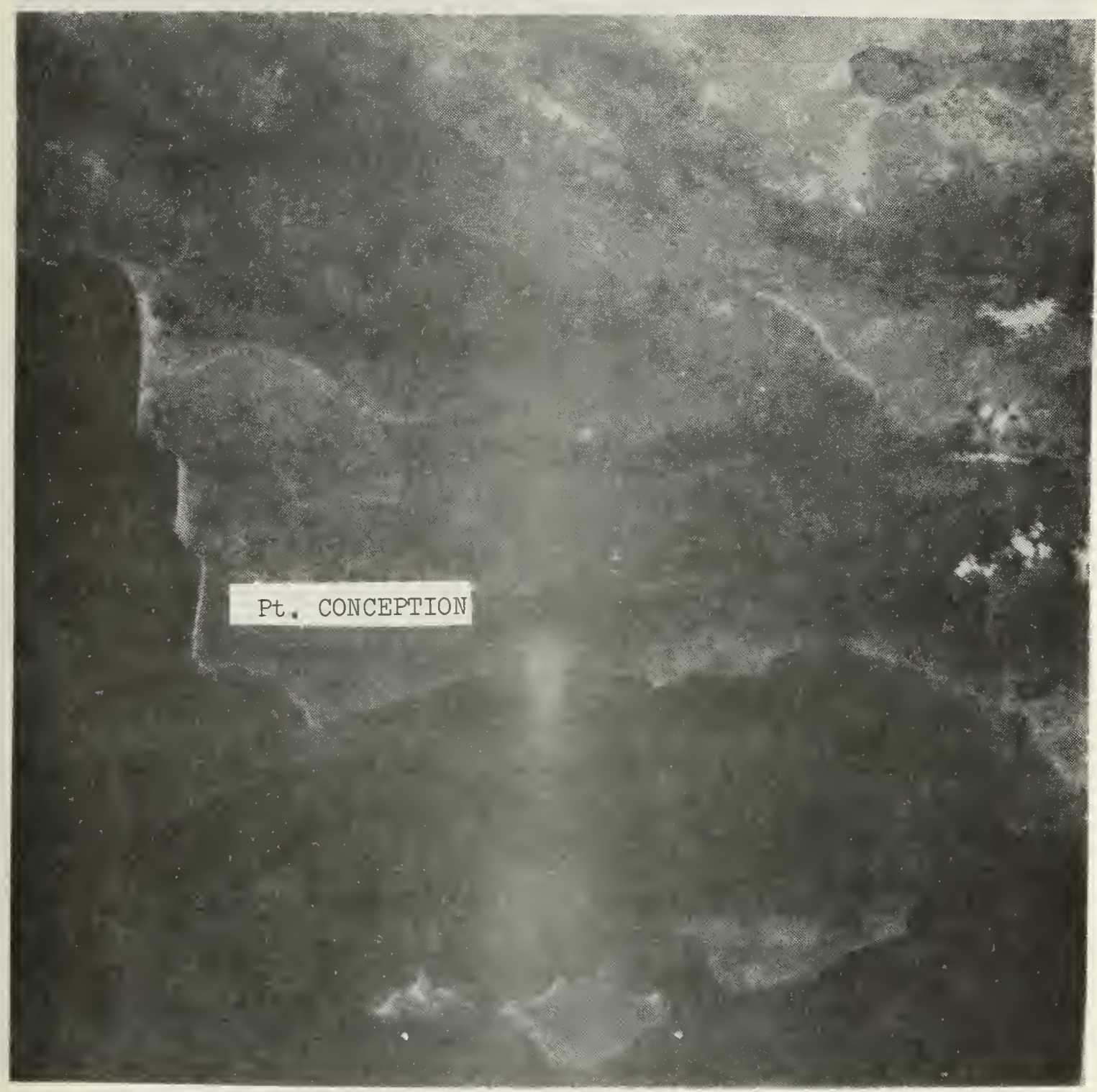

Figure 26. ERTS Standard Archived Product, 20 April 1973, 1271-18075, Band 4 .

Image shows the formation of a gyre, much smaller than the one recorded in Figures 24 and 25 , off Point Conception during the same time of the year.

Received from EROS Data Center, Sioux Falls, South Dakota. 



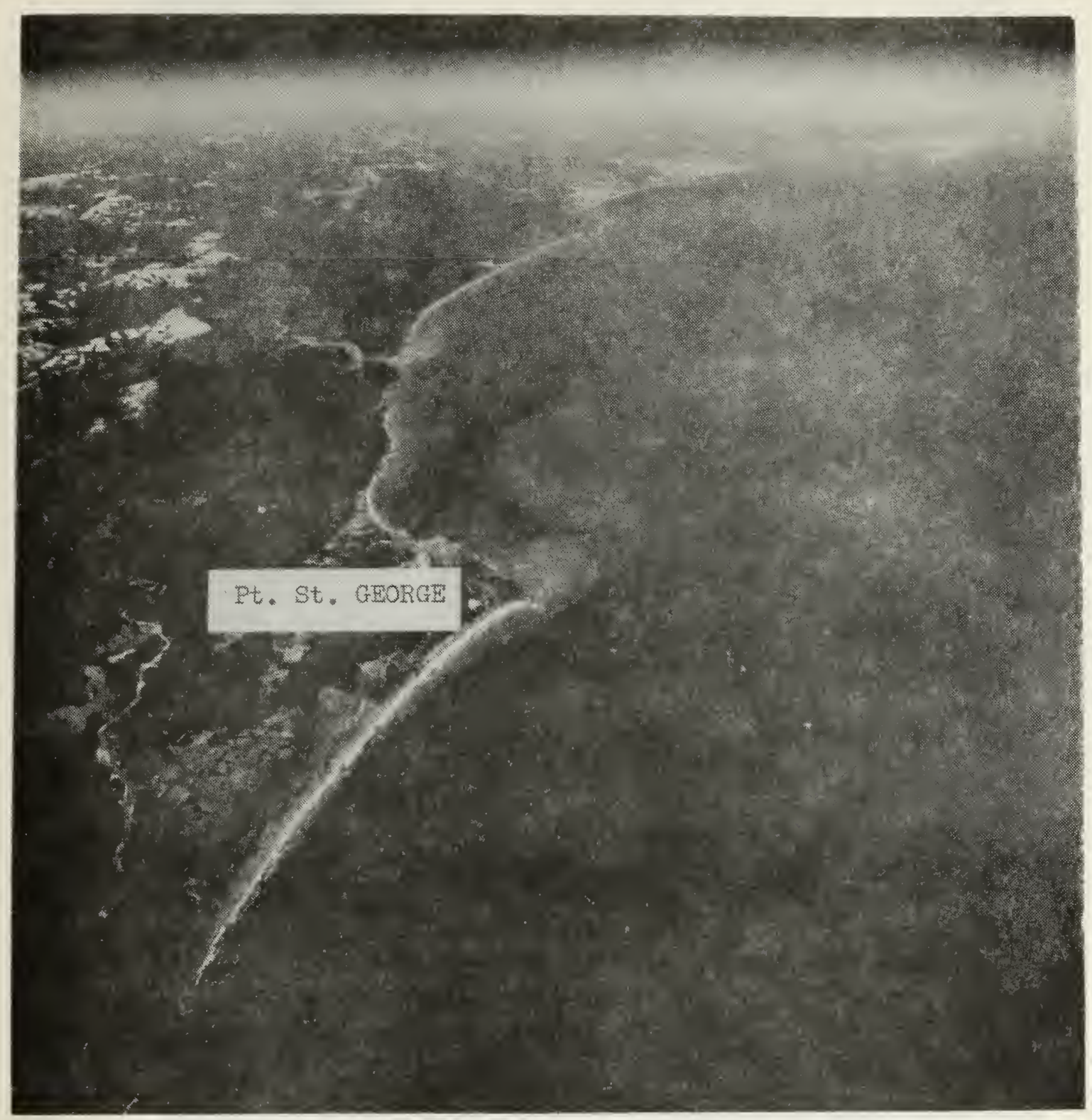

Figure 27. U-2, NASA Flown $70 \mathrm{~mm}$ Infrared Color Photo. Picture shows flow past Point st. George toward the south during the Davidson Current Period. The counterclockwise gyre is similar to those shown in Figure 16 (laboratory results). This oblique view was taken from approximately 19812 meters and yet the wakes behind the rocks south of the st. George Reefs are visible.

Provided by Doug Pirie, Army Corps of Engineers, San Francisco, CA., [Pirie and Steller, 1974]. 


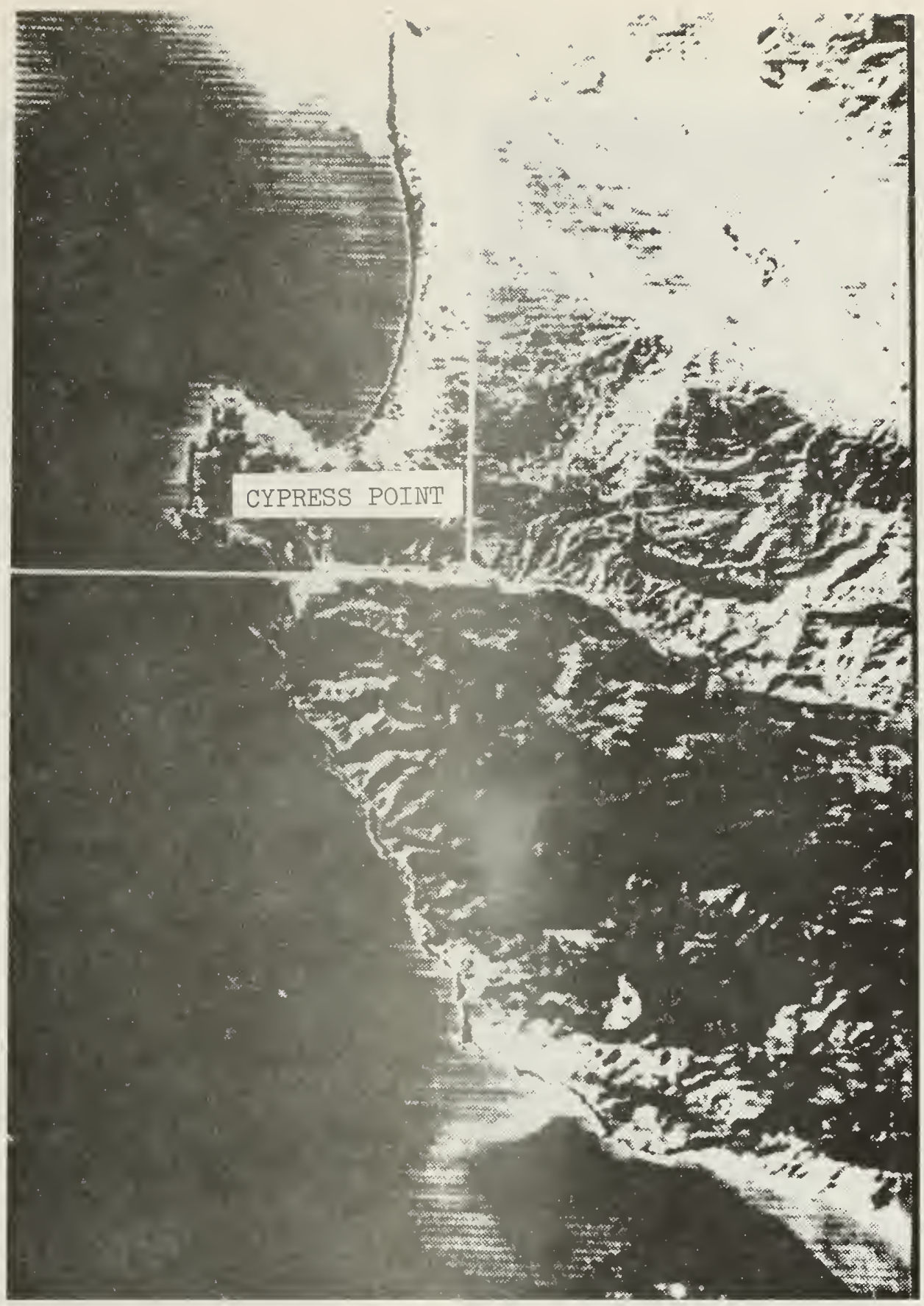

Figure 28. ERTS FSS Enhancement, 22 January 1973, of scene 1183-18182.

Image shows the formation of gyres caused by the surface flow past Cypress Point south of Monterey Bay.

Provided by Doug Pirie, Army Corps of Engineers, San Francisco, CA., [Pirie and Steller, 1974]. 



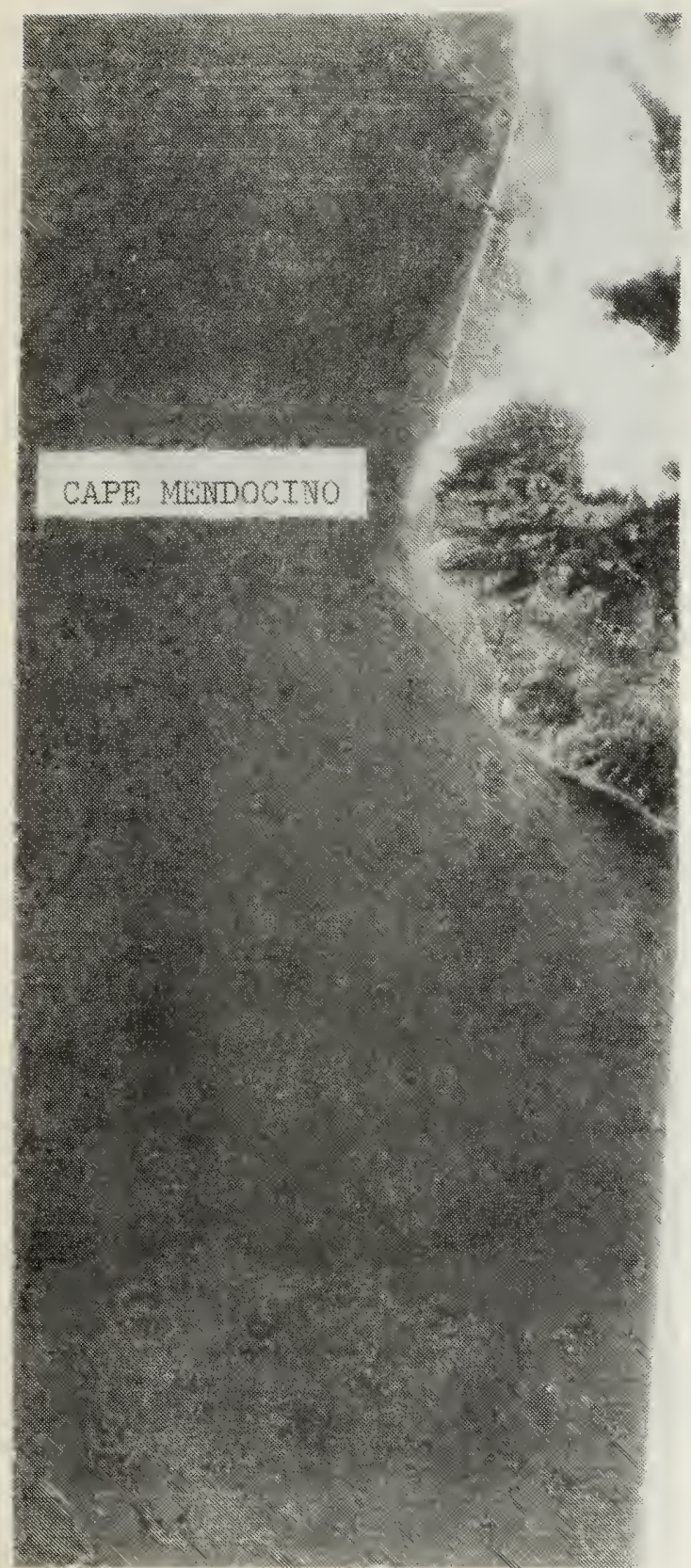

(a)

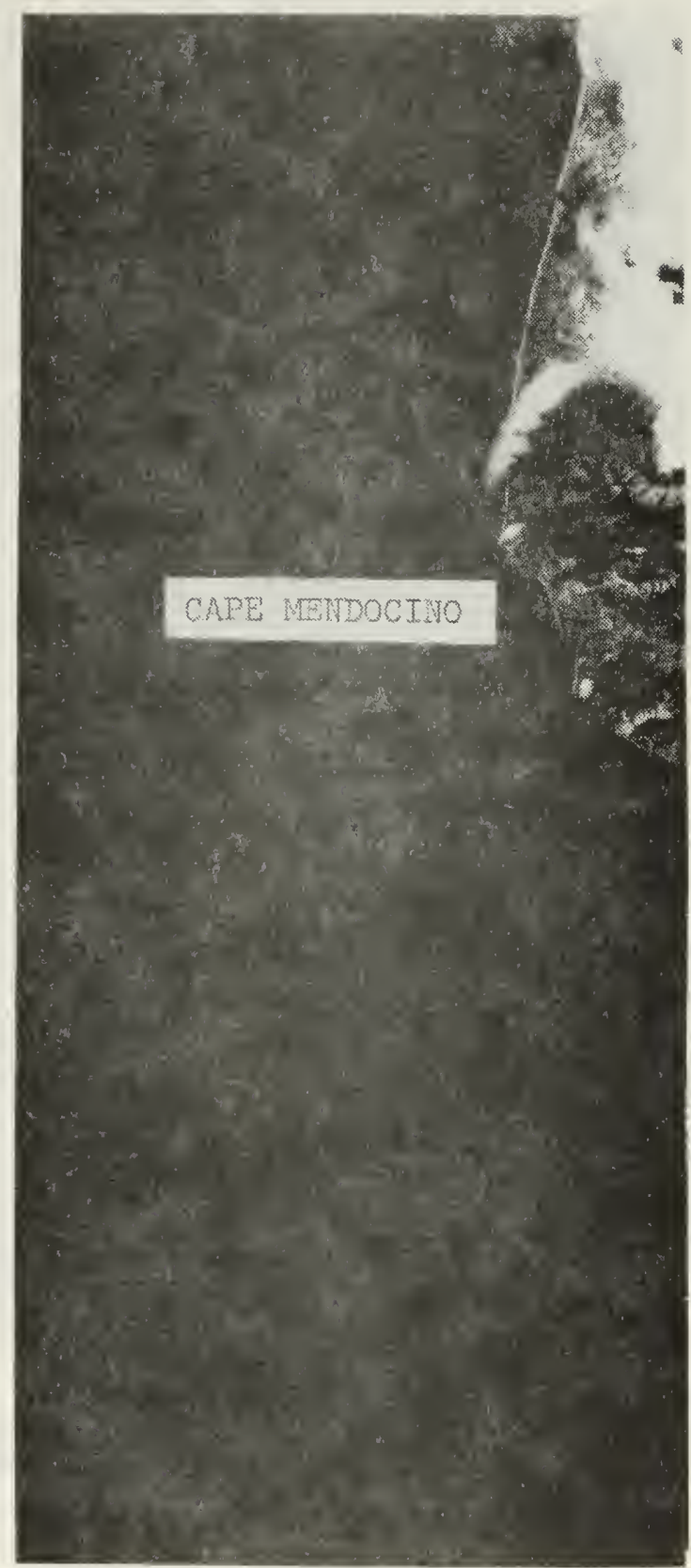

(b)

Figure 29. ERTS Standard Archived Products, 6 Aug. 1974.

(a) 1744-18251, Band 4 .

(b) 1744-18251, Band 5 .

Images show coastal current interactions off Cape Mendocino. A weak influence of upwelling appears to be acting against the southerly moving sediment transport.

Received from ERoS Data Center, Sioux Falls, South Dakota. 



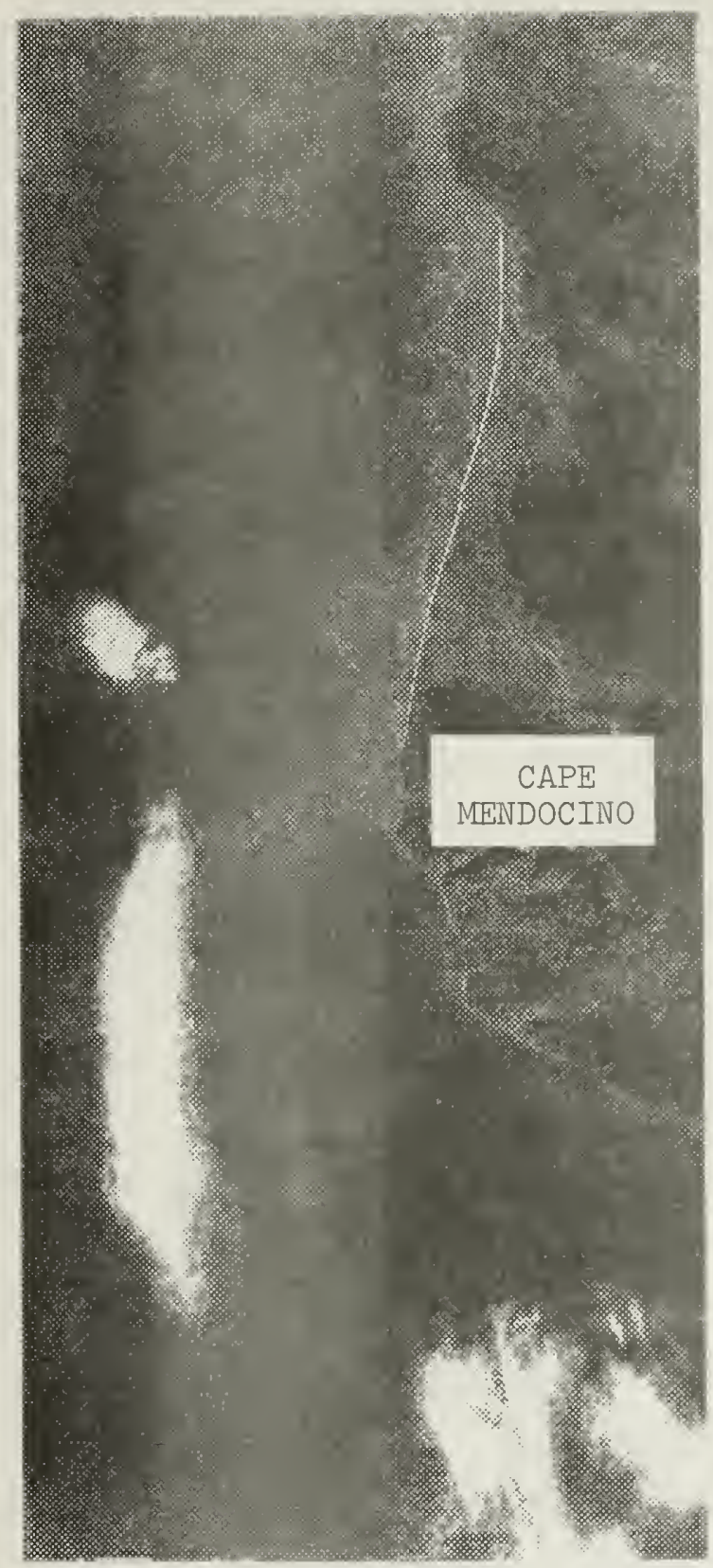

(a)

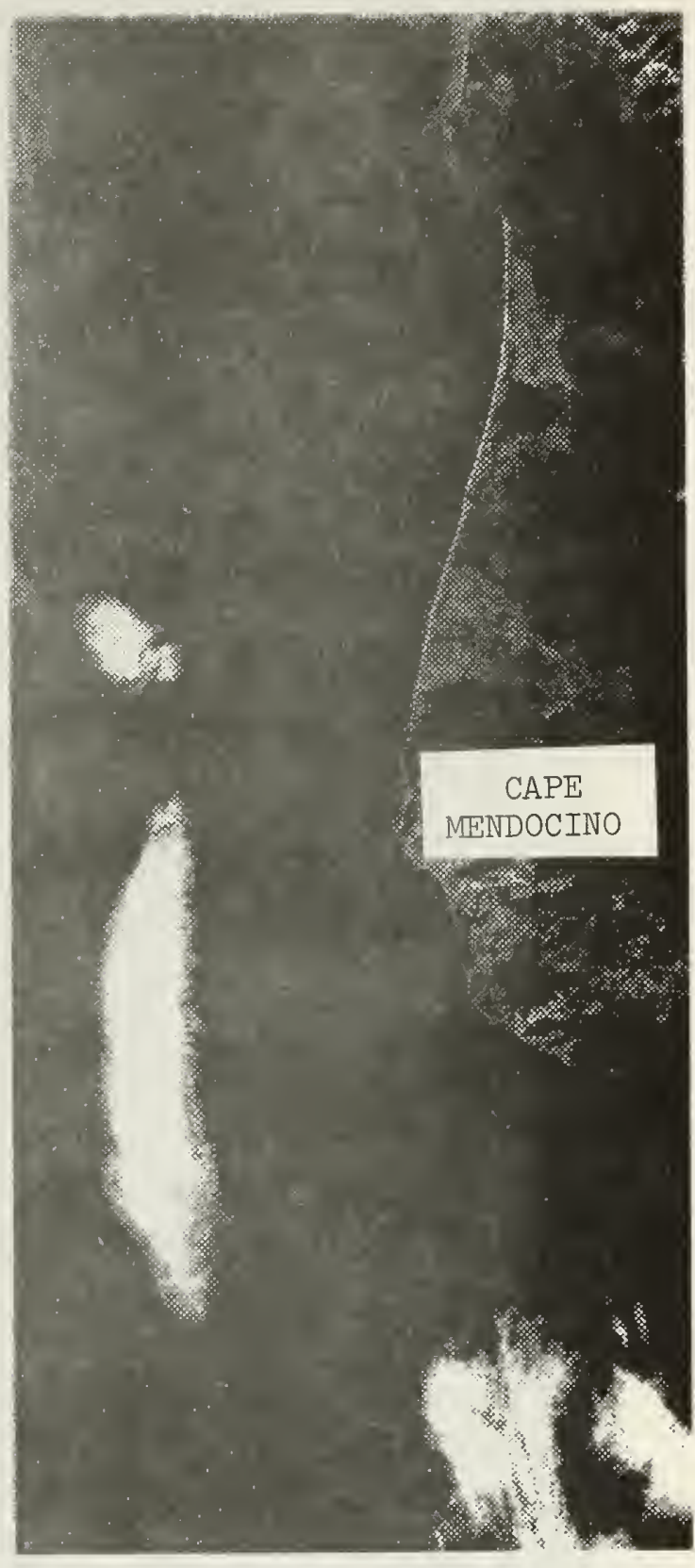

(b)

Figure 30. ERTS Standard Archived Products, 3 Nov. 1974. (a) 1833-18161, $\mathrm{B}$ and 4.

Images show coastal current interactions off Cape Mendocino. sediment from rivers flowing into the ocean for this month is much greater than depicted in Figure 29. A counterflow of upwelled water, acting against the southerly surface transport is evidently instigating the formation of the counterclockwise gyre.

Received from EROS Data Center, Sioux Falls, South Dakota. 



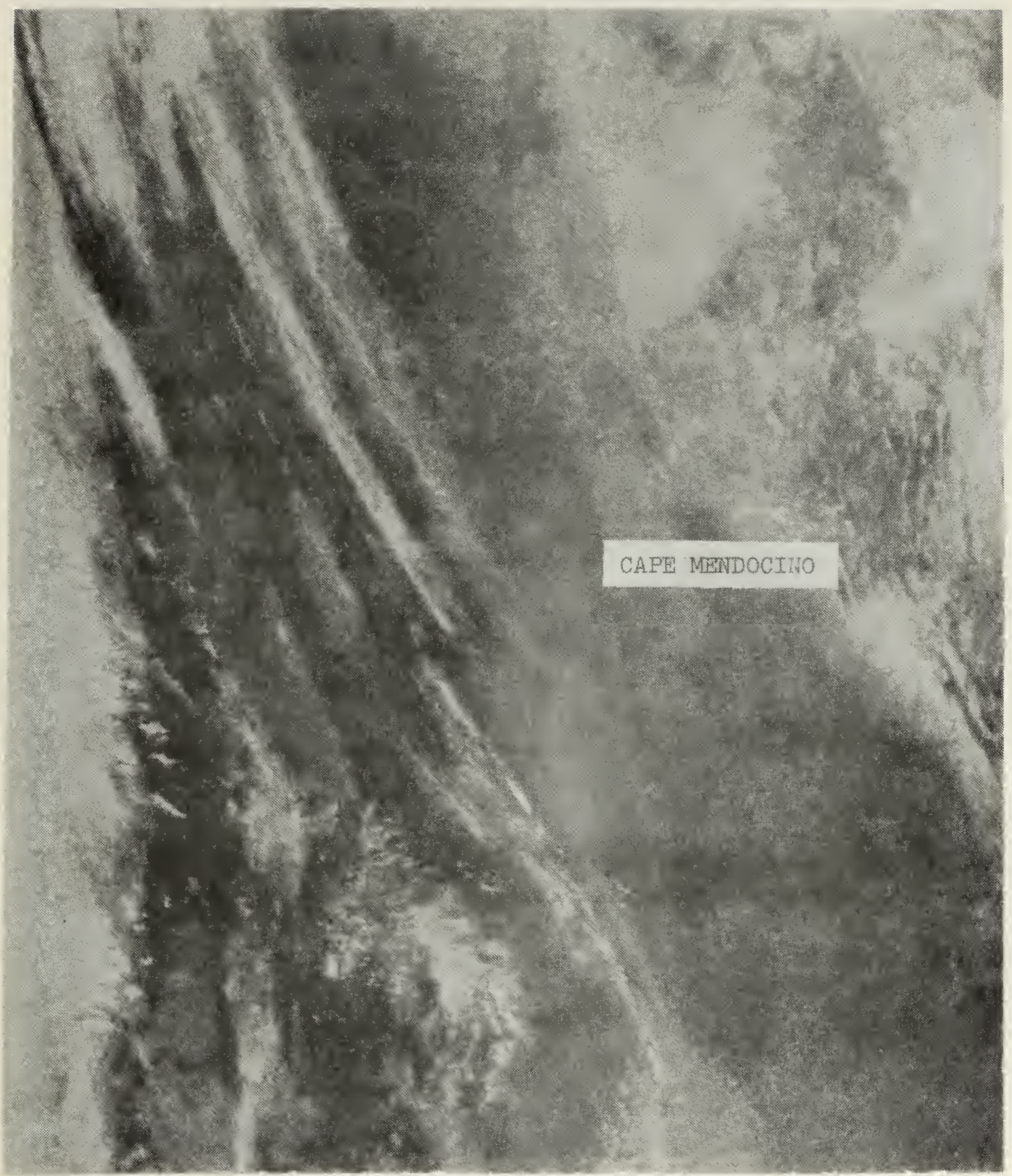

Figure 31. NOAA-3 VHRR Standard Archived Product, 3 Nov. 1974.

This is an infrared image showing the coast of California, compare with Figure 30, which does not give any indication as to the flow off Cape Mendocino. This image demonstrates the inability of the NOAA sensors to pick up smaller scale features observed in ERTS images.

Received from NOAA-NESS Satellite Data Service, Washington, D.C. 


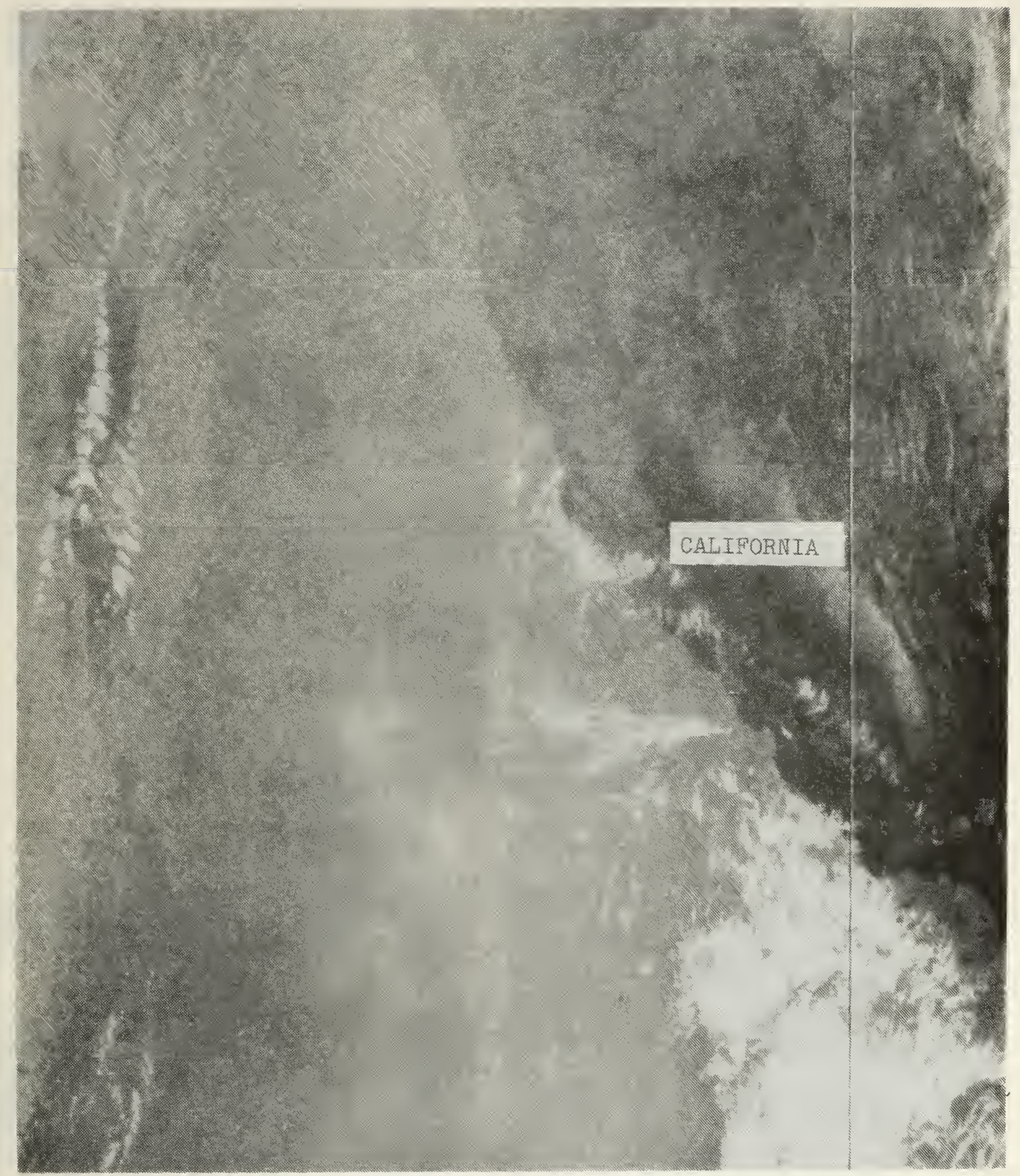

Figure 32. NOAA-3 VHRR Standard Archived Product, 10 Oct. 1974.

This is an infrared image showing the coast of California. Unlike Figure 31, this image shows the weak thermal contrasts between the coastal upwelled waters and the oceanic mass. It is difficult to infer the general surface current drift as well as the difference between the oceanic and atmospheric features, without the visual image.

Received from NOAA-NESS Satellite Data Service, Washington, D.C. 



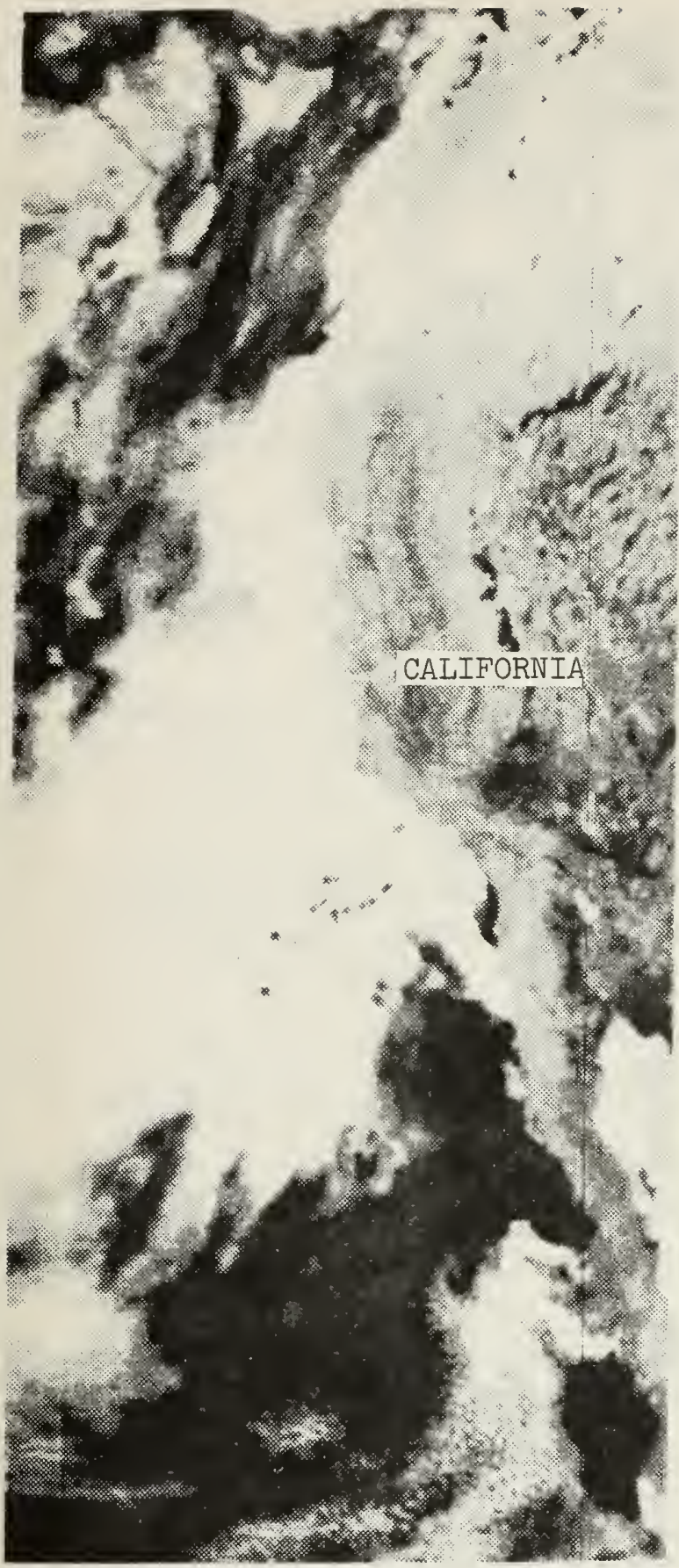

(a)

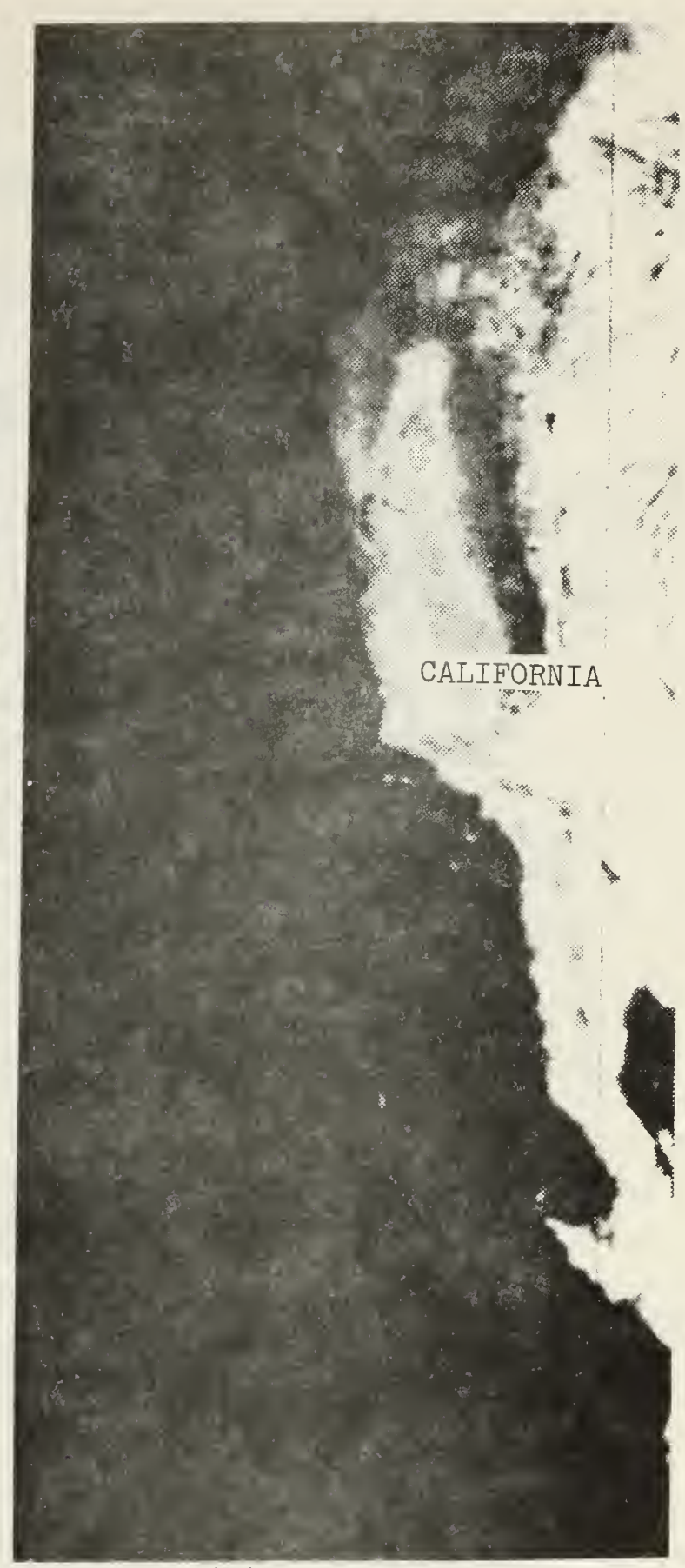

(b)

Figure 33. DMSP Standard Archived Products, 19 June 1973.

(a) Portion of a high resolution visual image of the California coast.

(b) Portion of a high resclution infrared image of the California coast.

Images show the common effect found in the majority of DMSP products; delineation between the atmospheric and oceanic thermal structures is not possible.

Received from the University of Wisconsin, Madison. 

1. Barclay, R.A., "Johnston Atoll's Wake," Journal of Marine Research, vol. 30, p. 201-216, May, 1972.

2. Batchelor, G.K., An Introduction to Fluid Dynamics, University Press, Cambridge, 1967.

3. Braeker, L. and Jurick, F., "Providing Near Real-Time Sea Surface Temperatures to the California North Coast Fishing Fleet: An Approach," Oceans 75 Conference, IEEE, New York, 1975, p. 794-797.

4. Chopra, K.P., and L.F. Hubert, "Mesoscale Eddies in Wake of Islands," Journal of Atmospheric Sciences, vol. 22, p. 652-657, 1965 .

5. Cram, R., and Hanson, K., "The Detection by ERTS-1 of Wind-Induced Ocean Surface Features in the Lee of the Antilles Islands," Journal of Physical Oceanography, v. 4, p. 594-596, october, 1974.

6. Curle, N., and Davies, H.J., Modern Fluid Dynamics, Volume 1: Incompressible Flow, D. Van Nostrand Company, London, p. 290, 1968 .

7. Defense Meteorological Satellite Program (DMSP) Users Guide, AWS-TR-74-250, published by Air Weather Service (MAC), U.S. Air Force, December, 1974.

8. Earth Resources Program Results and Projected Applications, ERTS-1 Application Investigations, National Aeronautics and Space Administration, Lyndon B. Johnson space Center, Houston, Texas, May, 1974.

9. Earth Resources Technology Satellite Data Users Handbook, published by NASA/Goddard Space Flight Center, Greenbelt, Maryland, 1972 .

10. Edmisten, J.R., California Nearshore Surface Currents: Past Observations and Recent Remote Sensing Information, CE 299, University of California, p. 20, June, 1974.

11. Fett, R.W., "Fishing Fleet Activities Revealed by NightTime Data from the Defense Meteorological Satellite Program (DMSP)," Marine Fisheries Review, vol. 34, p. 4, April, 1975. 

12. Fett, R.W., and Rabe, K., "Island Barrier Effects on Sea State and Atmospheric Moisture as Detected by a Numerical Wave Model and Sensors of the Defense Meteorological Satellite Program (DMSP)," unpublished as of this date, p. 30, Environmental Prediction Research Facility Technical Report for 1975.

13. Fromm, J.E., and Harlow, F.H., "Numerical solution of the Problem of Vortex Street Development," The Physics of Fluids, Vol. 6, No. 7, p. 975-982, July, 1975.

14. Hendy, R., and Wunsch, C., "High Reynolds Number Flow Past an Equatorial Island," Journal of Fluid Mechanics, vol. 58, p. 97-114, 1973 .

15. Hogg, N.G., "Steady Flow Past an Island with Applications to Bermuda," Geophysical Fluid Dynamics, vol. 4, p. 58-81, $197 \overline{2 .}$

16. La Violette, P.E., "Remote Optical Sensing in Oceanography Utilizing Satellite Sensors," Optical Aspects of Oceanography, edited by N.G. Jerlov and E.S. Nielsen, p. 289-316, London, Academic Press, 1974.

17. La Violette, P.E., Stewart, I., and Vermiliion, C.H., "Use of the APT Satellite Infrared Data in Oceanographic Survey Operations," Transactions, American Geophysical Union, V. 56, p. 276-282, May, 1975.

18. Lavoie, R.L., "A Numerical Model of Trade Wind Weather on Oahu," Monthly Weather Review, Vol. 1.02, p. 630-637, September, 1974 .

19. Magoon, O.T., "Use of Earth Resources Technology Satellite (ERTS-I) in Coastal Studies," NASA/Goddard Space Flight Center ERTS-1 Symposium, September, 1973.

20. National Oceanic and Atmospheric Administration Technical Memorandum NESS 35, A Modified Version of the Improved TIROS Operational Satellite (ITOS D-G), by A. Schwalb, p. 48, April, 1972 .

21. National Oceanic and Atmospheric Administration Technical Memorandum NESS 60, The Operation of the NOAA Polar Satellite system, by J.J. Fortuna and L.N. Hambrick, p. 127, November, 1974.

22. Naval Oceanographic Office Technical Report 241, Coastal Oceanographic Use of the U.S. Air Force Data Acquisition and Processing Program (DAPP), by O.K. Huh, P. 11, September, 1973. 

23. Naval Oceanographic Office Technical Note No. 6110-6-75, Detection of Oceanic Thermal Fronts off Korea with the Defense Meteorological Satellite System, by O.K. Huh, p. 33, July, 1975 .

24. Patzert, W.C., "Eddies in Hawaiian Waters," Hawaiian Institute of Geophysics, ONR Contract No. NONR-3748(06), p. 51, 1969.

25. Pierce, D., "Photographic Evidence of the Formation and Growth of Vorticity Behind Plates Accelerated from

Rest in Still Air," Journal of Fluid Mechanics, Vol. 11, p. 460-464, 1961 .

26. Pirie, D.M. and Steller, D.D., California Coast Nearshore Processes Study Final Report - ERTS-1 Experiment \#088, Goddard Space Flight Center, Greenbelt, Maryland, p. $164,1974$.

27. Stevenson, R.E., "Oceanographic Data Requirements for the Development of an Operational Satellite System," Reprint from: The Proceedings of the Princeton University Conference on Aerospace Methods for Revealing and Evaluating Earth's Resources, held Sept. 25-26, 1969 at Princeton, New Jersey, p. 12, 1970.

28. Stolt, N.W., and Havanac, P.J., Compendium of Meteorological Satellites and Instrumentation, p. 455, prepared for NASA Goddard Space Flight Center, Greenbelt, Maryland, 1973.

29. Strong, A.E., De Rycke, R.J., and Stumpf, H.G., "Extensive Areas of Reduced Waves Leeward of the Lesser Antilles," Geological Research Letters, Vol. 1, p. 47-49, 1974.

30. Szekielda, K.H., "The Development of Upwelling Along the Somali Coast as Detected with Nimbus 2 and Nimbus 3 Satellites," NASA-GSFC Document, $X-651-70-415$, p. 52, Greenbelt, Maryland, 1970 .

31. Warnecke, G.L., and others, "Remote Sensing of Ocean Currents and Sea Surface Temperature Changes Derived from the Nimbus 2 Satellite," Journal of Physical Oceanography, V. 1, p. 45-60, January, 1971 . 

1. Defense Documentation Center Cameron Station

Alexandria, Virginia 22314

2. Library, Code 0212

Naval Postgraduate School

Monterey, California 93940

3. COMPT (PTP)

U. S. Coast Guard

washington, D. C. 20590

4. Oceanography Department

Naval Postgraduate School

Monterey, California 93940

5. Dr. J. J. von Schwind, Code 58vs

Department of Oceanography

Naval Postgraduate School

Monterey, California 93940

6. Assoc Prof. E.B. Thornton, Code $58 \mathrm{Tn}$

2

Department of Oceanography

Naval Postgraduate School

Monterey, California 93940

7. Oceanographer of the Navy

Hof fman Building Number-2

2461 Eisenhower Avenue

Alexandria, Virginia 22314

8. Office of Naval Research

Code 480-D

Arlington, Virginia 22217

9. U.S. Coast Guard Oceanographic Unit

Bldg. 159E, Washington Navy Yard Annex

Washington, D.C. 20390

10. LT B.W. Platz, Jr.

U.S.C.G. Oceanographic Unit

Bldg. 159E, Washington Navy Yard Annex

Washington, D.C. 20390 

11. Library, Code 3330

Naval Oceanographic Office

Washington, D.C. 20373

12. SIO Library

University of California, San Diego

P.O. Box 2367

La Jolla, California 92037

13. Department of Oceanography Library

1

University of Washington

Seattle, Washington 98105

14. Department of Oceanography Library 1

Oregon State University

Corvallis, Oregon 97331

15. Commanding Officer

1

Fleet Numerical Weather Central

Monterey, California 93940

16. Commanding officer

Environmental Prediction Research Facility Monterey, California 93940 





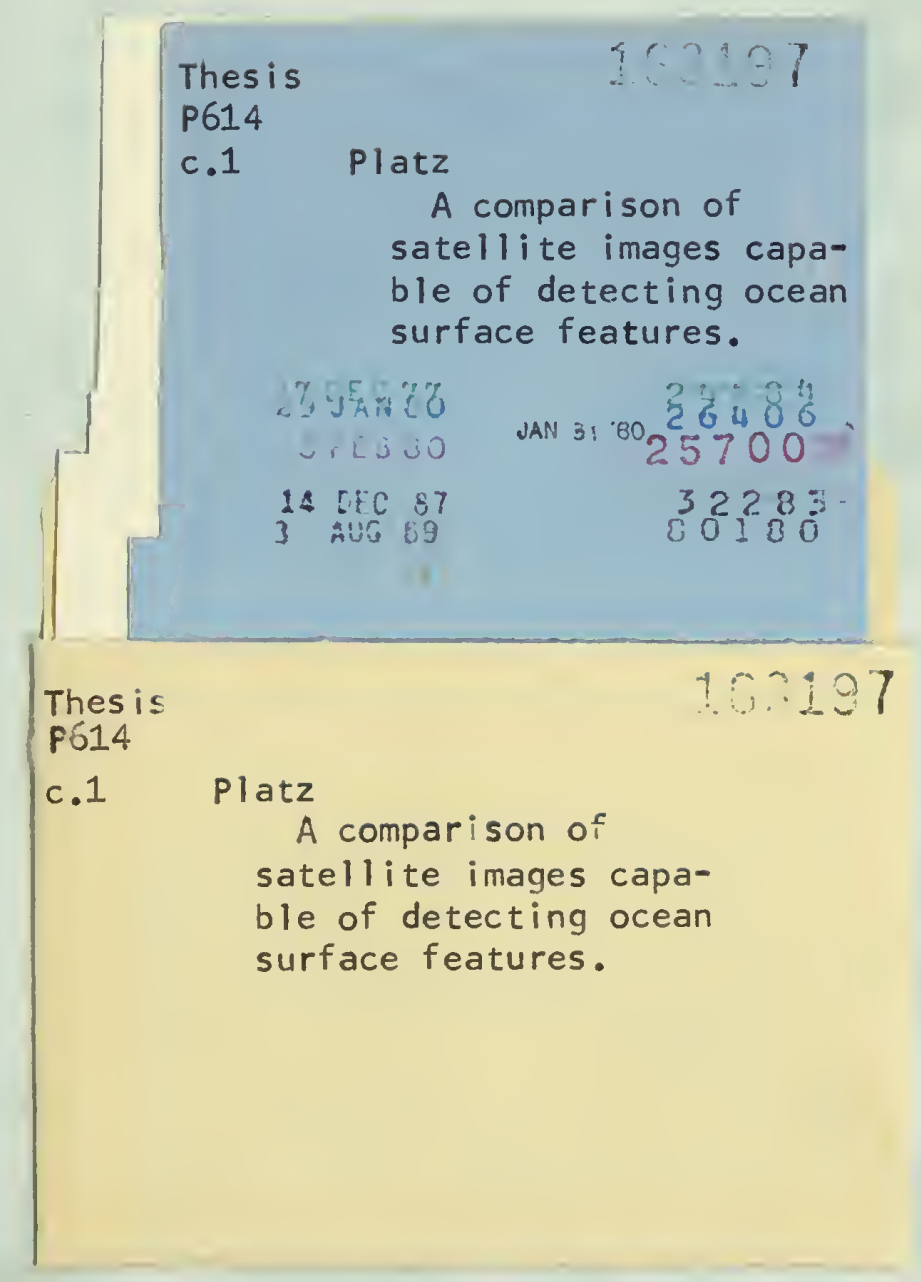


thesP614

A comparison of satellite images capable

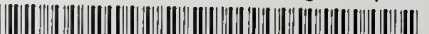

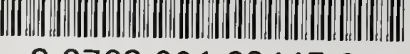

32768001924459 DUDLEY KNOX LIBRARY 